\author{
UNIVERSIDADE DE SÃO PAULO \\ ESCOLA DE ENFERMAGEM DE RIBEIRÃO PRETO
}

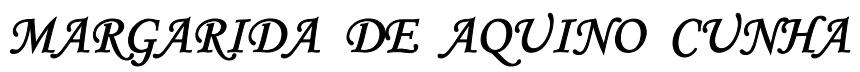

Assistência pré-natal por profissionais de enfermagem no município de Rio Branco-AC: contribuição para o estudo da atenção qualificada no ciclo grávido-puerperal

Ribeirão Preto-SP

2008 


\section{Assistência pré-natal por profissionais de enfermagem no município de Rio Branco-AC: contribuição para o estudo da atenção qualificada no ciclo grávido-puerperal}
Tese apresentada ao Programa Interunidades de Doutoramento em Enfermagem da Escola de Enfermagem de Ribeirão Preto da Universidade de São Paulo, para obtenção do título de Doutor em Enfermagem.

Área de Concentração: Enfermagem

Linha de Pesquisa: Sociedade, Saúde e Enfermagem.

Orientadora: Profa. Dra. Marli Villela Mamede 
AUTORIZO A REPRODUÇÃO E DIVULGAÇÃO TOTAL OU PARCIAL DESTE TRABALHO, POR QUALQUER MEIO CONVENCIONAL OU ELETRÔNICO, PARA FINS DE ESTUDO E PESQUISA, DESDE QUE CITADA A FONTE.

\section{FICHA CATALOGRÁFICA}

Cunha, Margarida de Aquino

Assistência pré-natal por profissionais de enfermagem no município de Rio Branco-AC: contribuição para o estudo da atenção qualificada no ciclo grávido-puerperal. Ribeirão Preto, 2008.

$159 f . ; 30 \mathrm{~cm}$.

Tese de Doutorado, apresentada à Escola de Enfermagem de Ribeirão Preto/USP - Programa Interunidades de Doutoramento em Enfermagem. Área de concentração: Enfermagem.

Orientadora: Mamede, Marli Villela

1. Cuidado pré-natal. 2. Equipe de enfermagem. 3. Gestação. 4. Enfermagem obstétrica. 5. Competência profissional. 6. Atenção qualificada. 


\section{FOLHA DE APROVAÇÃO}

Margarida de Aquino Cunha

Assistência pré-natal por profissionais de enfermagem no município de Rio BrancoAC: contribuição para o estudo da atenção qualificada no ciclo grávido-puerperal

Tese apresentada ao Programa Interunidades de Doutoramento em Enfermagem da Escola de Enfermagem de Ribeirão Preto, da Universidade de São Paulo, para obtenção do título de Doutor em Enfermagem.

Área de Concentração: Enfermagem.

Aprovada em: / 2008

\section{BANCA EXAMINADORA}

Profa. Dra. Marli Villela Mamede Instituição: EERP-USP

Assinatura:

Prof. Dr.

Instituição:

Assinatura:

Prof. Dr.:

Instituição:

Assinatura:

Prof. Dr.:

Instituição:

Assinatura:

Prof. Dr.:

Instituição:

Assinatura: 
Ao meu marido, Orlando Sabino, e a meus filhos, Orlando Sabino Neto e Mel Sabino, pelo apoio e amor em todos os momentos desta importante etapa de nossas vidas. 


\section{AGRADECIMENTOS}

Aos meus pais, Ismael e Aninha, pessoas que sempre foram exemplos de coragem, amor, determinação e perseverança, e, em especial, à minha irmã, Ellen, pelo apoio em todos os momentos desta e de outras caminhadas.

A minha querida orientadora Profa. Dra. Marli Villela Mamede, pela dedicação, paciência, estímulo, confiança, competência e excelente orientação prestada ao longo desta caminhada. Por sua amizade, principalmente, meu muito obrigado de coração.

Aos Professores das disciplinas de pós-graduação, pelo conhecimento transmitido ao longo do curso.

Às Professoras Maria José Clapis e Marislei Sanches Panobianco, pelas contribuições e pela atenção na etapa da qualificação.

Às amigas e colegas da pós-graduação, em especial, as amigas Anne, Terê, Márcia Gil, pelos momentos de aprendizagem, pela amizade e convivência ao longo deste período.

Aos colegas de Departamento, em especial, as amigas Leila e Simone, pelo apoio quando cheguei a Ribeirão Preto. A todos, muito obrigada. 
À Escola de Enfermagem de Ribeirão Preto e a todos os funcionários pela acolhida. Obrigada por tudo.

À Secretaria da Pós-Graduação da EERP/USP, em especial, a Carla, Rosana e Kethleen, pela preciosa colaboração e pela atenção a mim dispensadas, durante todo o curso.

À Universidade Federal do Acre e à CAPES, pelo suporte financeiro durante o curso.

Ao Dr. Eduardo Farias, Secretário Municipal de Saúde, por autorizar a realização desta pesquisa nos Centros de Saúde e Unidades de Saúde da Família do município de Rio Branco.

Às colegas enfermeiras e funcionários da Secretaria Municipal de Saúde, pela atenção dispensada durante a realização desta pesquisa.

À equipe de enfermagem dos Centros de Saúde e Unidades de Saúde Família que gentilmente aceitou participar deste estudo.

Às gestantes, por terem, gentilmente consentido a observação, durante as consultas. 
Aos membros da banca examinadora, por terem aceitado participar da avaliação deste estudo.

Aos que direta ou indiretamente contribuíram para a realização deste trabalho.

E finalmente a "Deus" por sempre me iluminar e me guiar. 


\section{RESUMO}

CUNHA, M.A. Assistência pré-natal por profissionais de enfermagem no município de Rio Branco-AC: contribuição para o estudo da atenção qualificada no ciclo grávido-puerperal. 2008. 159 f. Tese (Doutorado em Enfermagem) - Escola de Enfermagem de Ribeirão Preto, Universidade de São Paulo. Ribeirão Preto, 2008.

No mundo, a cada ano, ocorrem 120 milhões de gravidezes, entre as quais, mais de meio milhão de mulheres morre em conseqüência de complicações, durante a gravidez ou o parto, e mais de 50 milhões sofrem enfermidades ou incapacidades sérias relacionadas à gravidez. Vários estudos apontam que a atenção qualificada no pré-natal pode contribuir significativamente na redução dessas taxas e promover uma maternidade sem risco. Objetivos: Identificar e descrever o perfil dos profissionais de enfermagem que participam na atenção ao pré-natal e analisar as competências essenciais desenvolvidas por eles na prática. Metodologia: estudo descritivo de abordagem quantitativa, realizado em 03 Centros de Saúde (CS) e 13 Unidades de Saúde da Família (USF) de Rio Branco-Acre. A população estudada foi composta por 23 profissionais de enfermagem (15 enfermeiros, 02 enfermeiras obstétricas, 04 técnicas em enfermagem e 02 auxiliares de enfermagem). A coleta de dados foi realizada por meio de entrevistas e observação não participante e sistemática das competências essenciais em obstetrícia. Foram observadas 61 consultas de pré-natal, 57 pré-consultas e 03 consultas puerperais. A estatística descritiva foi utilizada para a análise das variáveis. Resultados: os profissionais entrevistados são predominantemente do sexo feminino (91,30\%), com uma idade média de 34,3 anos, 69,6\% são casados, 60,87\% com seis anos de formação profissional, com uma média de 54,1 meses de experiência na assistência pré-natal, com carga horária média semanal de trabalho de 53,26 horas e 52,17\% trabalham em mais de uma instituição. Nos CSs, a pré-consulta é de responsabilidade das técnicas e auxiliares de enfermagem, já nas USFs, em sua grande maioria (84,62\%), são os enfermeiros que realizam essa atividade. A consulta pré-natal e puerperal é realizada pelos enfermeiros, nos dois modelos de atenção. Dos enfermeiros que realizam a consulta pré-natal, apenas 02 (11,76\%) cursaram especialização em obstetrícia e os demais $(88,24 \%)$ fizeram uma capacitação em assistência pré-natal 
com duração de 24 a 40 horas. A grande maioria das competências essenciais esperadas na assistência pré-natal, neste estudo, foi desenvolvida, entretanto, algumas foram realizadas com baixa freqüência. As ações e procedimentos mais freqüentemente realizados foram: aferição da PA, verificação do peso e altura, realização da história inicial, ausculta do BCF, medida da altura uterina e solicitação de exames laboratoriais, e os menos freqüentes: avaliação do estado nutricional, exame clínico de mamas, palpação abdominal para verificação da posição e apresentação fetal. As atividades de educação em saúde não foram realizadas. Conclusões: os resultados revelaram que, apesar do bom desempenho dos enfermeiros, há que se avaliar a necessidade de investimentos na formação de pessoal qualificado, para o atendimento à mulher no ciclo grávido-puerperal, assim como a incorporação de protocolos que traduzam padrões baseados em evidências científicas, na prática obstétrica, deve ser incentivada.

Palavras-chave: cuidado pré-natal, equipe de enfermagem, gestação, enfermagem obstétrica, competência profissional, atenção qualificada. 


\section{ABSTRACT}

CUNHA, M.A. Prenatal care by nursing professionals in Rio Branco-AC: contribution to the study of qualified care in the pregnancy-puerperal cycle. 2008. 159 p. Doctoral Dissertation in Nursing - University of São Paulo at Ribeirão Preto College of Nursing. Ribeirão Preto, 2008.

Every year, 120 million pregnancies occur around the world, in which more than half a million women die due to pregnancy or delivery complications and more than 50 million suffer from serious pregnancy-related diseases or disabilities. Various studies appoint that qualified prenatal care can significantly contribute to the reduction of these rates and to promote risk-free motherhood. Objectives: Identify and describe the profile of nursing professionals who participate in prenatal care and analyze the core competencies they develop in practice. Methodology: Descriptive study with a quantitative approach, carried out at 03 Health Centers $(\mathrm{HC})$ and 13 Family Health Units (FHU) in Rio Branco-Acre. The study population consisted of 23 nursing professionals (15 nurses, 02 nurse midwives, 04 nursing technicians and 02 nursing auxiliaries). Data were collected through interviews, as well as systematic and nonparticipant observation of core competencies in obstetrics. Sixty-one prenatal consultations, 57 pre-consultations and 03 puerperal consultations were observed. Descriptive statistics was used to analyze the variables. Results: the interviewed professionals are mostly female (91.30\%), with a mean age of 34.3 years; $69.6 \%$ are married; $60.87 \%$ have six years of professional training, with a mean prenatal care experience of 54.1 months; the mean weekly hour load is 53.26 hours and $52.17 \%$ work in more than one institution. At the $\mathrm{HC}$, nursing technicians and auxiliaries are responsible for pre-consultations, but mostly (84.62\%) nurses at the FHU. Nurses perform prenatal and puerperal consultations in the two care models. Among the nurses who perform prenatal consultations, only 02 (11.76\%) had taken a specialization course in obstetrics, while the remainder (88.24\%) received prenatal care training for between 24 and 40 hours. The large majority of the core competencies expected in prenatal care, in this study, was developed, although frequency levels for some were low. The most frequently performed actions and procedures were: BP measurement, weight and height measurement, initial history, fetal heart beat listening, uterine height measurement and request for laboratory exams, while the least frequent were: assessment of nutritional state, clinical breast 
exam, abdominal palpation to verify fetal position and presentation. Health education activities were not performed. Conclusions: the results revealed that, despite the nurses' good performance, the need for investment in qualified staff training needs to be assessed for care to women in the pregnancy-puerperal cycle, and the incorporation of protocols that translate evidence-based standards into obstetric practice needs to be encouraged.

Key Words: prenatal care, nursing team, pregnancy, obstetric nursing, Professional competency, qualified care. 


\section{RESUMEN}

CUNHA, M.A. Atención prenatal por profesionales de enfermería en Rio BrancoAC: contribución para el estudio de la atención calificada en el ciclo grávidopuerperal. 2008. 159 h. Tesis (Doctorado en Enfermería) - Escuela de Enfermería de Ribeirão Preto, Universidad de São Paulo. Ribeirão Preto, 2008.

A cada año ocurren 120 millones de embarazos en el mundo, entre los cuales más que medio millón de mujeres mueren como consecuencia de complicaciones durante el embarazo o el parto y más que 50 millones sufren enfermedades o incapacidades serias relacionadas al embarazo. Varios estudios apuntan que la atención calificada en el prenatal puede contribuir significativamente en la reducción de esas tasas y promover una maternidad sin riesgo. Objetivos: Identificar y describir el perfil de los profesionales de enfermería que participan en la atención al prenatal y analizar las competencias esenciales desarrolladas por ellos en la práctica. Metodología: estudio descriptivo de aproximación cuantitativa, realizado en 03 Centros de Salud (CS) y 13 Unidades de Salud de la Familia (USF) de Rio Branco-Acre. La población estudiada fue compuesta por 23 profesionales de enfermería (15 enfermeros, 02 enfermeras obstétricas, 04 técnicas en enfermería y 02 auxiliares de enfermería). La recolecta de datos fue realizada mediante entrevistas y observación no participante y sistemática de las competencias esenciales en obstetricia. Fueron observadas 61 consultas de prenatal, 57 pre-consultas y 03 consultas puerperales. La estadística descriptiva fue utilizada para análisis de las variables. Resultados: los profesionales entrevistados son predominantemente del sexo femenino (91,30\%), con edad promedia de 34.3 años, el $69.6 \%$ es casado, 60.87\% con seis años de formación profesional, con un promedio de 54.1 meses de experiencia en la atención prenatal, con carga horaria promedia semanal de trabajo de 53.26 horas, y el $52.17 \%$ trabaja en más que una institución. En los CS, la pre-consulta es de responsabilidad de las técnicas y auxiliares de enfermería mientras, en las USF, en la gran mayoría $(84,62 \%)$ son los enfermeros que realizan esa actividad. La consulta prenatal y puerperal es realizada por los enfermeros en los dos modelos de atención. De los enfermeros que realizan la consulta prenatal, sólo 02 (11,76\%) cursaron especialización en obstetricia y las demás $(88,24 \%)$ hicieron una capacitación en atención prenatal con duración de 24 a 40 horas. La gran mayoría de las 
competencias esenciales esperadas en la atención prenatal, en este estudio, fue desarrollada. Sin embargo, algunas fueron realizadas con frecuencia baja. Las acciones y procedimientos más frecuentemente realizados fueron: contraste de la PA, verificación del peso y altura, realización de la historia inicial, ausculta del BCF, medida de la altura uterina y solicitación de exámenes laboratoriales y los menos frecuentes: evaluación del estado nutricional, examen clínico de mamas, palpación abdominal para verificación de la posición y presentación fetal. Las actividades de educación en salud no fueron realizadas. Conclusiones: los resultados revelaron que, a pesar del desempeño bueno de los enfermeros, se debe evaluar la necesidad de inversiones en la formación de personal calificado para la atención a la mujer en el ciclo grávido-puerperal. Además, la incorporación de protocolos que traducen estándares basados en evidencias científicas en la práctica obstétrica debe ser incentivada.

Palabras-clave: cuidado prenatal, equipo de enfermería, embarazo, enfermería obstétrica, competencia profesional, atención calificada. 


\section{LISTA DE TABELAS}

Tabela 1 Distribuição dos profissionais de saúde da rede básica de Rio Branco (AC), segundo a unidade de saúde, Rio Branco, 2006 .....

Tabela 2 Distribuição dos profissionais de enfermagem da rede básica do município de Rio Branco (AC), segundo a idade, estado conjugal e número de filhos. Rio Branco, 2006.

Tabela 3 Distribuição dos profissionais de enfermagem da rede básica do município de Rio Branco (AC), segundo a renda familiar. Rio Branco, 2006.

Tabela 4 Distribuição dos profissionais de enfermagem da rede básica do município de Rio Branco (AC), segundo a remuneração na instituição pesquisada. Rio Branco, 2006.

Tabela 5 Distribuição dos profissionais de enfermagem da rede básica do município de Rio Branco (AC), segundo os anos de formação. Rio Branco, 2006.

Tabela 6 Distribuição dos profissionais de enfermagem da rede básica do município de Rio Branco (AC), segundo o tempo de trabalho na assistência pré-natal. Rio Branco, 2006.

Tabela 7 Distribuição dos profissionais de enfermagem da rede básica do município de Rio Branco (AC), segundo os cursos de atualização realizados após a formação profissional. Rio Branco, 2006.

Tabela 8 Distribuição das freqüências dos procedimentos realizados pelos profissionais de enfermagem da rede básica do município de Rio Branco (AC), segundo a categoria profissional, durante a préconsulta de 57 gestantes observadas. Rio Branco, 2006.

Tabela 9 Distribuição das gestantes das unidades de saúde estudadas da rede básica do município de Rio Branco (AC), segundo a fase gestacional, durante a consulta pré-natal. Rio Branco, 2006..........

Tabela 10 Distribuição da freqüência do conteúdo da anamnese na primeira consulta feita pelos enfermeiros da rede básica do município de Rio Branco (AC), durante a consulta pré-natal de 17 gestantes observadas. Rio Branco, 2006. 
Tabela 11 Distribuição de freqüências do conteúdo da anamnese a partir da segunda consulta feita pelos enfermeiros da rede básica do município de Rio Branco (AC), durante a consulta pré-natal de 44 gestantes observadas. Rio Branco, 2006.

Tabela 12 Distribuição de freqüências dos procedimentos realizados no exame físico pelos enfermeiros da rede básica do município de Rio Branco (AC), segundo a instituição estudada, durante 61 consultas de pré-natal observadas. Rio Branco, 2006.

Tabela 13 Distribuição de freqüências dos procedimentos realizados durante o exame obstétrico pelos enfermeiros da rede básica do município de Rio Branco (AC), segundo a instituição estudada, durante 61 consultas de pré-natal observadas. Rio Branco, 2006.

Tabela 14 Distribuição de freqüências das orientações passadas às gestantes pelos enfermeiros da rede básica do município de Rio Branco (AC), segundo a instituição estudada, durante 61 consultas de pré-natal observadas. Rio Branco, 2006.

Tabela 15 Distribuição de freqüências de exames solicitados na primeira consulta realizada pelos enfermeiros da rede básica do município de Rio Branco (AC), durante 17 consultas de pré-natal observadas. Rio Branco, 2006.

Tabela 16 Distribuição de freqüências de medicamentos prescritos pelos enfermeiros da rede básica do município de Rio Branco (AC), segundo a instituição estudada, durante 61 consultas de prénatal observadas. Rio Branco, 2006.

Tabela 17 Distribuição de freqüências de motivos da prescrição de medicamentos pelos enfermeiros da rede básica do município de Rio Branco (AC), segundo a instituição estudada, durante 61 consultas de pré-natal observadas. Rio Branco, 2006.

Tabela 18 Distribuição de freqüências das atividades realizadas ao final da consulta pelos enfermeiros da rede básica do município de Rio Branco (AC), segundo a instituição estudada, durante 61 consultas de pré-natal observadas. Rio Branco, 2006. 


\section{LISTA DE FIGURAS}

Figura 1 Média da remuneração salarial dos profissionais de enfermagem da rede básica do município de Rio Branco (AC).

Figura 2 Distribuição dos profissionais de enfermagem da rede básica do município de Rio Branco (AC), segundo o número de empregos...

Figura 3 Distribuição das 17 gestantes de primeira consulta das unidades de saúde estudadas da rede básica do município de Rio Branco (AC), segundo o trimestre gestacional, durante a consulta prénatal. Rio Branco, 2006. 


\section{LISTA DE QUADROS}

Quadro 1 Taxa de mortalidade materna no Estado do Acre, no período de 1999 a 2003. 


\section{SUMÁRIO}

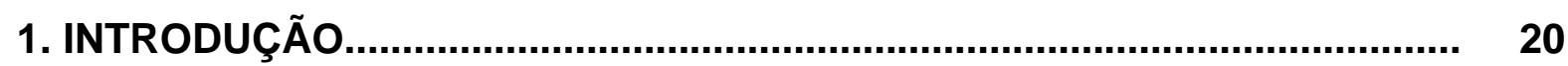

1.1 Competências essenciais no atendimento à gestação................................ 28

1.2 Pressuposto e questões da pesquisa................................................ 40

2. OBJETIVOS

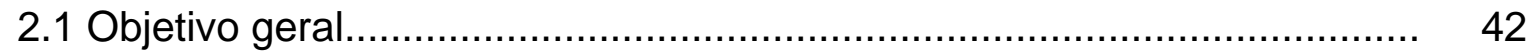

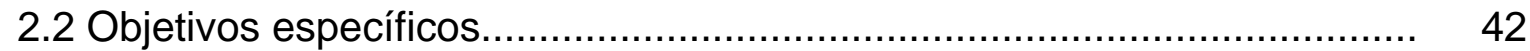

3. METODOLOGIA

3.1 Tipo do estudo............................................................................. 44

3.2 Local do estudo....................................................................... 45

3.2.1 O Estado do Acre................................................................. 45

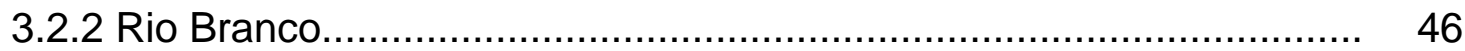

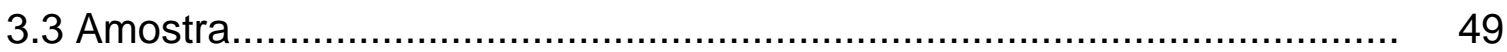

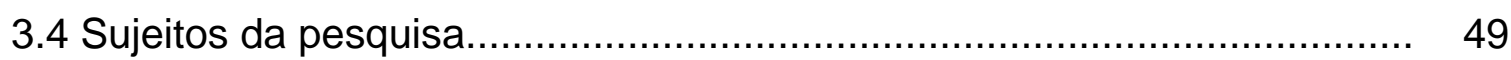

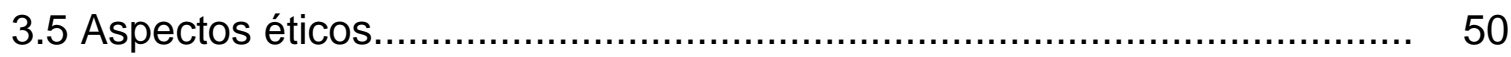

3.6 Coleta de dados......................................................................... 50

3.7 Análise dos dados......................................................................... 53

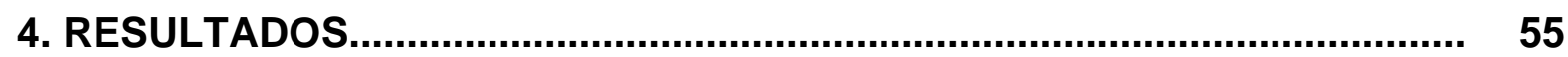

4.1 Caracterização dos serviços............................................................ 56

4.1.1 Centros de Saúde.................................................................. 56

4.1.2 Unidades de Saúde da Família.................................................... 58

4.2 Caracterização dos sujeitos........................................................... 60

4.3 Assistência pré-natal: descrição do observado.......................................... 71

4.3.1 Pré-consulta da gestante........................................................ $\quad 72$

4.3.2 Atenção pré-natal: consulta........................................................ 74

4.3.3 Consulta puerperal............................................................. 87

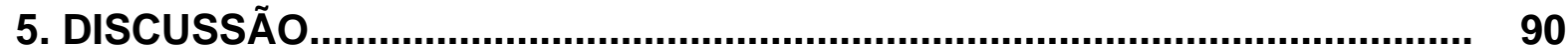

5.1 A equipe de enfermagem............................................................... 91 
6. CONCLUSÕES.

7. IMPLICAÇÕES PARA O ENSINO, ASSISTÊNCIA E PESQUISA

APÊNDICES.

Apêndice $A$

Apêndice $B$

Apêndice $C$

Apêndice D

ANEXOS.

Anexo A

Anexo B 
Anualmente, quase 600.000 mulheres em todo o mundo morrem vítimas de complicações ligadas ao ciclo gravídico-puerperal. Dessas, 95\% ocorrem nos países em desenvolvimento e subdesenvolvidos e 5\% nos países desenvolvidos. No mundo, a cada ano, ocorrem 120 milhões de gravidezes, entre as quais, mais de meio milhão de mulheres morre em conseqüência de complicações, durante a gravidez ou o parto, e mais de 50 milhões sofrem enfermidades ou incapacidades sérias relacionadas à gravidez (MAcDONALD; STARRS, 2003).

No Canadá e nos Estados Unidos ocorrem nove óbitos para cada 100 mil nascidos vivos, enquanto nas regiões das Américas, como Bolívia, Peru e Haiti esse número chega a mais de 200. Outros países em desenvolvimento, como Chile, Cuba, Costa Rica e Uruguai, apresentam mortalidade materna em torno de 40 por 100 mil nascidos vivos (BRASIL, 2002).

A mortalidade materna na América Latina se apresenta como um grave problema de saúde, morrendo nesta região anualmente 30.000 mulheres por complicações da gravidez, parto e puerpério (BRASIL, 1995).

Nos países desenvolvidos, a morte por causa materna está entre as últimas causas de morte, enquanto no Brasil está entre as dez primeiras (TANAKA, 2001). O Brasil tem um bom Sistema de Informação sobre Mortalidade Materna, gerido pelo Ministério da Saúde (SIM/MS), que foi implantado desde a década de 1970. Estima-se que a cobertura do SIM/MS seja em torno de $85 \%$, atribuindo essa subnotificação quase que exclusivamente às regiões Norte e Nordeste do país. Nos Estados do Sul e Sudeste, a abrangência aproxima-se de 100\%, particularmente nas suas capitais (VALONGUEIRO; LUDERMIR; GOMINHO, 2003; LAURENTI ; JORGE; GOTLIEB, 2004).

Por outro lado, verifica-se que apesar do Sistema de Informação de 
Mortalidade ter uma cobertura aceitável, no sentido de aproximar-se em quantidade, a sua qualidade ainda deixa a desejar, muitas vezes. As dificuldades, presentes no processo de obtenção de informações sobre a morte materna, geralmente referemse a incorreções técnicas na certificação médica dos óbitos, à má qualidade dos registros institucionais sobre a assistência, à existência de cemitérios clandestinos e à incriminação do aborto (LAURENTI; JORGE; GOTLIEB, 2000; RODRIGUES; SIQUEIRA, 2003).

Gomes, Mamede e Costa-Junior (2004) realizaram, nos anos de 1999 e 2000, uma pesquisa nos Estados de São Paulo, Paraná, Pará, Ceará e Mato Grosso para identificar mortes maternas não registradas e/ou mascaradas, por meio das informações disponibilizadas no Sistema de Informações Hospitalares do Sistema Único de Saúde (SIH-SUS). Nesse período foram registradas no Sistema 596 mortes maternas, e os pesquisadores encontraram mais 55 casos de mortes de mulheres em idade reprodutiva que deveriam estar informadas como morte materna, totalizando 651 óbitos. Tais achados confirmam que o sistema de informação ainda apresenta fragilidade na identificação de mortes maternas.

A razão da mortalidade materna no Brasil, segundo o Ministério da Saúde (BRASIL, 2004), em 2002, foi de 50,3 por cem mil nascidos vivos. A região Nordeste teve o maior índice, 60,8, seguida da região Centro-Oeste, com 60,3, região Sul, com 56,6, Norte, com 53,2 e o menor índice foi encontrado na região Sudeste, com 45,9 .

Portanto, esses dados confirmam que a mortalidade materna é um indicador de desigualdade social que reflete o nível de desenvolvimento socioeconômico de cada região, representando hoje um problema de saúde pública (BRASIL, 2002). 
No Estado do Acre, a taxa de mortalidade materna nos anos de 1999 a 2003, segundo o Plano Estadual de Saúde (2004), apresenta os seguintes valores:

Quadro 1 - Taxa de mortalidade materna no Estado do Acre, no período de 1999 a 2003

\begin{tabular}{|c|c|}
\hline Ano & Tx de Mort. Materna/100.000 \\
\hline \hline 1999 & 40,10 \\
\hline 2000 & 58,74 \\
\hline 2001 & 20,16 \\
\hline 2002 & 37,94 \\
\hline 2003 & 51,97 \\
\hline
\end{tabular}

Fonte: SIM/VE/SESACRE

Pode-se verificar que houve um crescimento, nos dois últimos anos pesquisados, indicando a necessidade de melhoria na qualidade da assistência à saúde materna. Esses dados são preocupantes, tendo em vista que a Razão de Mortalidade Materna aceitável pela Organização Mundial de Saúde (OMS) é de 10 óbitos por 100 mil nascidos vivos (MOURA; HOLANDA-JUNIOR; RODRIGUES, 2003).

As mortes maternas são aquelas ocorridas durante a gravidez, o parto e o puerpério, em decorrência de complicações específicas desse período ou de doenças preexistentes ou adquiridas durante o mesmo. As causas de mortes maternas, do ponto de vista clínico e obstétrico, são classificadas em dois grupos: as chamadas causas obstétricas diretas que são as complicações específicas do ciclo gravídico-puerperal, entre elas, a eclampsia, as hemorragias, a infecção puerperal e o aborto que são perfeitamente preveníeis com uma boa assistência no pré-natal e 
no parto. No outro grupo, estão as causas obstétricas indiretas, ou seja, as outras doenças que podem complicar a gestação e o parto e que também podem ser controladas por um bom serviço de pré-natal, prevenindo, tratando esses agravos e conseqüentemente evitando essas mortes (LAURENTI, 1998; BRASIL, 2003b).

Em 2002, Laurenti, Jorge e Gotlieb (2004) estudaram 26 capitais de Estados brasileiros e Distrito Federal quanto às causas de morte em mulheres de 10 a 49 anos, encontraram que dos 7.332 óbitos, $458(6,2 \%)$ ocorreram no ciclo gravídico-puerperal. Essa proporção foi maior nas regiões Norte $(8,4 \%)$ e Nordeste $(8,2 \%)$, em relação ao Sudeste $(5,1 \%)$, Sul $(6,4 \%)$ e Centro-Oeste $(6,4 \%)$.

O risco de morte materna decorrente do parto cesárea é mais elevado que no parto normal. Além das causas tradicionais de morte materna em países em desenvolvimento, especialmente a infecção e a hemorragia, há também a embolia pulmonar e os acidentes anestésicos. Portanto, é importante que o profissional de saúde conheça tais riscos e suas possíveis repercussões no momento de decidir pela via de parto (BRASIL, 2003b).

O percentual de cesariana no Estado do Acre em 2003 foi de 23,2\%. Esse valor, mesmo que muito mais baixo em relação a muitas regiões do país, demonstra ainda nível acima daquele recomendado pela OMS, que é de, no máximo, 15\%. O incremento nas taxas de utilização da cesariana é um fenômeno que vem ocorrendo em todo o mundo, mais especificamente no Brasil, onde chega a ser considerada epidêmica (BRASIL, 2003b). No ano de 2005, o número total de partos em Rio Branco foi de 7.201 , sendo $56,1 \%$ de partos vaginais e $43,9 \%$ de cesáreas (RIO BRANCO, 2006a).

A instituição do Programa de Assistência Integral à Saúde da Mulher (PAISM), pelo Ministério da Saúde, em 1984, por meio de suas ações, trouxe um 
importante significado social para a saúde das mulheres, destacando a sua singularidade enquanto uma proposta de mudança na maneira como até então a saúde das mulheres era tratada, bem como a incorporação, em seu conteúdo, dos princípios de integralidade e universalidade da assistência em saúde, em todas as fases da vida da mulher. Dentre as prioridades para a atenção à saúde da mulher, o PAISM destaca o atendimento das necessidades das gestantes, no que concerne a melhores condições de assistência à mãe e ao concepto (OSIS, 1998; LOPES; PORTELA; PAES, 2001).

No ano de 1996, o Ministério da Saúde, em parceria com a Federação Brasileira das Sociedades de Ginecologia e Obstetrícia (Febrasgo), o Fundo das Nações Unidas para a Infância (UNICEF) e a Organização Pan-Americana da Saúde (OPAS), incorporou, em suas políticas de saúde à atenção materno-infantil, o Projeto Maternidade Segura, com o propósito de reduzir a mortalidade materna e perinatal, por meio da melhoria da assistência ao parto e ao nascimento (BRASIL, 2003a).

Tal projeto está embasado na iniciativa do Grupo Interagencial (IAG) por uma Maternidade Sem Risco (MSR) lançada, em 1987, pela OMS e estabelecida para aumentar a consciência e promover ação em nível global e nacional para conseguir que as gravidezes e partos sejam mais seguros para as mulheres e recém-nascidos (MAcDONALD; STARRS, 2003).

O enfoque central desse programa é diminuir a morbimortalidade materna e infantil, por meio de ações para enfrentar os obstáculos já conhecidos, mas ainda não vencidos. Essas preocupações fundamentam-se no conhecimento sobre a magnitude do problema da morte materna, em vários países como no Brasil, e na convicção de que tal problema é reflexo da qualidade da assistência recebida pelas mulheres durante o ciclo gravídico-puerperal, pois a assistência pronta, oportuna e 
adequada pode evitar a maioria dessas mortes (TANAKA, 2000).

Em 1997, o IAG convocou uma conferência internacional com o objetivo de examinar as lições aprendidas, durante o primeiro decênio da Iniciativa, identificar estratégias mais eficazes e mobilizar a ação em nível nacional, para implementar estas estratégias. Surgiu desta conferência, um claro consenso sobre o valor da atenção qualificada durante o parto, como uma intervenção fundamental para tornar as gravidezes e partos mais seguros (MAcDONALD; STARRS, 2003).

Nesse sentido, a Confederação Internacional de Parteiras (ICM) e a Federação Internacional de Ginecologia e Obstetrícia (FIGO) estabeleceram a necessidade de um profissional com habilidade em atenção ao parto para cada 5.000 habitantes. Em um país em desenvolvimento, isto se traduziria na necessidade de uma pessoa qualificada oferecendo atenção para cada 200 nascimentos por ano. No entanto, os países desenvolvidos têm fixado metas de pessoal qualificado muito mais baixas do que estas, as quais variam entre 30 e 120 nascimentos atendidos por uma pessoa qualificada (MAcDONALD; STARRS, 2003).

A atenção qualificada se refere ao processo pelo qual uma mulher grávida e o recém-nascido recebem atendimento adequado durante a gravidez, o trabalho de parto, o parto, o período pós-parto e o neonatal, independente do parto acontecer no domicílio, no centro de saúde ou no hospital (MAcDONALD; STARRS, 2003).

Os países que têm dado prioridade à ampliação da atenção qualificada, durante o parto, têm alcançado uma redução substantiva na mortalidade materna. Há evidência histórica e epidemiológica de que a atenção qualificada, durante o parto e pós-parto, tem um efeito significativo na redução das mortes maternas. Mas, apesar dessas evidências dos países desenvolvidos sobre o quantitativo do pessoal qualificado, permanecem números insuficientes de profissionais com tais habilidades 
em muitos países em desenvolvimento (MAcDONALD; STARRS, 2003; WORLD HEALTH ORGANIZATION, 2004).

As experiências da Colômbia, Malásia, Sri Lanka e Tailândia têm mostrado que é possível conseguir atenção qualificada onde exista compromisso político e cujo compromisso seja transformado em ação. Todos os países podem direcionar para um modelo de atenção ao parto, mas o tempo que levará para que esse modelo funcione dependerá da capacidade de cada sistema de saúde em experimentar e focalizar nos profissionais qualificados. Assim, oferecer uma atenção qualificada para todos necessitará ser uma prioridade (WHO, 2004).

No Brasil, o Ministério da Saúde, desde 1999, vem financiando o Programa de Capacitação de Parteiras Tradicionais e cursos de especialização em enfermagem obstétrica, mediante convênio firmado com universidades e secretarias de saúde em todo o país. Esses programas procuram dar ênfase ao ensino da assistência no pré-natal e parto. Tais políticas estão assentadas na necessidade de formação de pessoal qualificado para o atendimento à mulher no ciclo grávidopuerperal e na redução da morbimortalidade materna e neonatal (RIESCO; TSUNECHIRO, 2002).

No ano de 2000, aconteceu o maior encontro de líderes de Estado das Nações Unidas em Nova York, EUA, quando adotaram a Declaração do Milênio constituída por oito objetivos críticos, a fim de combater a pobreza e acelerar o desenvolvimento humano. Dois dos oitos objetivos relacionam-se à redução da mortalidade infantil e melhora da saúde materna (WHO, 2004).

Nesse sentido, é importante destacar que, após muitos anos de luta para o reconhecimento da ligação entre o desenvolvimento e a saúde materna, a OMS, a ICM e a FIGO conseguiram incluir, entre as metas de desenvolvimento do milênio, a 
redução em três quartos, nas taxas de mortalidade materna entre 1990 e 2015 (WHO, 2004).

Com o objetivo de assegurar a melhoria no acesso, na cobertura e na qualidade do acompanhamento pré-natal, como também na assistência ao parto e puerpério, às gestantes e ao recém-nascido no Brasil, o Ministério da Saúde lançou o Programa de Humanização no Pré-natal e Nascimento (PHPN), por meio da Portaria/GM n $\mathrm{n}^{0} 569$, de 1/6/2000. A proposta do programa traz, em seu bojo, a discussão sobre as práticas pré-natais e suas bases conceituais, em consonância com os modelos utilizados em todo o mundo (BRASIL, 2000b).

O PHPN possui um sistema de informação, o Sisprenatal, um sistema informatizado através do DATASUS, que possibilita 0 monitoramento e acompanhamento de cada gestante, com o objetivo de gerar parâmetros para avaliação da assistência pré-natal oferecida à clientela pelas unidades básicas de saúde. A avaliação preliminar do Sisprenatal, gerada nos anos de 2001 e 2002, demonstrou que apenas $25 \%$ das gestantes cadastradas conseguiram o número de seis consultas ou mais. Os dados geridos pelo programa possibilitam, além de avaliar, ampliar as ações já adotadas pelo Ministério da Saúde na área de atenção à gestante (BRASIL, 2000b; SILVA; CECATTI; SERRUYA, 2005).

A assistência pré-natal é um fator importante na redução da mortalidade materna e perinatal, de modo que muitas das patologias, no período gravídicopuerperal, podem ser tratadas e controladas, já que um pré-natal de qualidade, certamente orientará, no sentido de se evitarem complicações no parto, nos cuidados imediatos ao recém-nascido e no período puerperal (OBA; TAVARES, 2000).

A atenção à mulher na gestação e parto permanece um desafio para a 
assistência. Pesquisas qualitativas sobre assistência pré-natal indicam que a qualidade da assistência representa uma situação crítica, mantendo-a como tema de permanente preocupação e discussão (SERRUYA; LAGO; CECATTI, 2004b).

Ações muito importantes para o controle da mortalidade materna são dependentes do acesso e da qualidade da atenção realizada pelos serviços de saúde, especialmente na atenção ao parto, puerpério e nas ações de acompanhamento ao pré-natal (COSTA; GUILHEM, WALTER, 2005).

As altas taxas de morbimortalidade materna ainda permanecem como um desafio, e a atenção qualificada no pré-natal pode contribuir significativamente na redução dessas taxas e promover uma maternidade sem risco. Por outro lado, o oferecimento de uma atenção qualificada está na dependência de desempenho qualificado por partes dos profissionais que assistem mulheres na gestação. Nesse sentido, a ICM vem assumindo o compromisso de estabelecer as competências essenciais em obstetrícia de que um profissional necessita para atender de forma competente.

\subsection{Competências essenciais no atendimento à gestação}

A assistência pré-natal é a principal forma de conhecimento prévio sobre o parto e o puerpério, uma vez que possibilita prevenir e detectar alterações da gravidez como também tratá-las de forma precoce, reduzindo assim os índices de morbimortalidade materna e fetal (CARVALHO et al., 2004). Para Alexander e Kotelchuck (2001), um atendimento de qualidade no pré-natal pode desempenhar um papel importante na redução da mortalidade materna, além de evidenciar outros 
benefícios à saúde materna e infantil. O cuidado pré-natal contribui para a melhoria dos resultados da gravidez, no entanto, apesar das evidências, muitas mulheres nos países subdesenvolvidos e em desenvolvimento são carentes de assistência prénatal (RODRIGUES FILHO; COSTA; LENO, 1994).

A maioria dos programas de atenção pré-natal no Brasil é originada de modelos desenvolvidos em países ocidentais, nas primeiras décadas do século passado. Embora significativa parcela tenha conteúdo e calendários similares, os programas diferem quanto ao tipo de profissionais envolvidos, às práticas recomendadas e realizadas, além de diferentes taxas de adesão de mulheres (SILVA; CECATTI ; SERRUYA, 2005).

Segundo o Ministério da Saúde, um bom pré-natal deve incluir o mínimo de seis consultas, iniciando no primeiro trimestre, duas no segundo e três no terceiro trimestre de gestação. Reforça que o principal objetivo da assistência pré-natal é acolher a mulher, desde o início da gravidez (BRASIL, 2000a).

Para que isso ocorra, cabe ao profissional de saúde acolher integralmente a história de cada gestante, a partir de seu relato e de seus acompanhantes como também buscar compreender os múltiplos significados da gestação para aquela mulher e sua família. O diálogo aberto, a sensibilidade e a capacidade de percepção do profissional que acompanha o pré-natal são condições básicas, para que o saber em saúde seja colocado à disposição da mulher e de seus familiares. Assim, para assegurar a qualidade do atendimento pré-natal, principalmente quanto aos aspectos emocionais, é imprescindível que o profissional consiga manter um relacionamento efetivo com a cliente (BRASIL, 2000a; MERIGUI, 1998).

No Reino Unido, o modelo de cuidado pré-natal que não passou por mudanças, por quase 50 anos, constava de visitas mensais até as 28 semanas, a 
cada 15 dias até 36 semanas e semanalmente até o parto. Nos últimos anos, naquele país, tem sido discutida a modificação desse modelo, com a finalidade de reduzir o número de consultas. Na Inglaterra, nos últimos 20 anos, a Faculdade Royal de Obstetras e Ginecologistas estabeleceu um guia para grávidas de baixo risco, reduzindo seu modelo de 13 consultas pré-natais para oito consultas para primíparas e cinco para multíparas. Outros países europeus como a França, Suíça e Luxemburgo têm incorporado modelo similar (SANDERS et al., 1999; WALKER et al., 2002).

Vários estudos na Europa, África e Estados Unidos têm comparado o número de visitas tradicionais com o número de consultas reduzidas. Embora esses estudos variem, em número de consultas, eles não encontraram diferença estatisticamente significativa nos resultados perinatais entre as mulheres com freqüência reduzida, de aproximadamente oito consultas e aquelas com assistência pré-natal usando o modelo tradicional de 14 consultas (WALKER et al., 2002). Walker et al. (2002) chamam atenção para um estudo multicêntrico da OMS realizado com 30.000 mulheres, de quatro países diferentes, demonstrando semelhança nos resultados maternos ou perinatais entre mulheres nos grupos de consultas com freqüência tradicional versus freqüência reduzida. Portanto, para mulheres de baixo risco obstétrico, é mais provável que a qualidade e não a quantidade de consultas pré-natais promova resultados saudáveis.

Segundo a Pesquisa Nacional de Demografia e Saúde (PNDS), realizada em 1996, no Brasil, 13\% das mulheres no país não haviam realizado nenhuma consulta de pré-natal. Nas regiões urbana e rural, esses valores foram $9 \%$ e $32 \%$ respectivamente. A menor cobertura foi encontrada na região Nordeste $(75 \%)$ e a maior no Estado do Rio de Janeiro (96\%) (BRASIL, 2003b). 
No Estado do Acre, a razão entre o número de nascidos vivos e o número de consultas de pré-natal é de 46\%, segundo a Agenda Estadual de Saúde - 2001, da Secretaria de Saúde e Saneamento do Acre - SESSACRE (ACRE. Governo do Estado do Acre, 2001).

A cobertura de pré-natal em todo o Estado do Acre, em 2003, segundo o Sistema de Informação de Nascidos Vivos (SINASC), a Vigilância Epidemiológica (VE) e a Secretaria Estadual de Saúde (SESACRE), aumentou para 57,9\%, em relação a 1999, que foi de 32,3\% (ACRE. Governo do Estado do Acre, 2004). Vale salientar que, no Estado do Acre, municípios com pequenas populações apresentam forte característica rural e sobrevivem com grandes dificuldades financeiras, devido à longa crise da sua economia extrativista. São grandes as deficiências educacionais, habitacionais, de acesso ao saneamento básico e à assistência à saúde.

Segundo o manual de Assistência Pré-Natal do Ministério da Saúde, para que a assistência pré-natal seja efetiva, devem-se garantir as seguintes condições: a) identificação precoce das gestantes na comunidade; b) sistema eficiente de referência e contra-referência; c) recursos humanos treinados; d) área física adequada; e) equipamento e instrumental mínimos; f) apoio laboratorial; g) instrumentos de registro, h) medicamentos essenciais; j) avaliação permanente da assistência pré-natal (BRASIL, 2000a).

No entanto, essa não é a condição que se apresenta nas instituições públicas. Estudos mostram que, entre as condições nas quais as enfermeiras desenvolvem seu trabalho, várias inadequações são encontradas, como: área física inadequada; equipamentos e materiais obsoletos e em pouca quantidade; recursos humanos escassos, etc. Com isso, a assistência fica prejudicada, levando, muitas vezes, os profissionais a procurar diversos caminhos, além do recurso do improviso, 
na tentativa de solucionar tal situação (NUNES; FERREIRA; PAIVA, 2002).

Outra situação encontrada é o acúmulo de funções das enfermeiras nas unidades de assistência pré-natal, onde estão sob seu encargo vários programas, tais como o da Saúde da Criança, do Hipertenso, do Diabético, da Imunização, entre outros, deixando a área materna, considerada como de prioridade da população, em descoberto (GARDENAL et al., 2002).

Nos Estados Unidos, foi desenvolvido, por meio de uma equipe experiente em cuidado pré-natal, o centro para grávidas. Esse centro é um lugar onde as mulheres de baixo risco recebem assistência pré-natal por vários profissionais capacitados, incluindo parteiras, enfermeiras, médicos, educadores, assistentes sociais, entre outros. Desde 2004, tem sido replicada a experiência em mais de 50 locais ativos, nos Estados Unidos e Canadá, o que está despertando um crescente interesse internacional (RISING; KENNEDY; KLIMA, 2004).

A adesão das mulheres ao pré-natal está relacionada com a qualidade da assistência prestada pelos serviços e pelos profissionais de saúde. Hadad, França e Uchôa (2002) estudaram a avaliação das mães sobre o atendimento recebido nos serviços de saúde e concluíram que 43\% das avaliações negativas estavam relacionadas tanto à estrutura dos serviços de saúde como também ao profissional que prestava atendimento. Vários estudos apontam que há ainda um lócus de vulnerabilidade na assistência e que variáveis como: renda, região, localização, escolaridade, qualidade dos serviços, entre outros, exercem influência na baixa adesão das mulheres ao pré-natal (ALEXANDER; KOTELCHUCK, 2001; SERRUYA; LAGO; CECATTI, 2004a).

A assistência pré-natal deve ser organizada para atender às reais necessidades da população de gestantes, mediante utilização dos conhecimentos 
técnico-científicos existentes e dos meios e recursos adequados para cada caso. Um pré-natal de qualidade deve ser um caminho para fortalecer a mulher e torná-la protagonista do processo de nascimento e da sua vida (BRASIL, 2000a).

O adequado preparo da gestante para o momento do nascimento deve ser iniciado precocemente durante o pré-natal. Além dos aspectos técnicos, o preparo da gestante para o parto abrange a incorporação de um conjunto de cuidados, medidas e atividades que têm como objetivo oferecer à mulher a possibilidade de vivenciar a experiência do trabalho de parto e parto como processos fisiológicos, sentindo-se protagonista desse processo (BRASIL, 2003a).

As enfermeiras, nas últimas décadas, vêm gradativamente integrando-se às atividades de assistência às gestantes e ocupando espaços relevantes nas instituições de saúde que prestam atendimento a tal clientela. A consulta de enfermagem visa a oferecer assistência clínico-obstétrica, atentando aos fatores de risco para a gestante e o concepto, e deve utilizar, como referência, o roteiro do manual de Assistência Pré-Natal do Ministério da Saúde. (BRASIL, 2000a, MOURA; LOPES, 2003).

A Organização Mundial de Saúde (1996), por meio da publicação "Maternidade Segura - assistência ao parto normal: um guia prático", identifica a enfermeira obstétrica como o profissional mais adequado e com melhor custoefetividade de prestador de cuidados de saúde, responsável pela assistência à gestação e ao parto normal, incluindo a avaliação de riscos e o reconhecimento de complicações (OMS, 1996).

A(o) enfermeira(o) possui embasamento teórico-científico e respaldo legal para prestar assistência pré-natal de baixo risco, e se esperam dela(dele) o acompanhamento e a assistência à população de gestantes em Rio Branco. A 
assistência pré-natal é um momento oportuno e favorável à discussão e a esclarecimentos de questões que permeiam a gravidez, e a atuação da enfermeira nesta assistência possibilita uma apreensão mais ampliada dos problemas da gestante (BOCARDI; MAMEDE; CLAPIS, 2004; BRIENZA , 2005).

Estudos mostram que, na Suécia, país onde o atendimento às gestantes cabe à enfermeira obstétrica, os índices de mortalidade materna e neonatal são baixos, e que o trabalho da enfermeira, consubstanciado o do médico, permite que ela atenda mais clientes e de forma mais satisfatória (LIMA, 1997).

No Brasil, Koffman e Bonadio (2005) realizaram estudo em uma instituição de São Paulo, na qual a assistência pré-natal é prestada, exclusivamente, por enfermeiras obstétricas e alunos dos cursos de graduação e pós-graduação em enfermagem. Identificaram que, segundo as usuárias daquele serviço de pré-natal, a grande procura pela assistência no local acontece devido ao perfil dos profissionais, compromissados com a qualidade técnica, com os aspectos ético-políticos e com os direitos da mulher.

Clapis (2005), estudando enfermeiras obstétricas, egressas do Curso de Especialização em Enfermagem Obstétrica e Neonatal, modalidade residência, da Escola de Enfermagem de Ribeirão Preto, que concluíram sua formação entre os anos de 1999 a 2005, verificou que, das 26 estudadas, apenas uma referiu que, entre as atividades desenvolvidas, acompanhava o pré-natal em todas as fases da gravidez. Outras referiram atuar com gestantes apenas em situação de ensino, acompanhando alunos de graduação ou especialização, ou ainda, oferecendo cursos de gestantes.

A presença e o papel da enfermeira obstétrica na atenção pré-natal têm sido incentivados no país, dada a contribuição que esta profissional pode dar à 
ampliação da cobertura e da qualidade dos serviços. No entanto, Costa, Guilhem e Walter (2005) realizaram pesquisa em 627 municípios brasileiros e identificaram que, em 72,6\% desses municípios, as secretarias municipais não empregam enfermeiros obstetras na rede de serviços de saúde.

No norte da Nigéria, no entanto, a presença de somente um médico treinado não obstetra, nos serviços de obstetrícia, possibilita às enfermeiras realizar quase todo o atendimento obstétrico, exceto a cesariana. Em Matlab e Bangladesh, as enfermeiras obstétricas registradas atendem $40 \%$ de todas as mulheres com complicações, mas elas têm contado com suporte ambulatorial e hospitalar. O treinamento desse pessoal foi o principal fator para a melhora dos serviços. Por outro lado, a carência de enfermeiras treinadas com habilidades para salvar vidas na comunidade é ainda uma realidade encontrada (KWAST, 1998).

Os dados atuais indicam que somente $53 \%$ de todos os nascimentos, nos países em desenvolvimento, são atendidos por pessoal qualificado e, na última década, têm havido poucas mudanças na cobertura da atenção qualificada em obstetrícia (MAcDONALD; STARRS, 2003).

O termo "pessoal ou provedor qualificado" refere-se àquelas pessoas com habilidades para prestar atenção profissional à gestação, parto e pós-parto, sendo considerados pela OMS os enfermeiros, médicos e parteiras profissionais. Uma pessoa qualificada é aquele profissional de saúde autorizado que tenha sido educado e treinado, com proficiência nas habilidades necessárias para o cuidado e tratamento de gravidezes e nascimentos normais e período pós-natal imediato (MAcDONALD; STARRS, 2003; WHO, 2004).

O enfoque do atendimento qualificado baseia-se na premissa de que cada mulher deve ter acesso à assistência com profissionais que tenham habilidades 
necessárias para oferecer cuidados competentes, durante a gravidez e o parto. Para que isso ocorra, o profissional qualificado necessita de um contexto facilitador que ajude e apóie seu trabalho. Isto inclui um marco legal e normativo de respaldo, acesso a equipamentos e medicamentos essenciais, um sistema de referência em funcionamento e sistemas de educação e de saúde que fomentem o pensamento crítico, a competência clínica e o desenvolvimento de habilidades interpessoais e de comunicação eficazes (MAcDONALD; STARRS, 2003).

Na gravidez, a mulher necessita de cuidado contínuo para assegurar a melhor saúde possível para ela e para o recém-nascido. O início do cuidado deve estar na sua própria casa, isto é, por meio de autocuidado e prevenção, seguido pelo primeiro nível de cuidado de saúde, que pode ser em um posto de saúde, clínica ou na casa da cliente, envolvendo o fornecimento de cuidados obstétricos de alta qualidade. O fornecimento de cuidados contínuos bem-sucedidos requer um sistema de saúde funcionando com infra-estrutura necessária no local, incluindo transporte entre o nível primário de saúde e orientações em clínicas e hospitais. São importantes, também, a colaboração e eficiência entre todos aqueles envolvidos no atendimento à mulher grávida e ao seu recém-nascido (WHO, 2004).

A qualificação de um indivíduo é sua capacidade de resolver de forma rápida e adequada os problemas concretos, mais ou menos complexos, que surgem no exercício de sua atividade profissional. O exercício dessa capacidade implicaria a mobilização de competências adquiridas ou construídas mediante aprendizagem, no decurso da vida ativa, tanto em situações de trabalho como fora deste (MANFREDI, 1998).

A Confederação Internacional das Parteiras (INTERNATIONAL CONFEDERATION OF MIDWIVES, 2002) definiu no documento "Competências 
Essenciais para o Exercício Básico da Obstetrícia" as competências essenciais em obstetrícia, cujos conhecimentos e habilidades o profissional qualificado deve possuir para proporcionar à mulher uma atenção de forma competente:

Competência 1: as parteiras têm o conhecimento e habilidades requeridas das ciências sociais, saúde pública e ética que constituem a base do cuidado de alta qualidade, culturalmente pertinente, apropriado para as mulheres, recém-nascido e famílias no período reprodutivo.

Competência 2: as parteiras proporcionam educação para saúde de alta qualidade, culturalmente sensível, e oferecem serviços para toda a comunidade para promover uma vida familiar saudável, gestações planejadas e uma maternidade/paternidade positiva.

Competência 3: as parteiras proporcionam um cuidado pré-natal de alta qualidade; elas se preocupam em otimizar a saúde da mulher durante a gravidez, e isso inclui a detecção precoce, tratamento ou encaminhamento das complicações detectadas.

Competência 4: as parteiras proporcionam, durante o parto, um cuidado de alta qualidade, culturalmente sensível. Administram um parto higiênico e seguro e manejam situações de emergência para melhorar a saúde das mulheres e dos recém-nascidos.

Competência 5: as parteiras proporcionam à mulher cuidados integrais, de alta qualidade, culturalmente sensível, durante o pós-parto.

Competência 6: as parteiras proporcionam cuidado integral de alta qualidade para o recém-nascido saudável, do nascimento até dois meses de idade (INTERNATIONAL CONFEDERATION OF MIDWIVES, 2002).

Para o atendimento de qualidade, especificamente durante a gravidez, o 
profissional qualificado deve ter as seguintes Competências Essenciais:

Monitorar a saúde da mulher e do feto ;

Realizar tratamento preventivo e curativo para enfermidades comuns (anemia, infecções de transmissão sexual, infecções das vias urinárias e malária) e imunizar contra toxóide tetânico;

Educar as usuárias sobre os sinais de perigo à saúde materna e fetal e orientá-las no planejamento do parto;

Oferecer aconselhamento e apoio para enfrentar uma gravidez não desejada (MAcDONALD; STARRS, 2003).

De acordo com a ICM, todos os profissionais qualificados (tais como parteira, profissional médico ou enfermeira) devem ter habilidades essenciais em obstetrícia. As habilidades adicionais requeridas variam de país para país, e possivelmente até mesmo dentro de um país, tendo expectativas para diferentes locais, tais como zonas urbanas e rurais.

Os profissionais qualificados em obstetrícia, em todos os níveis de sistema de saúde, devem ter habilidades e capacidade para realizar todas as funções essenciais durante a gravidez, a saber:

No cuidado da gravidez: tomar uma história detalhada, perguntando questões apropriadas; calcular a data do parto e realizar teste para HIV;

Assistir a gravidez da mulher e seus familiares nos planos para o nascimento (isto é, onde o parto será, quem estará presente, em caso de complicação, como orientar);

Educar a mulher (e seus familiares e outros que apóiam a mulher 
grávida) sobre estratégias de autocuidado durante a gravidez, nascimento e período pós-natal;

Identificar doenças e condições prejudiciais à saúde durante a gravidez, realizar tratamento de primeira linha (incluindo procedimentos de emergência quando necessário) e dar orientações eficazes (WHO, 2004).

A definição desses padrões de competência é importante, pois além de possibilitar a explicitação da qualidade esperada, no desempenho das atividades relacionadas à atenção à saúde materna e neonatal dos serviços de saúde, ela colabora com a redução da morbi-mortalidade materna e neonatal.

Analisar as competências essenciais, desenvolvidas pelos profissionais de enfermagem na assistência pré-natal, é uma forma de identificar a contribuição desses profissionais no atendimento à gestação, visto que o atendimento à saúde da população vem passando por transformações, na medida em que o município tem procurado adaptar-se ao modelo assistencial proposto pelo SUS.

Esta pesquisa propõe um estudo da realidade da atenção às gestantes, no município de Rio Branco (AC), como forma de trazer subsídios para uma atenção eficaz e de boa qualidade e uma atuação de forma competente, durante a gravidez, como também contribuir para com as políticas nacionais de formação de recursos humanos em saúde e, em especial, em saúde materna e neonatal. 


\subsection{Pressuposto e questões de pesquisa}

Várias instâncias internacionais e nacionais têm definido metas para a redução da morte materna e a expansão do atendimento qualificado à mulher, durante o processo de nascimento. Pressupomos que a melhoria da qualidade de assistência ao pré-natal e a participação de um profissional qualificado possam contribuir significativamente para a redução da mortalidade materna.

Com base neste pressuposto, emergiram as seguintes questões:

$\Rightarrow$ Quais são os serviços que atendem a mulher na atenção pré-natal, no município de Rio Branco?

$\Rightarrow \quad$ Quem são os profissionais que estão prestando assistência à mulher durante a gestação?

$\Rightarrow \quad$ Quais as competências essenciais na atenção à gestação que os profissionais de enfermagem desenvolvem na sua prática? 
2 OBJETIVOS 


\subsection{Geral:}

- Analisar a atenção dada pelos profissionais de enfermagem à assistência pré-natal, no município de Rio Branco-AC.

\subsection{Específicos:}

- Identificar os profissionais que atuam no pré-natal;

- Descrever o perfil dos profissionais de enfermagem que participam na atenção ao pré-natal;

- Analisar as competências essenciais desenvolvidas, na prática, pelos profissionais de enfermagem que atuam na atenção ao pré-natal. 
3 METODOLOGIA 


\subsection{Tipo do estudo}

O delineamento do presente estudo é descritivo de abordagem quantitativa. Em um estudo quantitativo, o delineamento de pesquisa apresenta estratégias que o pesquisador planeja adotar para desenvolver informações precisas e interpretáveis (POLIT; BECK; HUNGLER, 2004).

Segundo Pereira (1995), as investigações epidemiológicas, de cunho descritivo, têm o objetivo de informar sobre a distribuição de um evento, na população, em termos quantitativos. Nelas não há formação de grupo-controle para a comparação dos resultados. Podem ser usados dados secundários ou de inquéritos especiais. O pesquisador interessado em traçar o perfil dos temas listados tem apenas de observar como estas situações estão ocorrendo, em uma ou mais populações, e expressar as respectivas freqüências de modo apropriado.

Para Marconi e Lakatos (1996), os estudos descritivos descrevem: "um fenômeno ou situação, mediante um estudo realizado em determinado espaçotempo. "Delineia o que é"; aborda também quatro aspectos: descrição, registro, análise e interpretação de fenômenos atuais, objetivando o seu funcionamento no presente".

Os estudos transversais envolvem coleta de dados em um ponto de tempo. Os fenômenos sob estudo são obtidos durante um período de coleta de dados. São especialmente apropriados para descrever a situação, o status do fenômeno, ou as relações entre fenômenos em um ponto fixo. É também designado como seccional, corte, corte-transversal, vertical ou de prevalência (PEREIRA, 1995; POLIT; BECK; HUNGLER, 2004).

Esta pesquisa está inserida em um amplo projeto sobre o "Mapeamento 
dos Serviços de Obstetrícia/Parteria nas Américas", proposto pela OMS/OPAS, que tem o propósito de auxiliar na melhoria da qualidade da assistência dos serviços de obstetrícia e promover uma maternidade sem risco, em toda a América Latina e no Caribe. A vinculação do presente estudo é com o Centro Colaborador da Organização Mundial de Saúde para o desenvolvimento da pesquisa em enfermagem da Escola de Enfermagem de Ribeirão Preto da Universidade de São Paulo - EERP-USP já que está sob sua responsabilidade a coordenação do projeto em nível nacional (ORGANIZAÇÃO PAN-AMERICANA DE SAÚDE. OPAS, 2004).

\subsection{Local do estudo}

\subsubsection{O Estado do Acre}

O Estado do Acre, com extensão territorial de 164.221,36 km², está localizado na parte sudoeste da Amazônia, ocupando 4,26\% de sua área. Os limites do Estado são formados por fronteiras internacionais com Peru e Bolívia e por divisas estaduais com os Estados do Amazonas e Rondônia. O Estado tem 22 municípios. A capital, Rio Branco, é o município mais populoso, nela se concentra a maior parte da infra-estrutura administrativa do Estado, dos serviços de saúde e de outros setores que polarizam a vida na região e em todo o Estado (ACRE. Governo do Estado do Acre, 2006).

De acordo com o Instituto Brasileiro de Geografia e Estatística (IBGE, 2000), a população residente do Acre é de 557.526 habitantes, dos quais $66,41 \%$ residem na zona urbana e 33,59\%, na zona rural. A taxa de alfabetização é de 
76,9\% (INSTITUTO BRASILEIRO DE GEOGRAFIA E ESTATÍSTICA. IBGE, 2000a).

Considerando a distribuição da população por faixa etária, temos o seguinte comportamento: 2,71\% são menores de 1 ano; 23,85\% representam a população de 1 a 9 anos; 24,18\% a população de adolescentes(10 a 19 anos); 30,45\% representam a faixa etária de 20 a 39 anos; 17,34\% estão entre 40 e 59 anos e 5,45\% da população é maior de 60 anos. O índice de envelhecimento em 2003 foi 9,3\%, e a maior concentração da população está na faixa etária de 20 a 39 anos (ACRE. Governo do Estado do Acre, 2004).

Segundo dados do IBGE, o Produto Interno Bruto - PIB no Estado do Acre, em 2001, foi $\mathrm{R} \$$ 1.921.000.000,00 (Um bilhão, novecentos e vinte e um milhões de reais), e o PIB per capta foi $\mathrm{R} \$ 3.351,00$ (Três mil, trezentos e cinqüenta e um reais), que representa $3,36 \%$ do PIB da região Norte e $0,16 \%$ do PIB nacional (ACRE. Governo do Estado do Acre, 2004).

\subsubsection{Rio Branco}

A população, segundo o IBGE (2000), é de 253.059 habitantes. Rio Branco concentra $45,38 \%$ do total da população do Estado. A população de mulheres em idade fértil (10 a 49 anos), no ano de 2005, no município de Rio Branco foi de 104.246 mulheres. O rendimento médio mensal dessas mulheres é de $\mathrm{R} \$ 511,28$ reais (IBGE, 2000b; BRASIL. DATASUS, 2005).

No setor saúde, Rio Branco recebe grandes demandas do interior do Estado. No entanto, em diagnósticos clínicos que exigem maior especialidade, os pacientes seguem para tratamento fora do município, principalmente para Goiânia. 
A rede hospitalar conta com seis hospitais e uma maternidade, perfazendo um total de 765 leitos disponíveis ao Sistema Único de Saúde (SUS) (IBGE, 2002).

A atenção básica é de responsabilidade da gestão municipal, por meio da oferta das seguintes ações prioritárias:

Saúde da Mulher - assistência ao pré-natal, parto, puerpério, prevenção de câncer do colo de útero, mama, planejamento familiar, controle das doenças sexualmente transmissíveis e violência.

Saúde da Criança - ações prioritárias de vigilância nutricional, violência, imunização e assistência às doenças prevalentes na infância.

Saúde do Adolescente - ações prioritárias na prevenção da gravidez na adolescência, doenças sexualmente transmissíveis, uso indevido de drogas, violência e incentivo à cultura, ao lazer e esporte (ACRE. Governo do Estado do Acre, 2004).

As ações da atenção básica estão articuladas com a média e alta complexidade, porém ainda sem instrumentos formais de referência e contrareferência institucionalizados. As Unidades de Saúde da Família e os Centros de Saúde são as principais portas de entrada do Sistema e têm como objetivo proporcionar serviços essenciais à população da área de abrangência, atendimento na unidade ou no domicílio do paciente pelos profissionais (ACRE. Governo do Estado do Acre, 2004).

Os serviços de Atenção Básica à Saúde contam com 13 Centros de Saúde e 52 Unidades de Saúde da Família, sendo que apenas 17 unidades de saúde da família estão com a equipe completa, com os seguintes profissionais: médicos, 
enfermeiros, técnico de enfermagem, cirurgião dentista, auxiliar de consultório dentário e agente comunitário de saúde. Apenas 19 unidades contam com médicos, enfermeiros, técnico de enfermagem e agentes comunitários de saúde. O restante das unidades (16) conta com enfermeiro, técnico de enfermagem e agentes comunitários de saúde (RIO BRANCO, 2006b).

No quadro de recursos humanos da Secretaria Municipal de Saúde (SEMSA), encontramos: 98 enfermeiros, 114 auxiliares de enfermagem, 109 técnicos de enfermagem, 47 cirurgiões dentistas, sete psicólogos, quatro fisioterapeutas, três fonoaudiólogos, um assistente social, um pedagogo, 13 técnicos de higiene dental, 43 auxiliares de consultório dentário, 461 agentes comunitários de saúde, três técnicos de laboratório, um auxiliar de análises clínicas e três outros profissionais de nível superior. No quadro de profissionais médicos, encontramos: 36 médicos de saúde da família, 28 clínicos, nove ginecologistas/obstetras, um cirurgião geral, um psiquiatra e 17 pediatras (RIO BRANCO, 2006b).

O município de Rio Branco adota um Manual de Protocolos para pré-natal realizado pela Secretaria Municipal de Saúde, Gerência de Ações Básicas e pela Coordenação de Centros e Postos de Saúde, fazendo o cadastro no Sisprenatal de todas as usuárias com gravidez comprovada, garantindo no mínimo seis consultas de pré-natal e uma de puerpério. Os exames de rotina são oferecidos de acordo com a proposta do Ministério da Saúde, incluindo o teste anti-HIV (RIO BRANCO, 2004b).

Os serviços de enfermagem das Unidades Básicas de Saúde do município de Rio Branco são responsáveis pelas atividades de promoção, proteção e recuperação da saúde a uma população espontânea geograficamente delimitada, mas contando com uma equipe de saúde multidisciplinar em caráter permanente (RIO BRANCO, 2004b). 


\subsection{Amostra}

A amostragem aleatória simples foi composta por 13 Centros de Saúde (CS) e 52 Unidades de Saúde da Família (USF) de forma a contemplar $50 \%$ do total das unidades. Foram sorteados três CSs (25\%) e 13 USFs (25\%). A seleção se deu da seguinte forma: foram enumerados todos os serviços, dando a cada um deles um número e utilizando uma tabela de números aleatórios, procedeu-se o sorteio. A amostra final foi constituída por 16 unidades de saúde.

O processo de seleção aleatória é aquele em que cada elemento na população tem uma chance igual, independentemente de ser ou não selecionado. A amostragem aleatória simples é o delineamento mais básico de amostragem de probabilidade (POLIT; BECK; HUNGLER, 2004).

\subsection{Sujeitos da pesquisa}

Os participantes deste estudo foram 23 profissionais de enfermagem que atendem a mulher, durante a gestação, nas unidades sorteadas (CS e USF), no município de Rio Branco no ano de 2006.

Os sujeitos deste estudo foram: 15 enfermeiros, duas enfermeiras obstétricas, quatro técnicas em enfermagem e duas auxiliares de enfermagem que estavam atuando na assistência pré-natal, no momento da realização da coleta de dados, e que concordaram em participar do estudo. 


\subsection{Aspectos éticos}

Esta pesquisa foi desenvolvida dentro dos parâmetros da Resolução 196/96 do Conselho Nacional de Saúde e Ministério da Saúde (1997) que dispõe sobre pesquisa que envolve seres humanos.

Solicitamos junto à Secretaria Municipal de Saúde permissão para o desenvolvimento da pesquisa, antes de submeter o projeto de pesquisa ao Comitê de Ética em Pesquisa, da Escola de Enfermagem de Ribeirão Preto (ANEXO A).

O Termo de Consentimento Livre e Esclarecido foi assinado pelos profissionais de enfermagem, antes das entrevistas (APÊNDICE A), e todos eles foram informados sobre os objetivos da pesquisa, o sigilo e a não-identificação como participante.

A coleta de dados foi iniciada após a aprovação do projeto de pesquisa pelo Comitê de Ética em Pesquisa, da Escola de Enfermagem de Ribeirão Preto, sob o protocolo de $\mathrm{n}^{\circ}$ 0633/2005 (ANEXO B).

\subsection{Coleta de dados}

A coleta de dados foi desenvolvida em duas fases. A primeira foi através de entrevista estruturada com os profissionais com quem obtivemos informações sobre dados sóciodemográficos, formação profissional e atividades exercidas por esses profissionais na assistência pré-natal. O roteiro da entrevista constou de perguntas abertas e fechadas e foi conduzido pessoalmente pela própria autora (APÊNDICE B). 
A inclusão, no instrumento de coleta de dados, de questões que promovam o exercício da auto-reflexão é de importância também para a identificação das demandas de melhoria de desempenho, tanto pessoal quanto institucional. Auto-avaliação é definida como a habilidade de um profissional refletir sobre as fortalezas e fraquezas de seu próprio desempenho e levar a uma revisão de sua atuação, a fim de identificar necessidades de aprendizagem e melhora no desempenho. A auto-avaliação tem sido relacionada à melhora da qualidade (BOSE; OLIVERAS; EDSON, 2001).

A entrevista, neste estudo, teve uma duração média de 20 minutos e foi realizada na unidade de atuação do profissional entrevistado. A entrevista é aquela em que o entrevistador segue um roteiro previamente estabelecido, e as perguntas feitas ao indivíduo são predeterminadas (MARCONI; LAKATOS, 1996).

A segunda fase da coleta de dados foi a observação sistemática e não participante, do desempenho das atividades e habilidades desenvolvidas pelos profissionais de enfermagem na atenção pré-natal. As observações, neste estudo, foram realizadas em todas as unidades pesquisadas, no período da manhã ou tarde, tanto na pré-consulta, como na consulta.

A observação sistemática que também recebe várias designações, como estruturada, planejada e controlada, deve utilizar instrumentos para a coleta de dados ou fenômenos observados. Nesse tipo de observação, o observador sabe o que procura e o que carece de importância em determinada situação, deve ser objetivo, reconhecer possíveis erros e eliminar sua influência sobre o que vê ou recolhe (MARCONI; LAKATOS, 1996). Como neste estudo a preocupação foi focalizada nas competências essenciais desenvolvidas pelo pessoal de enfermagem na atenção pré-natal, a observação direta do contexto real das situações clínicas foi 
de fundamental importância para a descrição da realidade e suas demandas.

Quanto à observação não participante, o pesquisador toma contato com a comunidade, grupo ou realidade estudada, mas sem integrar-se a ela: permanece de fora. Presencia o fato, mas não participa dele, não se deixa envolver pelas situações, faz mais o papel de espectador. Isso, porém, não quer dizer que a observação não seja consciente, dirigida, ordenada para um fim determinado. Esse procedimento tem caráter sistemático (MARCONI; LAKATOS, 1996).

Vários instrumentos podem ser utilizados: quadros, anotações, escalas, etc. O instrumento de coleta de dados da observação sistemática, neste estudo, foi construído com base em documentos que traduzem os padrões baseados em evidência científica na prática obstétrica, como segue:

ICM (Confederação Internacional de Parteiras) Competências essenciais para o exercício básico da obstetrícia-2002;

Ministério da Saúde - Assistência Pré-Natal (2000)

OMS/OPAS: Perfil dos Serviços de Obstetrícia nas Américas.

Este instrumento foi elaborado na forma de check-list (APÊNDICE C). A utilização de instrumentos na forma de check-list, na avaliação de desempenho das enfermeiras obstétricas/parteiras, tem sido sugerida como forma de obtenção de evidência externa e objetiva de que a profissional adquiriu a habilidade para traduzir o conhecimento cognitivo no desempenho prático de uma habilidade (os passos ou procedimentos corretos em momentos corretos, levando em consideração a segurança do cliente ou a qualidade da assistência) (BUCKINGHAM, 2000).

A avaliação do desempenho profissional, de acordo com os padrões 
baseados em evidências, é a pedra fundamental da certificação de qualidade na atenção à saúde. Os padrões profissionais estabelecidos como melhores práticas são colocações explícitas da qualidade esperada no desempenho de uma atividade de atenção à saúde. Tais padrões podem tomar a forma de procedimentos, guias da prática clínica, protocolos de tratamento, entre outros, ou colocações de resultados esperados da assistência à saúde (MARQUEZ, 2001).

Antes da aplicação definitiva dos instrumentos de coleta de dados, foi realizado um estudo-piloto em uma unidade não sorteada, a fim de verificar a eventual falta de dados relevantes. Não foi necessária a reformulação dos instrumentos.

Em atendimento aos aspectos éticos em pesquisa, foi solicitado às gestantes o consentimento livre e esclarecido para a realização da observação do desempenho dos profissionais de enfermagem (APÊNDICE D).

\subsection{Análise dos dados}

A estatística descritiva é usada para descrever e sintetizar os dados, por exemplo, o cálculo de médias e porcentagens. Quando esses índices são calculados com os dados de uma população, são denominados parâmetros. A maior parte das questões científicas é sobre parâmetros, e os pesquisadores fazem cálculos estatísticos para estimá-los (POLIT; BECK; HUNGLER, 2004).

O tratamento estatístico foi realizado pela análise descritiva das variáveis, com apresentação de tabelas de contigências, com freqüências e percentuais. Os dados foram analisados, tendo como parâmetros os documentos que estabelecem 
as políticas e normas de atenção ao pré-natal que são: competências essenciais publicadas pela ICM/OMS/OPAS e Manual Técnico de Assistência Pré-Natal publicado pelo MS. 
4 RESULTADOS 


\subsection{Caracterização dos serviços}

\subsubsection{Centros de Saúde}

Os três CSs (Centros de Saúde) onde foi realizada a pesquisa, atualmente, possuem 46 profissionais de enfermagem (14 enfermeiros, 30 técnicos em enfermagem e 02 auxiliares de enfermagem). Possuem, também, 25 profissionais médicos (15 clínicos gerais, 07 pediatras e 03 ginecologistas). Existem ainda 07 cirurgiões dentistas, 08 auxiliares de consultório dentário e 02 técnicos de higiene dental. Os profissionais de enfermagem trabalham em regime de 30 horas semanais.

A estrutura física dos CSs é composta por: farmácia, laboratório (coleta de exames), almoxarifado, arquivo, auditório, sala de recepção, sala da direção, sala de administração, setor de pessoal, copa, banheiros feminino e masculino, sala de vacina, sala de curativo, sala de medicação e observação, sala de esterilização, sala de triagem, sala do teste do pezinho, sala do SIAM (Serviço de Incentivo ao Aleitamento Materno), CTA (Centro de Testagem e Aconselhamento), sala de prevenção às Doenças Sexualmente Transmissíveis (DST's), sala de exame de Prevenção do Câncer do Colo de Útero (PCCU), sala de vigilância em saúde, sala de programas (Diabetes, Hipertensão, Tuberculose, Hanseníase, Tabagismo e Leishmaniose), sala de pré-consultas (infantil, adulto e pré-natal), consultório médico clínico geral, consultório de enfermagem, consultório ginecológico, consultório odontológico adulto e infantil e consultório pediátrico.

A sala de pré-natal, em sua maioria, é equipada com uma mesa com duas cadeiras, uma mesa ginecológica, uma escadinha, uma mesa de mayo, um foco 
central, um aparelho de sonar portátil, um biombo, um armário com medicação e materiais educativos, um balde de lixo, uma pia e um ar-condicionado. Não há banheiro na sala. A sala de pré-consulta possui uma mesa com duas cadeiras, uma balança e um aparelho de verificar pressão arterial.

A porta de entrada desses CSs para atendimento à população é referenciada pelas USFs e demanda espontânea. Os CSs dispõem de laboratórios para realização de exames simplificados (hemograma, EAS, parasitológico de fezes e glicemia). Para realização de outros exames, a coleta é feita no CS e é encaminhada ao Laboratório Central (LACEN). Os CSs possuem serviços, além da clínica básica, como pediatras, ginecologistas e odontólogos.

Com relação à organização do serviço de pré-natal, o número de consultas agendadas diariamente varia de seis a oito consultas no período da manhã ou tarde e são de responsabilidade das enfermeiras. Apenas um centro de saúde atende nos dois períodos: manhã e tarde. As técnicas e auxiliares de enfermagem atuam no preparo das gestantes para a consulta de pré-natal, por meio de verificação de peso, pressão arterial e estatura.

As grávidas chegam à unidade, pegam a ficha por ordem de chegada e aguardam para fazer a pré-consulta. Após a pré-consulta, as gestantes ficam aguardando a consulta na sala de espera. Na realização de atividades educativas, apenas um profissional informou que são feitas quando há pessoal disponível, tratando dos seguintes temas: importância do pré-natal, planejamento familiar, DST's, aleitamento materno e tabagismo. Não existem grupos de gestante em nenhum dos centros. É importante ressaltar que, no momento da coleta de dados, não houve palestra educativa.

As gestantes adolescentes e as de alto risco (menores de 14 anos e acima 
de 35 anos) e com outras patologias que não forem de competência da enfermeira, as profissionais encaminham para o ginecologista da unidade ou para a Maternidade e Clínica de Mulheres Bárbara Heliodora (MBH). O exame de PCCU é realizado pelas enfermeiras que coletam o material e encaminham ao Centro de Controle Oncológico do Acre (CECON). As grávidas com resultado de Papiloma Vírus Humano (HPV) e Neoplasia Intra-Epitelial Cervical (NIC) de grau I são tratadas no CS e, em caso de outras alterações, são encaminhadas ao CECON.

\subsubsection{Unidades de Saúde da Família}

As 13 USFs possuem 23 profissionais de enfermagem (13 enfermeiros e 10 técnicas em enfermagem), 12 médicos da família, 75 Agentes Comunitários de Saúde (ACSs), 05 cirurgiões dentistas e 03 auxiliares de consultório dentário. Em uma unidade não existe profissional médico, em outra o médico consulta uma vez por semana e em outra somente no período da tarde. Os profissionais de enfermagem trabalham em regime de 40 horas semanais.

A estrutura física é composta por: sala de recepção, farmácia, almoxarifado, sala de vacina, sala de curativo, sala de medicação, consultório de enfermagem, médico e odontologia, copa e banheiros. Das 13 USFs pesquisadas, 09 têm 02 consultórios (enfermagem e médico), as demais têm apenas um consultório para atendimento das consultas. A pré-consulta, na grande maioria das unidades, é realizada na sala de espera.

A sala de pré-natal, em sua maioria, é equipada com uma mesa e duas cadeiras, uma mesa ginecológica, uma escadinha, uma mesa de mayo, um foco 
central, um aparelho de sonar portátil ou estetoscópio de Pinard, um armário com medicação e materiais educativos, um balde de lixo, uma balança, um aparelho de verificar pressão arterial, uma pia e um ar-condicionado ou ventilador. Em uma unidade, não havia balança, e em todas não há banheiro na sala.

Cada unidade possui sua área adstrita, atendendo a uma média de 700 famílias. As instalações físicas são próximas às moradias da população-alvo. As USFs dispõem de ACSs que efetuam uma visita domiciliar mensal a cada família. $\mathrm{Na}$ visita, eles captam as grávidas e as encaminham à USF para iniciar o pré-natal e, em casos das gestantes faltosas, os ACSs são responsáveis pela recondução dessas gestantes ao pré-natal.

As USFs não dispõem de laboratórios para realização de exames, e as gestantes são encaminhadas a qualquer CS que dispõe de laboratório ou ao LACEN. Também não possuem serviços além da clínica básica, ao contrário dos CSs. O serviço de saúde bucal é oferecido em apenas 05 USFs das 13 USFs pesquisadas.

As enfermeiras nas USFs são responsáveis não só pelo atendimento da saúde da mulher mas também pelos seguintes programas: saúde do idoso, hipertensão e diabetes, tabagismo, saúde do trabalhador, hanseníase, tuberculose, leishmaniose, núcleo de educação em saúde, saúde na comunidade e DST.

$\mathrm{Na}$ organização do atendimento de pré-natal quanto ao número de consultas, não é definido um número, os profissionais têm total autonomia para estabelecer as consultas, de acordo com a demanda e atendimento de outros programas. Em duas unidades as consultas são diárias no período da manhã. Nas demais (11), as consultas são realizadas uma ou duas vezes por semana pela manhã ou tarde. As consultas são agendadas em oito unidades, e nas cinco 
restantes é livre demanda. Em uma unidade, a primeira consulta de pré-natal é realizada pelo profissional médico, as demais são realizadas todas as consultas pelas enfermeiras. A pré-consulta, na maioria das unidades, é realizada pela enfermeira.

Em uma unidade, é realizada oficina com gestantes a cada 15 dias, em outra a cada três meses é realizado um encontro com as grávidas, e nas demais não há menção de ações educativas. Os profissionais informaram que a orientação da gestante é realizada durante a consulta.

Nas USFs, as gestantes menores de 15 anos e maiores de 35 anos e com patologias que são de competência do profissional médico são encaminhadas à $\mathrm{MBH}$, e algumas são encaminhadas ao ginecologista do centro de saúde de referência da unidade. O exame de PCCU é realizado pela enfermeira, e o material coletado é encaminhado ao CECON. As grávidas com resultado de HPV e NIC I são referenciadas para tratamento no CS, e em caso de outras alterações as gestantes são encaminhadas ao CECON.

Os dois modelos de atenção básica se diferenciam pelo acesso facilitado aos usuários das USFs e maior disponibilidade de serviços nos CSs, mas por outro lado atendem a populações similares e representam a porta de entrada ao sistema de saúde no município para os atendimentos eletivos.

\subsection{Caracterização dos sujeitos}

A população deste estudo foi composta por 23 profissionais de enfermagem que prestam atendimento à gestante em três CSs (Centros de Saúde) e 
13 USFs (Unidades de Saúde da Família), no município de Rio Branco-Acre.

A Tabela 1 apresenta as categorias profissionais envolvidas no atendimento de pré-natal nas unidades pesquisadas da rede básica do município de Rio Branco.

Tabela 1 - Distribuição dos profissionais de saúde da rede básica de Rio Branco (AC), segundo a unidade de saúde, Rio Branco, 2006.

\begin{tabular}{lcccccc}
\hline \hline & \multicolumn{5}{c}{ Profissionais de Saúde } \\
\cline { 2 - 7 } Unidade & Enf.Obst. & Enfermeira & $\begin{array}{c}\text { Técnica } \\
\text { em Enf. }\end{array}$ & $\begin{array}{c}\text { Auxiliar de } \\
\text { Enf. }\end{array}$ & ACS $^{\star}$ & Médico \\
\hline $\begin{array}{l}\text { Centro de } \\
\begin{array}{l}\text { Saúde } \\
\text { USF }\end{array}\end{array}$ & 01 & 03 & 02 & 02 & - & 03 \\
\hline \hline
\end{tabular}

* Agente Comunitário de Saúde

Quanto à categoria do grupo estudado, 15 são enfermeiras, duas enfermeiras obstétricas, quatro técnicas de enfermagem e duas auxiliares de enfermagem. Os profissionais entrevistados são predominantemente do sexo feminino (21), com uma idade média de 34,3 anos, sendo que 69,6\% são casados e 30,4\% não tiveram filhos (Tabela 2). A idade dos filhos destes profissionais variou de um ano a 27 anos de idade, sendo que 43,5\% (10) encontram-se com idade de até cinco anos. 
Tabela 2 - Distribuição dos profissionais de enfermagem da rede básica do município de Rio Branco ( $\mathrm{AC}$ ), segundo a idade, estado conjugal e número de filhos. Rio Branco, 2006.

\begin{tabular}{lccc}
\hline \hline Variáveis & Categorias & $\mathbf{F}$ & $\%$ \\
\hline \hline Idadelanos & $20-30$ & 11 & 47,8 \\
& $31-40$ & 08 & 34,8 \\
& $41-50$ & 01 & 4,3 \\
Estado conjugal & 51 e mais & 03 & 13,0 \\
& Casada (o) & 16 & 69,6 \\
Número de filhos & Solteira (o) & 07 & 30,4 \\
& Nenhum & 07 & 30,4 \\
& Um & 08 & 34,8 \\
& Dois & 03 & 13,0 \\
& Três & 04 & 17,4 \\
\hline \hline
\end{tabular}

A renda familiar (Tabela 3), entre as enfermeiras, está entre $R \$ 1.600,00$ e $R \$ 9.500,00$, enquanto para os profissionais de nível médio de ensino está entre $R \$ 900,00$ e $R \$ 3.150,00$. A média da renda familiar da enfermeira foi de $R \$ 4.511,76$, da técnica em enfermagem $\mathrm{R} \$ 2.112,50$ e da auxiliar de enfermagem $\mathrm{R} \$ 1.450,00$. Vale ressaltar que o valor do salário mínimo no momento da coleta de dados era de $\mathrm{R} \$ 350,00$. 
Tabela 3 - Distribuição dos profissionais de enfermagem da rede básica do município de Rio Branco (AC), segundo a renda familiar. Rio Branco, 2006.

\begin{tabular}{lccc}
\hline \hline \multirow{2}{*}{$\begin{array}{c}\text { Renda Familiar } \\
\text { (R\$) }\end{array}$} & \multicolumn{3}{c}{ Profissionais de Enfermagem } \\
\cline { 2 - 4 } & Enfermeira & $\begin{array}{c}\text { Técnico de } \\
\text { Enfermagem }\end{array}$ & $\begin{array}{c}\text { Auxiliar de } \\
\text { Enfermagem }\end{array}$ \\
\hline 500,00 a $1.500,00$ & - & 01 & 01 \\
$1.600,00$ a $2.500,00$ & 01 & 02 & 01 \\
$2.600,00$ a $3.500,00$ & 05 & 01 & - \\
$3.600,00$ a $4.500,00$ & 03 & - & - \\
$4.600,00$ a $5.500,00$ & 05 & - & - \\
Acima de 5.500,00 & 03 & - & $\mathbf{0 2}$ \\
TOTAL & $\mathbf{1 7}$ & $\mathbf{0 4}$ & - \\
\hline \hline
\end{tabular}

Quanto à remuneração, nas unidades pesquisadas, das enfermeiras, variou entre $R \$ 1.771,00$ e $R \$ 2.200,00$ e entre os profissionais de enfermagem de nível médio variou de $\mathrm{R} \$ 600,00$ a 970,00 (Tabela 4).

Tabela 4 - Distribuição dos profissionais de enfermagem da rede básica do município de Rio Branco (AC), segundo a remuneração na instituição pesquisada. Rio Branco, 2006.

\begin{tabular}{lccc}
\hline \hline & \multicolumn{3}{c}{ Profissionais de Enfermagem } \\
\cline { 2 - 4 } $\begin{array}{l}\text { Remuneração na } \\
\text { Instituição (R\$) }\end{array}$ & Enfermeira & $\begin{array}{c}\text { Técnico de } \\
\text { Enfermagem }\end{array}$ & $\begin{array}{c}\text { Auxiliar de } \\
\text { Enfermagem }\end{array}$ \\
\hline \hline 500,00 a 1.000,00 & - & 04 & 02 \\
$1.100,00$ a 1.500,00 & - & - & - \\
$1.600,00$ a $2.000,00$ & 16 & - & - \\
$2.100,00$ a $2.500,00$ & 01 & - & $\mathbf{0 2}$ \\
TOTAL & $\mathbf{1 7}$ & $\mathbf{0 4}$ & - \\
\hline \hline
\end{tabular}


Ao observarmos a Figura 1, podemos verificar que a média da remuneração salarial dos profissionais nas unidades pesquisadas, entre as enfermeiras, foi de $R \$ 1.827,70$, das técnicas em enfermagem, $R \$ 801,25$ e das auxiliares de enfermagem, $\mathrm{R} \$ 600,00$.

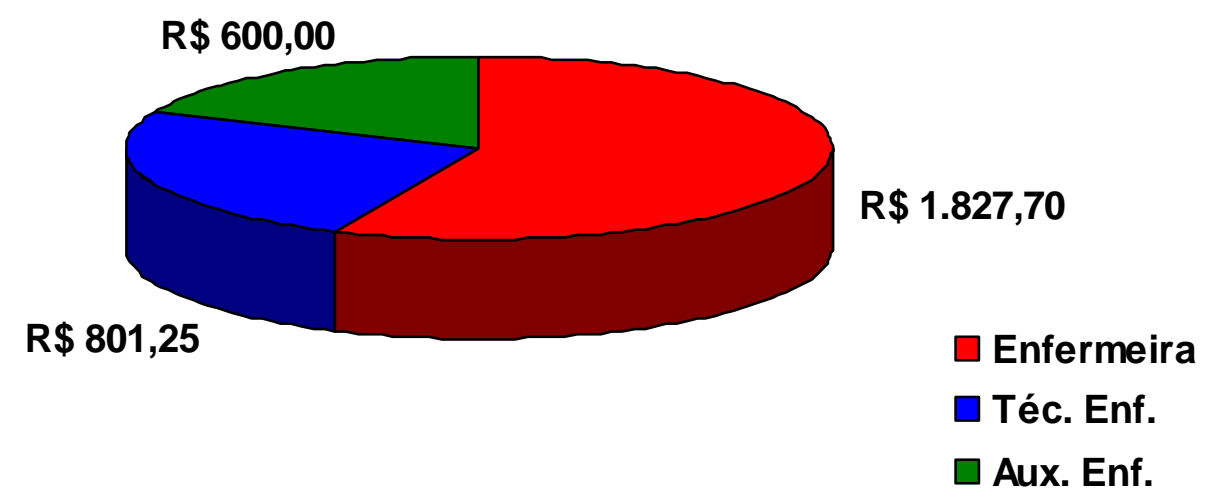

Figura 1 - Média da remuneração salarial dos profissionais de enfermagem da rede básica do município de Rio Branco (AC).

Com relação ao nível educacional dos profissionais de enfermagem que trabalham na assistência pré-natal, encontramos que 17 possuem educação superior (Enfermagem), sendo que 14 deles cursaram ou estão cursando mais de uma pósgraduação em programas lato sensu. As técnicas em enfermagem (04) possuem ensino médio completo, sendo que uma delas concluiu a educação básica no supletivo. Das duas auxiliares entrevistadas, uma possui o ensino médio incompleto.

De acordo com a Tabela 5, o tempo de formação profissional dos profissionais de enfermagem, em todas as categorias, foi superior a um ano. Observamos que 52,94\% (09) das enfermeiras possuem mais de cinco anos de formação. 
Tabela 5 - Distribuição dos profissionais de enfermagem da rede básica do município de Rio Branco (AC), segundo os anos de formação. Rio Branco, 2006.

\begin{tabular}{lccc}
\hline & \multicolumn{3}{c}{ Profissionais de Enfermagem } \\
\cline { 2 - 4 } Anos de & Enfermeira & $\begin{array}{c}\text { Técnico de } \\
\text { Enfermagem }\end{array}$ & $\begin{array}{c}\text { Auxiliar de } \\
\text { Enfermagem }\end{array}$ \\
\hline \hline Menos de 1 ano & & - & - \\
1 a 2 anos & 03 & 02 & - \\
3 a 4 anos & 05 & 01 & 01 \\
5 a 6 anos & 01 & 01 & - \\
7 a 8 anos & 02 & - & - \\
9 a 10 anos & 03 & - & 01 \\
Acima de 10 anos & 03 & - & $\mathbf{0 2}$ \\
TOTAL & $\mathbf{1 7}$ & $\mathbf{0 4}$ & - \\
\hline \hline
\end{tabular}

Das 17 enfermeiras entrevistadas, apenas duas cursaram especialização em enfermagem obstétrica com carga horária de 510 horas. Esse curso foi oferecido pela Universidade Federal do Acre (UFAC), com financiamento da Área Técnica da Saúde da Mulher do Ministério da Saúde. Além desse curso específico da área de saúde da mulher, encontramos: cinco enfermeiras com curso de especialização em Formação Pedagógica em Educação Profissional na Área da Saúde: Enfermagem, com carga horária de 660 horas; duas enfermeiras com especialização em Saúde da Família (510 horas); duas com especialização em Saúde Pública (430 horas); uma com especialização em Enfermagem Médico-Cirúrgica (500 horas); uma com especialização em Gestão de Sistemas e Serviços de Saúde (435horas) e uma com especialização em Gerência de Unidade Básica de Saúde (600 horas).

A carga horária média semanal de trabalho dos profissionais é de 53,26 horas, variando de 30 a 94 horas semanais, sendo que $12(52,17 \%)$ deles trabalham acima de 40 horas semanais. A Figura 2 mostra que $12(52,17 \%)$ profissionais 
possuem dois ou três empregos e trabalham em outras áreas de assistência como: hospitais gerais, maternidades, unidades de pronto-atendimento infantil e escola de enfermagem (curso técnico e auxiliar de enfermagem).

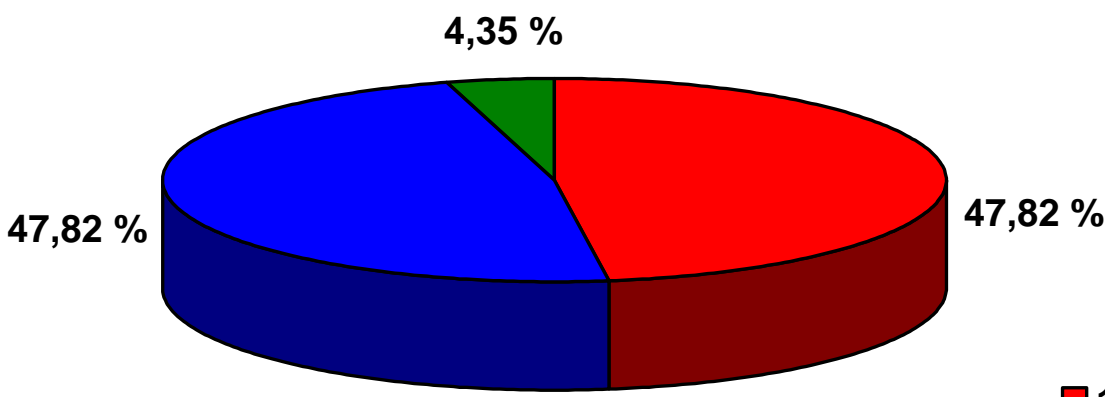

$\square 1$ Emprego

$\square 2$ Empregos

$\square 3$ Empregos

Figura 2 - Distribuição dos profissionais de enfermagem da rede básica do município de Rio Branco (AC), segundo o número de empregos.

De acordo com a Tabela 6, o tempo de trabalho, na assistência pré-natal, variou de 12 a 228 meses com uma média de 54,1 meses. A categoria de maior tempo de trabalho na área é a das enfermeiras (51 meses). É importante ressaltar que as técnicas e auxiliares de enfermagem não realizam consulta de pré-natal, elas atuam somente na pré-consulta, verificando altura, peso e pressão arterial das gestantes.

Dos profissionais que possuem experiência na assistência pré-natal, encontramos que $13,04 \%$ (03) destes profissionais trabalharam em Programa de Saúde da Família (PSF) em outros Estados, 4,35\% (01) que trabalharam no Programa de Agente Comunitário de Saúde (PACS) e 13,04\% (03) que trabalharam 
em Centro de Saúde, no município de Rio Branco.

Tabela 6 - Distribuição dos profissionais de enfermagem da rede básica do município de Rio Branco (AC), segundo o tempo de trabalho na assistência prénatal. Rio Branco, 2006.

\begin{tabular}{|c|c|c|c|c|c|}
\hline \multirow{2}{*}{$\begin{array}{l}\text { Tempo de } \\
\text { Trabalho }\end{array}$} & \multicolumn{4}{|c|}{ Profissionais de Enfermagem } & \multirow[b]{2}{*}{ TOTAL } \\
\hline & Enf. Obst. & Enfermeira & Téc. Enf. & Aux.Enf. & \\
\hline Menor que 12 meses & - & - & - & - & 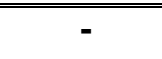 \\
\hline 12 a 24 meses & - & 03 & 01 & 01 & 05 \\
\hline 24 a 36 meses & 01 & 05 & 01 & - & 07 \\
\hline 36 a 48 meses & - & 01 & 01 & - & 02 \\
\hline 48 a 60 meses & 01 & - & - & - & 01 \\
\hline 60 a 72 meses & - & 02 & - & 01 & 03 \\
\hline 72 a 84 meses & - & 01 & - & - & 01 \\
\hline 84 a 96 meses & - & 01 & - & - & 01 \\
\hline 96 a 108 meses & - & 01 & - & - & 01 \\
\hline 108 a 120 meses & - & - & - & - & - \\
\hline Acima de 120 meses & - & 01 & 01 & - & 02 \\
\hline TOTAL & 02 & 15 & 04 & 02 & 23 \\
\hline
\end{tabular}

Quanto à realização de treinamento após a formação profissional, das 17 enfermeiras que realizam consulta de pré-natal, apenas duas são enfermeiras obstétricas, sendo que a capacitação foi realizada por meio do curso de especialização em obstetrícia, as demais disseram que aprenderam a realizar a consulta de pré-natal no curso de graduação. As técnicas e auxiliares de enfermagem informaram que aprenderam a realizar a pré-consulta durante o curso de auxiliar de enfermagem.

Com relação à atualização na área, após a formação profissional nos últimos cinco anos, a Tabela 7 mostra que a Assistência Pré-natal foi o curso que 
teve maior freqüência, $16(72,7 \%)$ com carga horária de 24 a 40 horas, seguido de DST's na Gravidez com 2 (9,1\%) enfermeiras com duração de 16 a 80 horas. É importante ressaltar que as técnicas e auxiliares de enfermagem não realizaram nenhum aprimoramento nos últimos cinco anos.

Tabela 7 - Distribuição dos profissionais de enfermagem da rede básica do município de Rio Branco (AC), segundo os cursos de atualização realizados após a formação profissional. Rio Branco, 2006.

\begin{tabular}{lccc}
\hline \hline & \multicolumn{3}{c}{ Profissionais de Enfermagem } \\
\cline { 2 - 4 } Curso de Atualização & Enfermeira & Enf. Obst. & TOTAL \\
\hline \hline 1- Assistência Pré-natal (24/40hs) & 14 & 02 & 16 \\
2- PCCU no Pré-natal (8hs) & 01 & - & 01 \\
3- Aleitamento Materno (40hs) & 01 & - & 01 \\
4- Planejamento Familiar (16hs) & 01 & - & 01 \\
5- DST's na Gravidez (16/80hs) & 02 & - & 02 \\
6- Saúde da Mulher e da Criança & 01 & & 01 \\
(120hs) & & $\mathbf{0 2}$ & $\mathbf{2 2}$ \\
TOTAL & $\mathbf{2 0}$ & & \\
\hline \hline
\end{tabular}

Quanto à participação dos profissionais em eventos científicos na área, 06 $(35,3 \%)$ enfermeiras informaram que participaram de eventos realizados em Rio Branco. Os eventos foram: Fórum na Área de Saúde da Mulher, Jornada de Obstetrícia, Seminário de Gestação e Amamentação, Doenças Sexualmente Transmissíveis na Amazônia e Seminário de Saúde da Mulher e do Adolescente.

Dos 16 serviços pesquisados, $14(82,4 \%)$ ofereceram cursos para 15 $(65,2 \%)$ profissionais de enfermagem, sendo 14 enfermeiras e uma técnica em enfermagem. Esses cursos são de responsabilidade da Secretaria Municipal de Saúde de Rio Branco (SEMSA) e Secretaria de Estado de Saúde do Acre 
(SESACRE) em parceria com o Ministério da Saúde (MS). Os temas tratados foram: Prescrição e Reposição de Sulfato Ferroso e Ácido Fólico na Gravidez; Atendimento à Saúde da Mulher, Criança e Adolescente; Aleitamento Materno; Planejamento Familiar; PCCU; DST's e AIDS e Vigilância Nutricional das Grávidas.

No que diz respeito à realização da consulta de pré-natal, encontramos que todas as enfermeiras estavam realizando a consulta nas 16 unidades pesquisadas. As quatro técnicas e as duas auxiliares de enfermagem participantes desta pesquisa estavam realizando a pré-consulta em três CSs e em duas USFs. No restante das unidades (11), a enfermeira é que realizava a pré-consulta.

Quanto à função desempenhada na assistência pré-natal por categoria profissional da enfermagem no atendimento à gestante, os profissionais informaram realizar os seguintes procedimentos:

1. Enfermeira: realiza a pré-consulta (verifica altura, peso e pressão arterial), faz o preenchimento dos formulários (livro de pré-natal, registro diário, ficha do Sisprenatal, ficha Perinatal, ficha da Reprolatina), faz a anamnese (queixas, dados sóciodemográficos e pessoais) e exame físico (avalia a pele, mucosas, membros, pesquisa edema, examina as mamas, verifica altura uterina, ausculta batimentos cardiofetais (BCFs), faz palpação e verifica posição fetal), calcula Idade Gestacional (IG), solicita e interpreta exames do $1^{\circ} \mathrm{e}$ $3^{\circ}$ trimestre de gestação, faz avaliação do peso corporal, faz prescrição de medicamentos respaldada na Resolução do Conselho Federal de Enfermagem (COFEN) 317/2007, faz encaminhamento da gestante quando necessário, realiza PCCU, entrega folheto 
educativo, encaminha para vacina anti-tetânica, fornece preservativo, faz orientações sobre: planejamento familiar, aleitamento materno, consulta puerperal, importância do PCCU, cuidado com os dentes, sinais de trabalho de parto, parto, pós-parto e com o recém-nascido, DST's, faz anotação no prontuário e no cartão da gestante e agenda a consulta subseqüente.

2. Técnicas e auxiliares de enfermagem: realizam a pré-consulta da gestante (verificam altura, peso e pressão arterial).

Com relação às dificuldades no atendimento à gestante, 70,59\% (12) das enfermeiras responderam ter dificuldades, enquanto $29,41 \%$ (05) relataram não ter dificuldade na consulta. As dificuldades informadas pelos profissionais foram: interpretação de exames (23,53\%); prescrição de medicamentos (17,65\%); tratamento das DST's e fazer abordagem às pacientes com NIC III e HIV positivas (5,88\%); realizar palpação em grávidas obesas que apresentam abdômen flácido $(11,76 \%)$, gestantes de alto risco $(11,76 \%)$; gestante Rh negativa $(11,76 \%)$ e pouco domínio do conteúdo de pré-natal (5,88\%). É importante destacar que 5,88\% dos profissionais informaram que há falta de materiais em alguns serviços, como: estetoscópio de Pinard, aparelho de Sonar, aparelho de Pressão Arterial (PA) e balança que dificultam e prejudicam o atendimento das gestantes.

Quanto ao encaminhamento da gestante para a assistência ao parto, as enfermeiras relataram que as pacientes são encaminhadas para a $\mathrm{MBH}$ ou para a maternidade do Hospital Santa Juliana (HSJ), sendo que 23,53\% (04) das 
enfermeiras fazem o encaminhamento por escrito, enquanto $76,47 \%$ (13) orientam as gestantes a levar o cartão de pré-natal.

Depois do parto, as enfermeiras informaram que os serviços não têm um programa específico para a puérpera, elas apenas orientam que as pacientes retornem para consulta pós-parto, ou seja, é livre demanda. Nas USFs, 52,94\% (09) enfermeiras disseram que fazem visita domiciliar à puérpera.

\subsection{Assistência pré-natal: descrição do observado}

As observações do atendimento à gestante nos CSs foram realizadas, no período da manhã, das 7 às 12 horas e, no período da tarde, das 12 às 17 horas, enquanto nas USFs foram realizadas das 7 às 12 horas, e em apenas uma unidade foi realizada das 13 às 17 horas. Foram efetuadas 61 observações relativas à consulta pré-natal, todas realizadas por enfermeiras, 57 pré-consultas (37 foram realizadas pelas enfermeiras e 20 pelas profissionais de nível médio) e três consultas puerperais.

Observamos que, nos CSs, a pré-consulta é de responsabilidade das técnicas e auxiliares de enfermagem, já nas USFs, em sua grande maioria, essa atividade é de responsabilidade das enfermeiras. A consulta pré-natal é realizada pelas enfermeiras, nos dois modelos de atenção (CS e USF).

Verificamos que os CSs atendem a pré-natal todos os dias, enquanto nas USFs, em sua grande maioria, atendem duas vezes por semana. A estrutura física dos CSs é toda em alvenaria, já as USFs algumas unidades são de madeira. As grávidas são agendadas e é definido um número de atendimento nos CSs, nas 
USFs, nem todas são agendadas e não é definido um número de consultas.

O local de realização da pré-consulta nos CSs é a sala de pré-consulta que tem uma balança, aparelho para aferição da pressão arterial e mesa com cadeira, já nas USFs não tem sala de pré-consulta, esse procedimento é realizado na sala de espera ou na sala da consulta. A sala de consulta, em todos os serviços, tem uma mesa com duas cadeiras e mesa ginecológica, para realizar o exame da grávida. Todos os serviços pesquisados não têm banheiro no consultório e a grande maioria não tem biombo. As anotações das enfermeiras são feitas no prontuário da gestante, durante e após consulta.

O tempo de espera da gestante para a consulta, nos serviços estudados, variou de 30 minutos a três horas. Apenas 07 (11,47\%), das 61 gestantes que aguardavam consulta estavam acompanhadas, cinco delas estavam acompanhadas do filho, uma com a sogra e uma com o esposo.

Durante o período de coleta de dados deste estudo, não foi observado grupo de gestante, nos dois modelos estudados.

\subsubsection{Pré-consulta da gestante}

Foram observadas 57 pré-consultas, sendo que 10 delas aconteceram nos CSs e 47 nas USFs. Dentre as pré-consultas observadas, 37 foram realizadas pelas enfermeiras e 20, pelas técnicas e auxiliares de enfermagem.

A Tabela 8 apresenta a freqüência dos procedimentos: verificação do peso corporal, altura e aferição da pressão arterial realizadas, durante a pré-consulta, nos dois modelos estudados, segundo a categoria profissional. 
Tabela 8 - Distribuição das freqüências dos procedimentos realizados pelos profissionais de enfermagem da rede básica do município de Rio Branco (AC), segundo a categoria profissional, durante a pré-consulta de 57 gestantes observadas. Rio Branco, 2006.

\begin{tabular}{|c|c|c|c|c|c|c|}
\hline \multirow{3}{*}{ Unidade } & \multicolumn{6}{|c|}{ Profissionais de Enfermagem } \\
\hline & \multicolumn{2}{|c|}{ Enfermeira } & \multicolumn{2}{|c|}{ Téc. Enfermagem } & \multicolumn{2}{|c|}{ Aux. Enfermagem } \\
\hline & $\mathrm{n}$ & $\%$ & $\mathrm{n}$ & $\%$ & $\mathrm{n}$ & $\%$ \\
\hline & Peso & & & & & \\
\hline CS & - & - & 07 & 70,0 & 03 & 30,0 \\
\hline \multirow[t]{2}{*}{ USF } & 38 & 88,4 & 05 & 11,6 & - & - \\
\hline & Altura & & & & & \\
\hline CS & - & - & 02 & 66,7 & 01 & 33,3 \\
\hline \multirow[t]{2}{*}{ USF } & 05 & 100 & - & - & - & - \\
\hline & $\begin{array}{c}\text { Pressão } \\
\text { Arterial }\end{array}$ & & & & & \\
\hline CS & - & - & 07 & 70,0 & 03 & 30,0 \\
\hline USF & 37 & 78,7 & 10 & 21,3 & - & - \\
\hline
\end{tabular}

Analisando a Tabela 8, podemos verificar que o procedimento de verificação do peso é realizado em $88,4 \%$ das gestantes pelas enfermeiras nas USFs, enquanto nos CSs, a freqüência de realização deste procedimento é dividida entre as técnicas (70\%) e auxiliares de enfermagem (30\%). Vale destacar que, durante a coleta de dados, quatro gestantes não foram pesadas em uma USF, porque a balança estava com defeito.

A mensuração da altura das gestantes, durante a coleta de dados, foi $100 \%$ executada pelas enfermeiras das USFs, e nos CSs foi dividida entre as profissionais de nível médio. Observamos que a medida da pressão arterial foi $78,7 \%$ realizada pelas enfermeiras e $21,3 \%$ pelas técnicas em enfermagem nas USFs, já nos CSs as técnicas e auxiliares de enfermagem realizam 70\% e 30\%, respectivamente, tal procedimento. 
Quando analisamos o número geral dos procedimentos realizados e a categoria profissional, durante a coleta de dados, pudemos constatar que $67,80 \%$ do total de procedimentos na pré-consulta das gestantes foram realizados pelas enfermeiras lotadas nas USFs.

\subsubsection{Atenção pré-natal: consulta}

Foram observadas 61 consultas de pré-natal, 14 (22,95\%) delas aconteceram nos CSs e $47(77,04 \%)$ nas USFs. Todas as consultas realizadas, durante o período de coleta de dados, foram assistidas pelas enfermeiras. O tempo médio da consulta, no período de observação, variou de 10 a 45 minutos nas consultas de retorno e 20 a 50 minutos nas consultas de primeira vez.

A Tabela 9 mostra o trimestre gestacional das 61 gestantes observadas, revelando que $02(3,28 \%)$ encontravam-se no primeiro trimestre, $32(52,46 \%)$, no segundo e 27 (44,26\%), no terceiro trimestre de gestação.

Tabela 9 - Distribuição das gestantes das unidades de saúde estudadas da rede básica do município de Rio Branco (AC), segundo a fase gestacional, durante a consulta pré-natal. Rio Branco, 2006.

\begin{tabular}{llc}
\hline \hline Fase Gestacional & $\mathbf{N}$ & $\%$ \\
\hline \hline $1^{\circ}$ Trimestre & 02 & 3,28 \\
$2^{\circ}$ Trimestre & 32 & 52,46 \\
$3^{\circ}$ Trimestre & 27 & 44,26 \\
TOTAL & $\mathbf{6 1}$ & $\mathbf{1 0 0 , 0 0}$ \\
\hline \hline
\end{tabular}


Com relação ao número da consulta, observamos que $17(27,87 \%)$ gestantes estavam na primeira consulta, $13(21,31 \%)$, na segunda, $12(19,67 \%)$, na terceira e as demais 19 (31,15\%) estavam entre a quarta e a décima consulta. Verificamos, também, que, das 17 gestantes de primeira consulta, 02 (11,76\%) estavam no primeiro trimestre, 12 (70,59\%), no segundo trimestre e $03(17,65 \%)$, no terceiro trimestre de gestação (Figura 3).

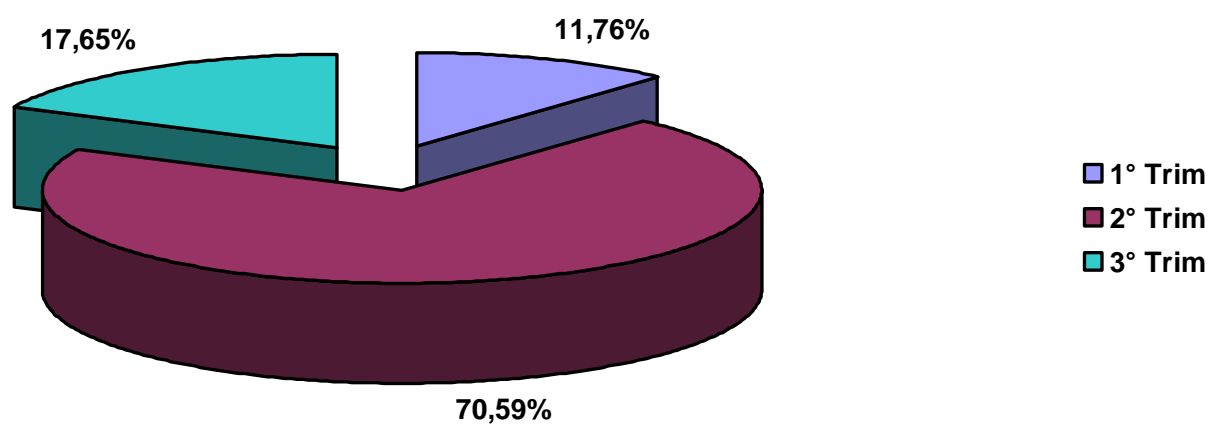

Figura 3 - Distribuição das 17 gestantes de primeira consulta das unidades de saúde estudadas da rede básica do município de Rio Branco (AC), segundo o trimestre gestacional, durante a consulta pré-natal. Rio Branco, 2006.

Verificamos que, quando a consulta da gestante é de primeira vez, as enfermeiras preenchem além do cartão da gestante, anotações no livro de registro, livro de pré-natal, ficha do Sisprenatal, ficha Perinatal, ficha da Reprolatina e prontuário. Algumas profissionais deixam para preencher a ficha Perinatal e da Reprolatina ao término dos atendimentos. O conteúdo da ficha Perinatal consta dos mesmos dados do cartão da gestante. 
A ficha da Reprolatina é um mapa diário de atendimento em saúde sexual e reprodutiva que faz parte do Projeto Reprolatina e conta com o apoio da OMS. Esse Projeto teve início no Brasil, em 2000, em 2001, na Bolívia e, em 2002, no Chile e tem como meta a melhoria do acesso e da qualidade de atenção em saúde sexual e reprodutiva. Os dados que constam no mapa são: procedência, idade, filhos vivos, principal motivo da consulta, método contraceptivo antes e após a consulta, causa abandono/troca, se prescreveu, entregou ou falou sobre anticoncepção de emergência.

Constatamos que, nos dois modelos estudados, durante a coleta de dados, não houve ações educativas na sala de espera e que o acolhimento é, na maioria das vezes, realizado durante as consultas.

Observamos que, na anamnese, os questionamentos iniciais feitos pela grande maioria das enfermeiras se referiam às queixas das gestantes. Das 61 gestantes, 36 (59,02\%) não relataram nenhuma queixa, e 25 (40,98\%) referiram: náuseas, azia, tontura, cefaléia, fraqueza, dor lombar, dor nas pernas, dor no baixo ventre, corrimento e prurido vaginal e disúria.

A Tabela 10 apresenta a freqüência de informações, durante a anamnese, na primeira consulta de pré-natal realizada nos CSs e nas USFs.

As informações sobre antecedentes pessoais, obstétricos, data da última menstruação e idade gestacional foram feitas em $94,12 \%$ das consultas de primeira vez, enquanto os antecedentes familiares e ginecológicos foram realizados em $88,24 \%$, e a informação sobre a data provável do parto foi feita em $82,35 \%$ das 17 consultas observadas. Vale destacar que para uma gestante a enfermeira solicitou o TIG para posteriormente iniciar o pré-natal. 
Tabela 10 - Distribuição da freqüência do conteúdo da anamnese na primeira consulta feita pelos enfermeiros da rede básica do município de Rio Branco (AC), durante a consulta pré-natal de 17 gestantes observadas. Rio Branco, 2006.

\begin{tabular}{lcc}
\hline \hline & \multicolumn{2}{c}{$\mathbf{n = 1 7}$} \\
\cline { 2 - 3 } Anamnese & $\mathbf{f}$ & $\mathbf{\%}$ \\
\hline \hline Antecedentes Familiares & 15 & 88,24 \\
Antecedentes Pessoais & 16 & 94,12 \\
Antecedentes Ginecológicos & 15 & 88,24 \\
Antecedentes Obstétricos & 16 & 94,12 \\
Data da Última Menstruação & 16 & 94,12 \\
Data Provável do Parto & 14 & 82,35 \\
Idade Gestacional & 16 & 94,12 \\
\hline \hline
\end{tabular}

Ao analisarmos a freqüência de informações, durante a anamnese, a partir da segunda consulta de pré-natal, por instituição estudada, mostradas na Tabela 11, observamos que a informação sobre idade gestacional foi realizada em $93,18 \%$ das consultas.

Observamos, também, durante o período de coleta de dados, que as informações sobre antecedentes familiares, data da última menstruação e data provável do parto foram feitas em 6,82\%, enquanto os dados sobre antecedentes pessoais, ginecológicos e obstétricos foram feitos em 4,55\% das consultas. 
Tabela 11 - Distribuição de freqüências do conteúdo da anamnese a partir da segunda consulta feita pelos enfermeiros da rede básica do município de Rio Branco (AC), durante a consulta pré-natal de 44 gestantes observadas. Rio Branco, 2006.

\begin{tabular}{|c|c|c|c|c|c|c|}
\hline \multirow[t]{2}{*}{ Anamnese } & \multicolumn{2}{|c|}{$\begin{array}{c}\text { CS } \\
n=13\end{array}$} & \multicolumn{2}{|c|}{$\begin{array}{l}\text { USF } \\
n=31\end{array}$} & \multicolumn{2}{|c|}{$\begin{array}{c}\text { TOTAL } \\
n=44\end{array}$} \\
\hline & $f$ & $\%$ & $f$ & $\%$ & $f$ & $\%$ \\
\hline Antecedentes Familiares & 02 & 15,38 & 01 & 3,23 & 03 & 6,82 \\
\hline Antecedentes Pessoais & 01 & 7,69 & 01 & 3,23 & 02 & 4,55 \\
\hline Antecedentes Ginecológicos & 01 & 7,69 & 01 & 3,23 & 02 & 4,55 \\
\hline Antecedentes Obstétricos & 01 & 7,69 & 01 & 3,23 & 02 & 4,55 \\
\hline Data da Última Menstruação & 01 & 7,69 & 02 & 6,45 & 03 & 6,82 \\
\hline Data Provável do Parto & 01 & 7,69 & 02 & 6,45 & 03 & 6,82 \\
\hline Idade Gestacional & 11 & 84,62 & 30 & 96,77 & 41 & 93,18 \\
\hline
\end{tabular}

Os procedimentos realizados no exame físico das gestantes pelos enfermeiros, durante o período de observação, foram: avaliação do estado nutricional, inspeção da pele e mucosas, palpação da tireóide, exame de Membros Inferiores (MMII) e pesquisa de edema (Tabela 12).

A avaliação do estado nutricional foi realizada no total de $24,59 \%$, a inspeção da pele e mucosas foi verificada em $32,79 \%$, e o exame de palpação da tireóide, em apenas 3,28\% do total das consultas.

Os dados da Tabela 12 destacam ainda que o exame de MMII e a pesquisa de edema foram realizados em $67,21 \%$ no total das consultas, nas duas instituições estudas. Chamamos atenção para o exame de palpação da tireóide que foi realizado apenas pelos profissionais da USF. 
Tabela 12 - Distribuição de freqüências dos procedimentos realizados no exame físico pelos enfermeiros da rede básica do município de Rio Branco (AC), segundo a instituição estudada, durante 61 consultas de prénatal observadas. Rio Branco, 2006.

\begin{tabular}{|c|c|c|c|c|c|c|}
\hline \multirow[t]{2}{*}{ Exame Físico } & \multicolumn{2}{|c|}{$\begin{array}{c}\text { CS } \\
n=14\end{array}$} & \multicolumn{2}{|c|}{$\begin{array}{c}\text { USF } \\
n=47\end{array}$} & \multicolumn{2}{|c|}{$\begin{array}{c}\text { TOTAL } \\
n=61\end{array}$} \\
\hline & $f$ & $\%$ & $f$ & $\%$ & $f$ & $\%$ \\
\hline Estado Nutricional & 08 & 257,14 & 07 & 14,89 & 15 & 24,59 \\
\hline Inspeção da Pele e Mucosas & 02 & 14,29 & 18 & 38,30 & 20 & 32,79 \\
\hline Palpação da Tireóide & - & - & 02 & 4,26 & 02 & 3,28 \\
\hline Exame de MMII & 08 & 57,14 & 33 & 70,21 & 41 & 67,21 \\
\hline Pesquisa de Edema & 07 & 50,0 & 34 & 72,34 & 41 & 67,21 \\
\hline
\end{tabular}

A Tabela 13 descreve a freqüência dos procedimentos clinico-obstétricos que constaram do exame das mamas, ausculta do BCF, medida da altura uterina e palpação, realizados durante a consulta, por instituição estudada.

Analisando os procedimentos clínico-obstétricos listados na Tabela 13, verificamos que a freqüência da medida da altura uterina foi realizada em $90,16 \%$ das consultas, seguida da ausculta do BCF $(81,97 \%)$. Vale destacar que, em uma unidade, não havia aparelho de Sonar ou estetoscópio de Pinard. 
Tabela 13 - Distribuição de freqüências dos procedimentos realizados durante 0 exame obstétrico pelos enfermeiros da rede básica do município de Rio Branco (AC), segundo a instituição estudada, durante 61 consultas de pré-natal observadas. Rio Branco, 2006.

\begin{tabular}{lcccccc}
\hline \hline \multirow{2}{*}{ Exame Obstétrico } & \multicolumn{2}{c}{ CS } & \multicolumn{2}{c}{ USF } & \multicolumn{2}{c}{ TOTAL } \\
& \multicolumn{2}{c}{$\mathbf{n = 1 4}$} & \multicolumn{2}{c}{ n=47 } & \multicolumn{2}{c}{$\mathbf{n = 6 1}$} \\
\cline { 2 - 8 } & $\mathbf{f}$ & $\mathbf{\%}$ & $\mathbf{f}$ & $\mathbf{\%}$ & $\mathbf{f}$ & $\mathbf{\%}$ \\
\hline Exame das Mamas & 06 & 42,86 & 18 & 38,30 & 24 & 39,34 \\
Ausculta do BCF & 12 & 85,71 & 38 & 80,85 & 50 & 81,97 \\
Medida da Altura uterina & 12 & 85,71 & 43 & 91,49 & 55 & 90,16 \\
Palpação: Posição Fetal & 06 & 42,86 & 31 & 65,96 & 37 & 60,66 \\
Palpação:Apresentação Fetal & 02 & 14,29 & 18 & 38,30 & 20 & 32,79 \\
\hline \hline
\end{tabular}

O exame clínico das mamas foi realizado em $39,34 \%$ das gestantes, enquanto a palpação, enquanto procedimento para verificar a posição e apresentação fetal, foi executada em $60,66 \%$ e $32,79 \%$ respectivamente. Foi possível constatar também que, nas instituições estudadas, durante o período de observação, nenhum profissional realizou a inspeção dos genitais externos, exame especular e coleta de Papanicolau.

Os dados da Tabela 14 mostram o conteúdo das orientações fornecidas pelos enfermeiros às gestantes durante a consulta pré-natal, segundo a instituição estudada.

Os conteúdos das orientações mais ofertadas foram: uso de medicamentos (47,54\%), aleitamento materno (44,26\%) e alimentação $(44,26 \%)$. Destacamos que as orientações relativas ao uso de medicamentos e aleitamento materno foram feitas pelos profissionais dos CSs em $50 \%$ das consultas. 
Tabela 14 - Distribuição de freqüências das orientações passadas às gestantes pelos enfermeiros da rede básica do município de Rio Branco (AC), segundo a instituição estudada, durante 61 consultas de pré-natal observadas. Rio Branco, 2006.

\begin{tabular}{|c|c|c|c|c|c|c|}
\hline \multirow[t]{2}{*}{ Orientações } & \multicolumn{2}{|c|}{$\begin{array}{c}\text { CS } \\
n=14\end{array}$} & \multicolumn{2}{|c|}{$\begin{array}{l}\text { USF } \\
n=47\end{array}$} & \multicolumn{2}{|c|}{$\begin{array}{c}\text { TOTAL } \\
n=61\end{array}$} \\
\hline & $f$ & $\%$ & f & $\%$ & f & $\%$ \\
\hline Aleitamento materno & 07 & 250,00 & 20 & 42,55 & 27 & 444,26 \\
\hline Alimentação & 05 & 35,71 & 22 & 46,81 & 27 & 44,26 \\
\hline Higiene corporal & 04 & 28,57 & 02 & 4,26 & 06 & 9,84 \\
\hline $\begin{array}{l}\text { Uso de cigarros, bebidas alcoólicas } \\
\text { e drogas }\end{array}$ & 01 & 7,14 & 02 & 4,26 & 03 & 4,92 \\
\hline Uso de medicamentos & 08 & 57,14 & 21 & 44,68 & 29 & 47,54 \\
\hline Sinais de perigo & 04 & 28,57 & 07 & 14,89 & 11 & 18,03 \\
\hline $\begin{array}{l}\text { Quando procurar o serviço de } \\
\text { saúde }\end{array}$ & 01 & 7,14 & 06 & 12,77 & 07 & 11,48 \\
\hline Sinais de trabalho de parto & 01 & 7,14 & 07 & 14,89 & 08 & 13,11 \\
\hline Medidas de desconforto & - & - & 06 & 12,77 & 06 & 9,84 \\
\hline Importância do sono/repouso & - & - & 03 & 6,38 & 03 & 4,92 \\
\hline Cuidados com as mamas & - & - & 04 & 8,51 & 04 & 6,56 \\
\hline Exercício físico & - & - & 02 & 4,26 & 02 & 3,28 \\
\hline Entrega de material didático & 05 & 35,71 & 03 & 6,38 & 08 & 13,11 \\
\hline Uso de tinturas de cabelo & 02 & 14,29 & - & - & 02 & 3,28 \\
\hline $\begin{array}{l}\text { Vacinas e cuidados com o recém- } \\
\text { nascido }\end{array}$ & 05 & 35,71 & - & - & 05 & 8,20 \\
\hline Importância da consulta puerperal & 01 & 7,14 & 01 & 2,13 & 02 & 3,28 \\
\hline Cuidados no pós-parto & - & - & 03 & 6,38 & 03 & 4,92 \\
\hline
\end{tabular}

No que se refere às orientações com relação a medidas de desconforto, importância do sono e repouso, cuidados com as mamas, exercício físico e cuidados no pós-parto, pudemos constatar que foram feitas apenas pelos profissionais das USFs, enquanto com relação às vacinas, aos cuidados com o recém-nascido e ao uso de tinturas de cabelo foram realizadas pelos enfermeiros lotados nos CSs. 
Foi possível verificar que, para as gestantes que estavam na primeira consulta pré-natal, os enfermeiros solicitaram os seguintes exames laboratoriais e de diagnóstico: grupo sanguíneo, fator Rh, hemograma, glicemia, sorologia para sífilis, hepatite e toxoplasmose, urina tipo I, parasitológico de fezes, teste anti-HIV e ultrasonografia (Tabela 15).

Das 17 consultas de primeira vez, 05 gestantes trouxeram os exames realizados no momento da consulta, uma gestante a enfermeira solicitou o TIG para posteriormente iniciar o pré-natal, e outra gestante estava na $36^{\mathrm{a}}$ semana de gestação. Para a gestante de 36 semanas, a enfermeira não solicitou os exames, justificando a demora destes exames tanto na realização como na entrega dos resultados, o que não daria mais tempo antes do parto. Excluindo essas gestantes, ficou um total de 10 consultas de primeira vez para serem solicitados os exames.

Observamos que a maioria dos exames laboratoriais, foi solicitada para 100\% das gestantes de primeira consulta pelos enfermeiros dos serviços estudados, já com relação à ultra-sonografia foi solicitada em 50\% das gestantes de primeira consulta. Constatamos também que, nos dois modelos estudados, a coleta de material para exame colpocitológico não foi efetuada em nenhuma consulta, durante o período de coleta de dados. 
Tabela 15 - Distribuição de freqüências de exames solicitados na primeira consulta realizada pelos enfermeiros da rede básica do município de Rio Branco (AC), durante 17 consultas de pré-natal observadas. Rio Branco, 2006.

\begin{tabular}{lcc}
\hline & & $\mathbf{n = 1 0}$ \\
\cline { 2 - 3 } Exames & $\mathbf{f}$ & $\mathbf{\%}$ \\
\hline \hline Grupo Sanguíneo & $\mathbf{0 9}$ & 90,0 \\
Fator Rh & 09 & 90,0 \\
Hemograma & 10 & 100 \\
Glicemia & 10 & 100 \\
Sorologia para Sífilis & 10 & 100 \\
Urina tipo I & 10 & 100 \\
Parasitológico de Fezes & 10 & 100 \\
Teste Anti-Hiv & 10 & 100 \\
Sorologia para Hepatite & 09 & 90,0 \\
Sorologia para Toxoplasmose & 10 & 100 \\
Ultra-Sonografia & 05 & 50,0 \\
\hline \hline
\end{tabular}

Vale destacar que os profissionais que solicitaram exames, no período de observação deste estudo, explicaram o motivo da realização desses exames a todas as gestantes.

A Tabela 16 apresenta os medicamentos prescritos, durante a consulta pré-natal, pelos enfermeiros, por instituição estudada.

Pudemos observar que os medicamentos sulfato ferroso e ácido fólico, foram prescritos com maior freqüência, enquanto os medicamentos como: cefalexina, miconazol, complexo B e benzoato de benzila tiveram menor freqüência de prescrição. 
Tabela 16 - Distribuição de freqüências de medicamentos prescritos pelos enfermeiros da rede básica do município de Rio Branco (AC), segundo a instituição estudada, durante 61 consultas de pré-natal observadas. Rio Branco, 2006.

\begin{tabular}{lcccccc}
\hline \hline \multirow{2}{*}{ Medicamentos } & \multicolumn{2}{c}{ CS } & \multicolumn{2}{c}{ USF } & \multicolumn{2}{c}{ TOTAL } \\
& \multicolumn{2}{c}{$\mathbf{n = 1 4}$} & \multicolumn{2}{c}{$\mathbf{n = 4 7}$} & \multicolumn{2}{c}{ n=61 } \\
\cline { 2 - 7 } & $\mathbf{f}$ & \% & $\mathbf{f}$ & \% & f & \% \\
\hline \hline Sulfato Ferroso & 05 & 35,71 & 15 & 31,91 & 20 & 32,79 \\
Ácido Fólico & 05 & 35,71 & 11 & 23,40 & 16 & 26,23 \\
Nistatina Creme Vaginal & 03 & 21,43 & 03 & 6,38 & 06 & 9,84 \\
Metronidazol Creme Vaginal & 01 & 7,14 & 02 & 4,26 & 03 & 4,92 \\
Paracetamol & 02 & 14,29 & 02 & 4,26 & 04 & 6,56 \\
Buscopan & 03 & 21,43 & 02 & 4,26 & 05 & 8,20 \\
Ampicilina & 01 & 7,14 & 04 & 8,51 & 05 & 8,20 \\
Cefalexina & 01 & 7,14 & - & - & 01 & 1,64 \\
Miconazol Creme Vaginal & - & - & 01 & 2,13 & 01 & 1,64 \\
Complexo B & - & - & 01 & 2,13 & 01 & 1,64 \\
Benzoato de Benzila & 01 & 7,14 & - & - & 01 & 1,64 \\
\hline \hline
\end{tabular}

Ainda analisando a Tabela 16, podemos observar que a cefalexina e o benzoato de benzila não foram prescritos pelos profissionais da USF, e os medicamentos miconazol e complexo B não tiveram prescrição pelos enfermeiros dos CSs.

Na Tabela 17, podemos verificar quais os motivos da prescrição pelos enfermeiros por instituição estudada. 
Tabela 17 - Distribuição de freqüências de motivos da prescrição de medicamentos pelos enfermeiros da rede básica do município de Rio Branco (AC), segundo a instituição estudada, durante 61 consultas de pré-natal observadas. Rio Branco, 2006.

\begin{tabular}{lrrrrrr}
\hline \multirow{2}{*}{ Motivo da Prescrição } & \multicolumn{2}{c}{ CS } & \multicolumn{2}{c}{ USF } & \multicolumn{2}{c}{ TOTAL } \\
& \multicolumn{2}{c}{ n=14 } & \multicolumn{2}{c}{ n=47 } & \multicolumn{2}{c}{ n=61 } \\
\cline { 2 - 8 } & $\mathbf{f}$ & \% & f & \% & f & \% \\
\hline \hline Reposição de ferro & 05 & 35,71 & 09 & 19,15 & 14 & 22,95 \\
Formação do Tubo Neural Fetal & 05 & 35,71 & 11 & 23,40 & 16 & 26,23 \\
Prurido Vaginal & 01 & 7,14 & 05 & 10,64 & 06 & 9,84 \\
Corrimento Vaginal & 04 & 28,57 & 01 & 2,13 & 05 & 8,20 \\
Dor no baixo ventre & 02 & 14,29 & 02 & 4,26 & 04 & 6,56 \\
Cefaléia & 02 & 14,29 & 02 & 4,26 & 04 & 6,56 \\
Anemia & 02 & 14,29 & 07 & 14,89 & 09 & 14,75 \\
Infecção Urinária & 01 & 7,14 & 04 & 8,51 & 05 & 8,20 \\
Micose & 01 & 7,14 & - & - & 01 & 1,64 \\
\hline \hline
\end{tabular}

De acordo com resultados da Tabela 17, verificamos que os motivos de maior freqüência para a prescrição dos medicamentos foram: para a formação do tubo neural fetal $(26,23 \%)$, reposição de ferro $(22,95 \%)$ e anemia $(14,75 \%)$. Observamos também que 6,56\% dos casos de dor no baixo ventre e cefaléia foram motivos para prescrição medicamentosa pelas enfermeiras dos dois modelos pesquisados, o mesmo ocorreu com os casos de corrimento vaginal e infecção urinária $(8,20 \%)$.

Identificamos, também, durante a observação das consultas, que 97,06\% dos profissionais explicaram o motivo da prescrição medicamentosa, e 94,12\% orientaram as gestantes quanto ao uso da medicação. 
Os resultados da Tabela 18 apresentam as seguintes atividades realizadas pelos enfermeiros, durante a consulta: encaminhamento para vacina antitetânica, explicação da importância da imunização na gestação, encaminhamentos para exame de PCCU e ginecologista, agendamento das consultas subseqüentes e anotações no prontuário e cartão da gestante.

Tabela 18 - Distribuição de freqüências das atividades realizadas ao final da consulta pelos enfermeiros da rede básica do município de Rio Branco (AC), segundo a instituição estudada, durante 61 consultas de prénatal observadas. Rio Branco, 2006.

\begin{tabular}{|c|c|c|c|c|c|c|}
\hline \multirow[t]{2}{*}{ Atividades } & \multicolumn{2}{|c|}{$\begin{array}{c}\text { CS } \\
n=14\end{array}$} & \multicolumn{2}{|c|}{$\begin{array}{l}\text { USF } \\
n=47\end{array}$} & \multicolumn{2}{|c|}{$\begin{array}{c}\text { TOTAL } \\
n=61\end{array}$} \\
\hline & $f$ & $\%$ & f & $\%$ & $\mathbf{f}$ & $\%$ \\
\hline Encaminha para vacina antitetânica & 06 & 42,86 & 30 & "63,83 & 36 & 59,02 \\
\hline Explica a importância da vacina & 04 & 28,57 & 12 & 25,53 & 16 & 26,23 \\
\hline Encaminha para exame de PCCU & - & - & 02 & 4,26 & 02 & 3,28 \\
\hline Encaminhamento ao ginecologista & 01 & 7,14 & 04 & 8,51 & 05 & 8,20 \\
\hline Agenda consulta subseqüente & 14 & 100 & 36 & 76,60 & 50 & 81,97 \\
\hline Anotação no prontuário & 14 & 100 & 46 & 97,87 & 60 & 98,36 \\
\hline Anotação no cartão da gestante & 14 & 100 & 45 & 95,74 & 59 & 96,72 \\
\hline
\end{tabular}

Das 61 gestantes consultadas, 21 já tinham sido vacinadas ou estavam em dia com a vacina antitetânica. Observamos que o encaminhamento da gestante para vacina antitetânica foi realizado em $59,02 \%$, e em $26,23 \%$ das consultas foi explicada a importância da vacinação.

Dentre as atividades realizadas, verificamos que a anotação/registro e no prontuário e cartão da gestante foi efetuada em $98,36 \%$ e 96,72\%, respectivamente. Cabe destacar que uma gestante da USF não levou o cartão da gestante no 
momento da consulta.

O agendamento das consultas subseqüentes foi realizado em $81,97 \%$ do total das consultas, já com relação ao encaminhamento para exame de PCCU, ele foi efetuado apenas em 3,28\%. Destaca-se ainda que 05 (8,20\%) gestantes foram encaminhadas ao ginecologista pelos seguintes motivos: pressão arterial elevada, adolescência (adolescente de 13 anos) e pós-datismo (gestante com mais de 40 semanas de gestação).

A Tabela 18 chama a atenção ainda que, durante a coleta de dados, as atividades de agendamento das consultas subseqüentes, anotação/registro no prontuário e anotação no cartão da gestante foram efetuadas em todas as consultas feitas pelos enfermeiros dos CSs.

\subsubsection{Consulta puerperal}

Foram observadas, durante o período de coleta de dados, três consultas de pós-parto, sendo duas (manhã e tarde) no CS e uma (manhã) na USF.

Observamos que, nos dois modelos estudados, a consulta puerperal não é sistematizada e ainda é muito baixa a adesão para esse atendimento. No CS as mães que levam os recém-nascidos (RN) ao serviço para fazer o teste do pezinho são encaminhadas para a consulta, já na USF a enfermeira realiza a visita domiciliar (o que não é uma rotina) ou quando as mães levam o RN para vacinar ou os ACSs captam as puerpéras para consulta pós-parto.

Descrevemos as consultas da seguinte forma: 


\section{Consulta 1: CS - Enfermeira Obstétrica}

Puérpera, com 27 dias de parto normal, retornou com queixa de prurido vaginal e urina escura, não veio acompanhada do RN. Durante a consulta observamos que foi perguntado pela enfermeira obstétrica sobre o tipo de parto, episiotomia e as queixas. A puérpera foi orientada quanto aos cuidados e vacinas do RN, aleitamento materno, alimentação e atividade sexual. Orientada também para guardar o cartão da gestante, justificando que em caso de uma nova gravidez, o cartão tem informações importantes, ressaltando os dados da vacina antitetânica. O exame de PCCU foi mencionado, sendo orientada quanto ao retorno para fazê-lo. Foi solicitado exame de urina, prescrito fluconazol e nistatina creme e encaminhamento ao ginecologista da unidade. Foi ainda fornecido à puerpéra preservativo e orientação quanto ao uso do mesmo.

\section{Consulta 2: CS - Enfermeira}

Puérpera, com 30 dias de parto normal, veio acompanhada do $\mathrm{RN}$. $\mathrm{Na}$ consulta, a enfermeira perguntou sobre como estava a amamentação. Foi orientada a continuar amamentando e prescrito contraceptivo oral (micronor 35 comprimidos).

\section{Consulta 3: USF - Enfermeira}

Puérpera, com 15 dias de parto normal, veio acompanhada do RN, a enfermeira anotou no livro de registro o nome da mãe, idade e nome do RN e fez um prontuário para o RN. Foi perguntado sobre a 
amamentação e o tipo de parto. A enfermeira fez avaliação do RN, verificando coto umbilical, reflexos e inspeção da pele e registrou no prontuário do RN. Finalizou com as seguintes orientações e encaminhamentos: passar álcool a $70 \%$ no coto umbilical e lavar com soro as narinas do $\mathrm{RN}$, continuar amamentando, agendar teste do pezinho no CS de referência e marcar consulta com o médico. 


\subsection{A equipe de enfermagem}

O conjunto dos profissionais nas unidades básicas de saúde pesquisadas deste estudo é constituído por 73,91\% enfermeiros, 17,39\% por técnicas em enfermagem e $8,70 \%$ por auxiliares de enfermagem, sendo a grande maioria do sexo feminino (91,30\%), com uma média de 34,3 anos de idade.

Do grupo de enfermeiros que atendem a gestante na consulta pré-natal, nas instituições estudadas no município de Rio Branco, observamos que, quanto à idade, $88,24 \%$ têm menos de 40 anos de idade e são do sexo feminino, uma média de 32,9 anos. Esses resultados quanto ao sexo e idade dos enfermeiros foram semelhantes aos dados da pesquisa de Ferrari, Thomson e Melchior (2005) acerca do perfil dos médicos e enfermeiros da cidade de Londrina (PR). Os autores verificaram que a grande maioria $(94,4 \%)$ dos enfermeiros era constituída por mulheres com menos de 40 anos, uma média de 33,9 anos.

No Brasil, segundo Girardi e Carvalho (2002), as mulheres representam cerca de $73 \%$ dos empregos nas ocupações de saúde. A participação feminina na região Norte é de $88,8 \%$, entre os enfermeiros, e de $80,2 \%$, entre os profissionais de enfermagem de nível médio. Com relação à idade, é em média 37 anos para os enfermeiros e 35 para demais membros do pessoal de enfermagem.

Os resultados deste estudo reafirmam que a enfermagem ainda é uma profissão predominantemente feminina, apesar de muitas pesquisas apontarem que o número de homens está aumentando com o passar dos anos.

A remuneração dos enfermeiros, nas instituições pesquisadas, não difere dos países da América Latina. Em geral os salários são baixos e variam de acordo com cada país. Os valores vão desde U\$120 na Nicarágua, U\$210 na Venezuela, 
U\$580 no Panamá, U\$830 no Brasil até U\$1.100 na Costa Rica (MALVÁREZ; AGUDELO, 2005).

No Brasil, o pessoal de enfermagem de nível médio ganha em média 41,9\% do salário dos enfermeiros (GIRARDI; CARVALHO, 2002). Em nosso estudo, a média dos salários desses profissionais foi de $32,83 \%$ da média dos salários dos enfermeiros que atendem a gestante nas unidades pesquisadas.

Neste estudo, verificamos que mais da metade dos enfermeiros tinha mais de cinco anos de formação. Gardenal et al. (2002) e Ferrari, Thomson e Melchior (2005) identificaram, em suas pesquisas acerca do perfil dos enfermeiros que atuam na saúde da família e unidades de atendimento à gestante, que os enfermeiros tinham $52,1 \%$ e $46,0 \%$, respectivamente, mais de nove anos de tempo decorrido após a graduação.

A média da carga horária semanal de trabalho, encontrada neste estudo (53,26 horas), difere da carga horária dos países da América Latina, que é de oito horas diárias e 45 horas semanais, com variação de seis horas diárias e 30 horas semanais e nove horas diárias e mais de 50 horas semanais As condições de trabalho da enfermagem se caracterizam por uma sobrecarga de trabalho, jornadas extensas, turnos rotativos, trabalho noturno, mudanças freqüentes de emprego e sobrecarga psicológica por lidar com situações críticas (MALVÁREZ; AGUDELO, 2005).

Em nossa pesquisa, dos enfermeiros entrevistados, 52,17\% trabalham em mais de uma instituição. O estudo de Gardenal et al. (2002), ainda sobre o perfil das enfermeiras que atuam na assistência à gestante, encontrou que 49,3\% das enfermeiras entrevistadas atuam em mais de um estabelecimento.

Quanto à qualificação profissional, 70,6\% dos enfermeiros que atendem a 
gestante no município de Rio Branco, nas unidades pesquisadas, referiram ter alguma especialização lato sensu. Apenas duas cursaram especialização em Obstetrícia, e as demais fizeram um curso de atualização em Assistência Pré-Natal. Essa capacitação variou de 24 a 40 horas de duração. Esses resultados diferem dos achados de Gardenal et al. (2002) em que $88,6 \%$ dos enfermeiros que trabalham na área da assistência à mulher no ciclo gravídico-puerperal tinham alguma especialização, sendo que $54,8 \%$ possuíam especialização ou habilitação na área, e as demais fizeram capacitação para desenvolverem funções da enfermeira obstétrica com duração de dois a 45 dias.

Outra pesquisa realizada com enfermeiros que trabalham em PSF e realizam consulta pré-natal, por Benigna, Nascimento e Martins (2004) em Campina Grande na Paraíba, mostrou que todos os enfermeiros participantes do estudo apresentavam alguma especialização, e apenas 25,0\% tinham especialização em Obstetrícia.

Uma razão que explica esse pequeno número de enfermeira obstétrica na assistência à gestante em nossa pesquisa, é que a Universidade Federal do Acre (UFAC) é a única instituição que oferece a especialização em Obstetrícia e em outras áreas da enfermagem. Cabe salientar que esses cursos de especialização são oferecidos quando há financiamento para sua realização.

A UFAC já formou 80 enfermeiras obstétricas no Estado, do ano de 1999 a 2007. As enfermeiras formadas atendem à demanda do município de Rio Branco e também outros municípios do Estado. Esses profissionais que atuam em outros municípios recebem uma ajuda de custo e uma bolsa para cursar a especialização.

De acordo com a literatura, profissionais com especialização em obstetrícia têm alguma vantagem sobre os outros profissionais, para o adequado 
manejo na assistência à gestante (BENIGNA; NASCIMENTO; MARTINS, 2004). No entanto, a qualificação desses profissionais ainda é restrita no município de Rio Branco.

O tempo de trabalho dos enfermeiros, nas unidades pesquisadas, em sua grande maioria tem mais de dois anos na assistência pré-natal, resultado semelhante ao estudo de Ferrari, Thomson e Melchior (2005), apontando que 80,9\% dos enfermeiros que trabalham na Saúde da Família tinham mais de dois anos de atuação nas unidades básicas de saúde.

Em outra pesquisa, realizada por Dotto, Moulin e Mamede (2006), com enfermeiras que atuavam na assistência pré-natal no ano de 2002, no município de Rio Branco/AC, verificou-se que as enfermeiras possuíam de um a 19 anos de experiência em pré-natal, com uma média de 6,4 anos.

O conteúdo referente à atualização de conhecimentos, após a graduação pelos enfermeiros estudados em nossa pesquisa nos últimos cinco anos, foi relacionado a temáticas importantes para atuação na assistência à gestante, e chamamos atenção para o curso de Assistência Pré-Natal em que a maioria dos profissionais teve participação.

Estabelecer programas de capacitação de alta qualidade reforça a capacidade do profissional qualificado na promoção e proteção à saúde materna, infantil e comunitária. Um processo educativo que alcance êxito fomenta na pessoa qualificada a aquisição de habilidades e competências práticas para a resolução de problemas, pensamento crítico e a tomada de decisões (MAcDONALD; STARRS, 2003).

Um sistema educativo que promova tais destrezas, habilidades e conhecimentos deve incluir os seguintes componentes básicos: 
Programas de capacitação apropriados (em aulas e em serviços), além da educação contínua e oportunidades de reciclagem para profissionais;

Materiais didáticos atualizados, completos e pertinentes às situações locais; e

Docentes qualificados que podem supervisionar a aprendizagem clínica dos estudantes, tanto no serviço como na comunidade (MAcDONALD; STARRS, 2003).

Outros cursos com temáticas voltadas à assistência à mulher foram oferecidos pela grande maioria das instituições estudadas, onde tanto os enfermeiros como os profissionais de nível médio tiveram participação.

Verificamos, neste estudo, que mais da metade dos enfermeiros não participou de nenhum evento científico na área. Os dados da pesquisa de Gardenal et al. (2002), nas instituições de Sorocaba (SP), também foram semelhantes ao deste estudo, apontando que $71,6 \%$ dos enfermeiros não participaram de nenhum evento na área, nos últimos dois anos. Outra pesquisa, realizada por Dotto (2006), em duas maternidades no município de Rio Branco (AC), mostrou que $77,8 \%$ dos enfermeiros dessas instituições não participaram de nenhum evento na área, nos últimos cinco anos.

A restrição de material em alguns serviços foi referida por apenas um enfermeiro (5,88\%), corroborando com o estudo de Gardenal et al. (2002) que verificou essa queixa por apenas uma enfermeira entrevistada, tanto nas instituições hospitalares quanto nas unidades básicas de saúde em Sorocaba (SP).

A forma de encaminhamento da gestante para a assistência ao parto é 
realizada algumas vezes por escrito, e, na maioria das vezes, as gestantes são apenas orientadas a procurar a maternidade de sua escolha. No Estado do Acre, as ações da atenção básica estão articuladas com a média e alta complexidade, porém ainda sem instrumentos formais de referência e contra-referência institucionalizados (ACRE. Governo do Estado do Acre, 2004).

Segundo Serruya, Lago e Cecatti (2004a), em trabalho sobre o Panorama da atenção pré-natal no Brasil e o Programa de Humanização do Pré-Natal e Nascimento, a questão da falta de vínculo entre a assistência pré-natal e parto leva as mulheres, em trabalho de parto, a uma peregrinação à procura de vagas nos hospitais. Além disso, a maioria das mortes maternas ocorre próxima ao parto, o que demanda intervenções que garantam melhor assistência à mulher nesse período.

Dos 12 óbitos maternos investigados pelo Comitê de Mortalidade Materna do Estado do Acre, no ano de 2003, 11 ocorreram no município de Rio Branco, dos quais nove óbitos foram por causa obstétrica, sendo seis por causas evitáveis (ACRE. Governo do Estado do Acre, 2004).

A desintegração da assistência no pré-natal com o parto e puerpério foi agravada, ainda mais, com a institucionalização do parto, após a Segunda Guerra Mundial, que tem gerado ao longo do tempo, uma verdadeira peregrinação na hora do parto, ou seja, não existe ligação do pré-natal ao parto (OBA; TAVARES, 1997).

Após o parto, segundo os depoimentos dos enfermeiros, inexiste um programa específico para a puérpera. Conforme Serruya, Lago e Cecatti (2004a), a assistência à mulher na gestação só deveria ser considerada como concluída após a consulta puerperal. O seguimento clínico, após a gestação, é imperativo por várias razões, como o estabelecimento de condutas para garantir o adequado intervalo interpartal que protege a mulher e melhora os resultados perinatais, com a 
orientação para a introdução de método contraceptivo, assim como avaliação que permita detectar alterações importantes nesse período.

Em todas as unidades estudadas, os enfermeiros são responsáveis pela assistência pré-natal, diferindo apenas no número de consultas entre os CSs e as USFs. Nas USFs, os enfermeiros realizam menos consultas devido à clientela de abrangência ser um número menor e o atendimento de pré-natal não ser realizado todos os dias. Nos dois modelos estudados, os enfermeiros são responsáveis por outras atividades além do pré-natal. Além da realização da consulta, $68,75 \%$ dos enfermeiros realizam também a pré-consulta.

O tempo médio das consultas assistidas foi superior ao encontrado no estudo de Rios e Vieira (2007) que observaram uma variação de 20 a 30 minutos nas consultas de pré-natal de primeira vez e 15 a 20 minutos nas consultas subseqüentes. Essas autoras referiram que, de acordo com o parâmetro estipulado pela OMS, o tempo das consultas (médicas ou de enfermagem) é de 15 minutos por cliente. Portanto, as consultas observadas, em nosso estudo, decorreram em um tempo maior da média estabelecida.

Ao analisar o trimestre das gestantes observadas na primeira consulta, apenas duas estavam no primeiro trimestre. A maioria das gestantes iniciou o prénatal, no segundo trimestre de gestação. Koffman e Bonadio (2005) apresentaram dados semelhantes em que $19,7 \%$ das gestantes iniciaram o pré-natal no primeiro trimestre, e a maioria $(57,2 \%)$ iniciou no segundo trimestre de gestação.

Por outro lado, outras pesquisas mostraram resultados diferentes. Em uma região metropolitana de São Paulo (SP), 65\% das grávidas começaram o pré-natal no primeiro trimestre, em outro estudo realizado no município de Santa Catarina (SC), $83,1 \%$ iniciaram as consultas durante o primeiro trimestre de gestação 
(NEUMANN et al., 2003; PUCCINI et al., 2003).

O MS chama atenção para a importância da identificação precoce das gestantes e o pronto início do acompanhamento pré-natal no primeiro trimestre da gravidez, visando às intervenções oportunas em todo o período gestacional, sejam elas preventivas ou terapêuticas (BRASIL. MS., 2000a). A realização da primeira consulta pré-natal até o quarto mês de gestação é uma das recomendações do PHPN (2000) (BRASIL, 2000b).

Penna, Progianti e Correa (1999) acreditam que a realização da consulta de enfermagem, no atendimento pré-natal, constitui um dos grandes recursos para a contribuição da expansão da cobertura assistencial à gestante. No ano de 2005 , 0 número de consultas de pré-natal em Rio Branco foi 22.538 , sendo que $76,2 \%$ dos atendimentos foram realizados por enfermeiros e apenas $23,8 \%$, pelos profissionais médicos (BRASIL, 2005).

Para Rios e Vieira (2007), o pré-natal é um espaço adequado para que a mulher prepare-se para viver o parto de forma positiva, integradora, enriquecedora e feliz e, para que isso ocorra, os profissionais de saúde devem assumir a postura de educadores, não só para a aquisição de conhecimentos sobre o processo de gestar e parir, mas também para que a mulher possa ser mais bem orientada, a fim de diminuir os riscos de complicações no puerpério e ter mais sucesso na amamentação. Penna, Progianti e Correa (1999) enfatizam que a consulta de enfermagem no pré-natal deve estar calcada nos princípios da educação em saúde, ser participativa, valorizando a integralidade da assistência à mulher, a fim de favorecer sua qualidade de vida. 


\subsection{Competências essenciais desenvolvidas no pré-natal}

Quanto à descrição das ações desenvolvidas no pré-natal, pelos enfermeiros e demais profissionais de enfermagem, percebe-se, nos depoimentos, que grande parte dos procedimentos preconizados no Manual Técnico de Assistência Pré-Natal do Ministério da Saúde e no documento sobre as Competências Essenciais para o Exercício Básico da Obstetrícia publicado pela Confederação Internacional de Parteiras (ICM) é desenvolvida pelos profissionais estudados (BRASIL, 2000a; INTERNATIONAL CONFEDERATION OF MIDWIVES, 2002).

No documento da ICM sobre as Competências Essenciais para o Exercício Básico da Obstetrícia é preconizado, para o alcance de uma prática segura, que os profissionais tenham conhecimentos e habilidades específicos e essenciais na atenção, durante a gravidez. O documento salienta que o Modelo de Cuidado em Obstetrícia deva estar baseado na premissa de que gravidez e nascimento são eventos de vida normais e que os profissionais devem assumir a responsabilidade e responder por sua prática profissional, aplicando conhecimentos e habilidades atualizados nos cuidados de saúde de cada mulher (INTERNATIONAL CONFEDERATION OF MIDWIVES, 2002).

De acordo com as falas dos profissionais entrevistados, foi afirmada por eles a aferição da PA em todas as gestantes. O controle da PA na gestação é uma das habilidades básicas recomendadas pela ICM, e em nosso estudo foi uma prática observada em $100 \%$ das consultas. A realização da história inicial, ou seja, a anamnese, habilidade básica importante no primeiro contato com a gestante durante a consulta, foi realizada em grande parte pelos enfermeiros, confirmando com o 
descrito por eles (INTERNATIONAL CONFEDERATION OF MIDWIVES, 2002).

O exame físico geral e o obstétrico são atividades fundamentais no acompanhamento pré-natal e são práticas recomendadas pelo MS e pela ICM (BRASIL, 2000a; INTERNATIONAL CONFEDERATION OF MIDWIVES, 2002). Os enfermeiros entrevistados afirmaram realizá-los, entretanto, observamos que não são realizados de forma completa em todas as consultas. Com relação ao exame físico geral, chamamos atenção em nosso estudo para avaliação da nutrição materna e sua relação com o crescimento fetal, habilidade básica recomendada pela ICM que foi realizada em menos da metade das gestantes observadas. Já para o exame obstétrico, observamos uma baixa freqüência do exame de mamas e palpação abdominal para verificação da posição e apresentação fetal.

O encaminhamento das gestantes de risco, uma das habilidades básicas que deve ser desenvolvida pelos enfermeiros, foi observado durante a coleta de dados. As anotações no prontuário e no cartão das gestantes também foram observadas em praticamente todas as consultas, conforme preconiza o documento da ICM sobre as Competências Essenciais para o Exercício Básico da Obstetrícia (INTERNATIONAL CONFEDERATION OF MIDWIVES, 2002).

Identificamos, ainda, neste estudo que os enfermeiros entrevistados referiram ter algumas dificuldades na assistência pré-natal. Dentre as atividades, observa-se que quatro $(23,53 \%)$ deles afirmaram ter dificuldade na interpretação de exames. Resultado similar ao estudo de Dotto, Moulin e Mamede (2006) sobre assistência pré-natal: dificuldades vivenciadas pelas enfermeiras, no município de Rio Branco (AC), sendo que as pesquisadoras identificaram que $28 \%$ das enfermeiras tinham dificuldades em solicitar e avaliar exames laboratoriais. Quanto à dificuldade de realizar as manobras de palpação abdominal, os dados da pesquisa 
das mesmas autoras também foram semelhantes aos deste estudo, diferindo em pouco mais de $4 \%$.

Outra dificuldade citada foi com relação à prescrição de medicamentos (17,65\%), na qual está incluído o tratamento das DST's. Conforme a Resolução 317/2007 do COFEN, como integrante da equipe de saúde: a enfermeira pode prescrever as medicações que são estabelecidas em Programas de Saúde Pública e por rotina aprovada pela instituição de saúde. O estudo de Dotto, Moulin e Mamede (2006) verificou que $20 \%$ das enfermeiras entrevistadas possuíam muita dificuldade com medicações que poderiam prescrever.

Nas atividades relacionadas ao acompanhamento das gestantes de alto risco e gestante $\mathrm{Rh}$ negativa, dois enfermeiros relataram ter dificuldades. Cabe salientar que as enfermeiras entrevistadas neste estudo não acompanham gestantes de alto risco, elas encaminham para a $\mathrm{MBH}$ ou para o médico da unidade de referência. O Manual Técnico de Gestação de Alto Risco do Ministério da Saúde (2000) chama a atenção dos profissionais, no sentido de identificar fatores de risco gestacional, a fim de favorecer o adequado manejo da gestante para um serviço de maior complexidade. Assim, o controle pré-natal da gestante de baixo risco será diferente daquele de alto risco, seja em objetivos, conteúdos, número de consultas e tipo de equipe que presta assistência (BRASIL, 2000c).

Na atividade "abordagem das clientes com NIC III e HIV positivas", um dos enfermeiros referiu ter dificuldade para realizar essa atividade. Essas duas patologias trazem a idéia de morte, principalmente no início de sua descoberta e por ser a gravidez um período de mudanças físicas e emocionais, e o profissional pode se sentir despreparado para lidar com tais situações. Segundo Rios e Vieira (2007), a comunicação em enfermagem constitui-se um instrumento básico para o cuidado 
de enfermagem, é uma competência que a enfermeira deve desenvolver. E é esta competência que usada de modo terapêutico vai permitir ao profissional assistir o cliente em todas as suas dimensões.

Para Kak, BurKhalter e Cooper (2001), a competência pode ser definida como a habilidade de desempenhar uma tarefa específica, de modo a produzir resultados desejáveis. A competência é considerada o principal marco do desenvolvimento profissional, mas não é o ponto final. Isso vem com a proficiência e o resultado de status de expert, vem com muitos anos de experiência e crescimento profissional.

Em relação à falta de domínio do conteúdo de pré-natal, 94,12\% dos enfermeiros entrevistados referiram não ter essa dificuldade. Tal resultado mostra que o conteúdo, durante a graduação, foi incorporado e revela também a competência destes profissionais para o atendimento à gestação de baixo risco. Cabe salientar que, comparando os dados do presente estudo com os de Dotto, Moulin e Mamede (2006), verifica-se que para aquelas autoras, dentre os motivos alegados pelas enfermeiras para as dificuldades enfrentadas no início do exercício profissional, foram identificadas as "falhas na graduação" (80\%).

Nos dois modelos de atenção pré-natal estudados, existe um protocolo para assistência pré-natal recomendado pela Secretaria Municipal de Saúde de Rio Branco, contudo, os enfermeiros não o seguem (RIO BRANCO, 2004b). Observamos, durante a observação realizada na coleta de dados, que grande parte deles utiliza a ficha perinatal como guia protocolar assistencial nas consultas de prénatal.

As normas de atenção ao pré-natal do MS têm o propósito de oferecer aos profissionais de saúde que prestam assistência à gestante a normatização de 
procedimentos e condutas a serem realizadas em toda consulta pré-natal (BRASIL, 2000a).

Os padrões e protocolos nacionais que definem o tipo de cuidado que se oferece em cada nível do sistema de saúde e a cada categoria de provedor são essenciais para orientar e apoiar a prática da atenção de qualidade, assim como para avaliar e melhorar o desempenho dos provedores. A elaboração de normas e protocolos eficazes exige o acordo entre os vários atores-chave da atenção à saúde, incluindo o Ministério da Saúde, os hospitais universitários, as associações de profissionais e os organismos fiscalizadores. Portanto, o desenvolvimento de modelos e protocolos assistenciais pode definir o que seja cuidado de alta qualidade da saúde materna e do recém-nascido (MAcDONALD; STARRS, 2003; WHO, 2004).

A importância de desempenhar tarefas, de acordo com os padrões estabelecidos, está na definição para ambos, profissionais e clientes, da necessidade de realizar um serviço de qualidade. Desempenhar e desenvolver as competências, de acordo com os padrões, é a base de sustentação para um adequado desempenho de atividades e da garantia da qualidade na saúde. (MARQUEZ, 2001). Portanto, a utilização de padrões baseados em evidências necessita ser incentivada em nosso universo estudado.

A habilidade de um profissional de saúde desempenhar suas tarefas de acordo com padrões preestabelecidos está relacionada à conceituação de competência e à oferta de serviço de qualidade. Entretanto os padrões de competência devem ser definidos cuidadosamente, mesmo para aqueles considerados profissionais experts na área de trabalho. (KAK; BURKHALTER; COOPER, 2001). Os padrões definem uma expectativa de como uma atividade particular do cuidado de saúde será realizada para produzir resultados desejados 
(MARQUEZ, 2001).

Enquanto se observa uma maior visibilidade, nos países industrializados, do movimento que se tem produzido para promover o estabelecimento de padrões nos serviços de saúde para incentivar o uso mais freqüente de padrões baseados em evidências (ex.: práticas apoiadas em pesquisas comprovadas cientificamente), nos países em desenvolvimento, este movimento está se iniciando, particularmente no contexto da reforma do setor da saúde (MARQUEZ, 2001).

O seguimento de padrões e procedimentos tem tradicionalmente sido uma prática na enfermagem e apenas mais recentemente ganhou familiaridade e aceitação na prática da medicina, principalmente na forma de guias clínicos. Com o passar das décadas, tem crescido o interesse por parte dos governantes, chefes de organizações de saúde, associações de profissionais e grupos de consumidores na promulgação de guias da prática clínica e outros tipos de padrões para melhorar a prática, reduzir o uso de procedimentos ineficazes e promover avanços biomédico e tecnológico (MARQUEZ, 2001).

Existem vários formatos para os padrões escritos. Cada tipo de padrão toma uma grande variedade de formas e serve a propósitos diferentes, mas todos têm como objetivo melhorar o serviço e o cuidado de saúde. Na enfermagem, os procedimentos são freqüentemente utilizados, para explicar passo a passo como desempenhar uma atividade específica baseada no conhecimento da técnica (MARQUEZ, 2001; ASHTON, s.d.).

Os dados obtidos, por meio da observação neste estudo, revelam que, com relação às competências essenciais esperadas na assistência pré-natal, a grande maioria destas foi desenvolvida, entretanto, algumas foram realizadas com baixa freqüência, ou seja, não foram realizadas em todas as consultas. 
Encontramos em nosso estudo, em todas as unidades estudadas, que os enfermeiros realizam as consultas de pré-natal às gestantes de baixo risco, corroborando com o que dizem as normas técnicas para a assistência pré-natal do MS.

Ao observar os procedimentos da pré-consulta, tendo como parâmetro as normas de atenção ao pré-natal do MS, verifica-se que todos os procedimentos de aferição do peso, altura e pressão arterial nos CSs são realizados pelos profissionais de nível médio. Por outro lado, a participação dos enfermeiros foi maior nessa atividade nas USFs. De acordo com as normas, essa é uma atividade de competência do profissional de nível médio (BRASIL, 2000a).

Moura e Rodrigues (2002), utilizando a técnica de observação participante sobre o desempenho profissional de enfermeiras na assistência pré-natal em uma microrregião do Estado do Ceará (Baturité), observaram que a verificação da PA, em todas as gestantes, foi realizada por auxiliares de enfermagem ou pessoa treinada.

Benigna, Nascimento e Martins (2004), ao entrevistar enfermeiros que prestam assistência pré-natal no Programa Saúde da Família, identificaram que 95,83\% da aferição do peso, altura e PA foi realizada pelos enfermeiros, durante a consulta pré-natal. Enquanto os achados na observação de Rios e Vieira (2007) revelam que essas aferições são realizadas pelos auxiliares de enfermagem.

O controle da PA na gestação tem como objetivo detectar precocemente estados hipertensivos que se constituam em risco materno e perinatal. A medida do peso deve ser realizada em todas as consultas, enquanto a altura deverá ser medida apenas na primeira consulta. Resultados perinatais ruins têm sido associados com peso materno pré-gravídico insuficiente, baixa estatura da mãe e aumento insuficiente ou excessivo de peso na gravidez, portanto, para essas atividades, são 
esperados rigor técnico e competência profissional de quem as realiza (BRASIL, 2000a).

Em nosso estudo, a medida de peso foi verificada na maioria das consultas, apenas quatro gestantes não foram pesadas, porque a balança estava com defeito em uma USF. Já a aferição da PA foi realizada em 100\% das gestantes e a altura apenas na primeira consulta, corroborando com as recomendações do MS.

É digno de nota o número excessivo de impressos que os enfermeiros têm de preencher, principalmente durante a primeira consulta. Rios e Vieira (2007) observaram situação semelhante na pesquisa realizada pelas autoras onde as enfermeiras referiram que o excesso de burocracia e o tempo curto interferiam na qualidade e quantidade de informações a serem oferecidas para as gestantes, além de prejudicar o processo ensino-aprendizagem para as mesmas. Em nosso estudo, observamos que os enfermeiros se organizam para preencher a maioria dos formulários, após a consulta.

Nas unidades estudadas, não observamos, durante o período de coleta de dados, ações educativas desenvolvidas na sala de espera. Entre a possível explicação para este achado pode estar a carência de pessoal para realizar tal atividade. No entanto, o MS preconiza que as informações sobre as diferentes vivências devem ser incentivadas e trocadas entre as mulheres e os profissionais de saúde. Essa possibilidade de troca de experiências e conhecimentos é considerada a melhor forma de promover a compreensão do processo de gestação e, entre as diferentes maneiras de realização do trabalho educativo, destacam-se: as discussões em grupos, as dramatizações e outras dinâmicas que facilitam a fala e a troca de experiências (BRASIL, 2000a). 
A qualidade de serviço é determinada não somente pela capacidade técnica dos profissionais, mas também pela apropriação cultural e pela interação dinâmica entre os clientes e profissionais. Há evidências de que o bom desempenho nas habilidades de interação dos profissionais com as mulheres, homens e comunidade é um elemento-chave de qualidade da atenção. Além disso, diferentes estudos têm mostrado que a melhoria no desempenho das competências interpessoais e interculturais pode influenciar a confiança das mulheres com relação às recomendações fornecidas sobre o cuidado, o conhecimento e percepção de qualidade do cuidado e o uso de serviços (WHO, 2003).

Penna, Progianti e Correa (1999) defendem que, durante a formação do enfermeiro, devam ser desenvolvidas junto ao estudante atividades baseadas em práticas educativas, com as quais não se exclua o modelo tradicional (modelo biomédico), mas que o supere, associando a ele as práticas assistenciais/educativas que valorizem o saber popular, as reais necessidades da(o) cliente, particularmente a mulher, a fim de que as mesmas sejam assistidas de forma integral.

Atitudes de acolhimento (escuta, diálogo, história da grávida, significado da gestação), em nosso estudo, foram constatadas durante a maioria das consultas observadas. Por ser uma atividade que demanda disponibilidade de tempo do profissional com a cliente, a não-realização em todas as consultas pode ser explicada por este motivo. A enfermeira, no acolhimento à mulher, deve desenvolver a capacidade de ouvir e de lidar com a pessoa como um todo, considerando a situação existencial em que esta se encontra. Este posicionamento exige a capacidade de percepção de mudanças significativas, como é o caso do ciclo gravídico-puerperal que afeta toda a existência da mulher e não apenas alguns de seus órgãos (MERIGHI, 1998). 
Na escuta, o sujeito se dispõe a conhecer aquilo que talvez esteja muito distante de sua experiência de vida e por isso exige um grande esforço do profissional para compreender e ser capaz de oferecer ajuda, ou melhor, trocar experiências (BRASIL, 2000a).

A consulta de enfermagem voltada para o atendimento a gestantes de baixo risco visa a oferecer assistência integral clínico-ginecológica e educativa, atentando para o aprimoramento do controle pré-natal, do parto e puerpério. A atuação do profissional que realiza o pré-natal é certamente fator decisivo na qualidade do acompanhamento à gestante. É desejável que esse profissional seja competente, a fim de identificar qualquer alteração na evolução da gravidez e corrigila de imediato (CORRÊA ; OLIVEIRA, 1999; LOPES et. al., 2000).

Geralmente na primeira consulta, se estabelecem as primeiras reações, positivas ou negativas, entre a gestante e o profissional. Portanto, é fundamental que a enfermeira conquiste a confiança e a simpatia da grávida, recebendo-a de maneira atenciosa, para que se estabeleça um vínculo, o que auxilia no sucesso e na continuidade da assistência (LACAVA ; BARROS, 2002). Em nossa observação, verificamos que os enfermeiros receberam as gestantes com simpatia, ouviram as queixas, e grande maioria esclareceu suas dúvidas, oportunizando, assim, a educação em saúde.

A anamnese representa o primeiro tempo da propedêutica obstétrica e tem a finalidade de obter informações referidas pela paciente e observadas pelo profissional. O levantamento rico e detalhado de dados auxilia a detecção precoce de fatores que impliquem uma gestação de risco, portanto a enfermeira deve estar sempre atenta à presença de intercorrências (LACAVA; BARROS, 2002). 
Identificamos, em nossa pesquisa, que a anamnese na primeira consulta foi realizada na maioria das consultas. Realizar a história inicial em cada consulta pré-natal é uma das habilidades básicas preconizadas pela Confederação Internacional das Parteiras. (INTERNATIONAL CONFEDERATION OF MIDWIVES, 2002). Conforme tais diretrizes no histórico, devem estar inclusos dados que possibilitem orientação e educação sobre o cuidado com a saúde da mulher e da criança. Esse cuidado inclui: preparação para a maternidade; oferecimento de métodos de planejamento familiar; identificação de condições anormais na mãe e criança; atenção especializada, quando necessário, e assistência de emergência primária e secundária, na ausência do médico (INTERNATIONAL CONFEDERATION OF MIDWIVES, 2002).

Das 17 consultas de primeira vez, observamos que o cálculo da data da última menstruação foi realizado em 16 consultas. Este resultado foi similar ao de Criciúma (SC), em 2003, onde foi constatado um percentual de 96,9\% para realização destes procedimentos, durante as consultas de pré-natal (NEUMANN et al., 2003).

Os cálculos da data provável do parto e da idade gestacional foram realizados em $82,35 \%$ e $94,12 \%$ das consultas, respectivamente. Em uma pesquisa sobre o desempenho profissional de enfermeiras na assistência pré-natal, realizada em 2002, no Estado do Ceará (Baturité), foi observado que a data provável do parto foi calculada em $87,5 \%$ e a idade gestacional em $100 \%$ das consultas (MOURA; RODRIGUES, 2002).

A confirmação da idade gestacional na consulta de pré-natal é importante tanto para a avaliação do estado nutricional da gestante como para a avaliação do crescimento fetal. Os cálculos da data da última menstruação e a data provável do 
parto também são parâmetros importantes para o profissional identificar a possibilidade de parto prematuro ou pós-datismo, assim como são informações que permitem um melhor planejamento da gestante quanto ao parto e puerpério (MOURA; RODRIGUES, 2002).

Quando analisamos os dados da anamnese a partir da segunda consulta em diante, observamos que os percentuais das informações foram menores com exceção do cálculo da idade gestacional que foi verificado em um pouco mais de 90\% das consultas. Em conformidade com as normas técnicas do MS, no item roteiro das consultas subseqüentes, estão preconizados "a revisão da ficha perinatal e anamnese atual" e o "cálculo e anotação da idade gestacional" (BRASIL, 2000a). Portanto os resultados corroboram em parte com o recomendado pelo MS.

Observamos que a avaliação do estado nutricional das gestantes foi realizada em 15 (24,59\%) consultas. Esse achado difere do estudo realizado por Moura e Rodrigues (2002), no Estado do Ceará, que constatou que 87,5\% das enfermeiras realizaram a avaliação do estado nutricional das gestantes. Em outro estudo, realizado por Benigna, Nascimento e Martins (2004), apenas 4,16\% dos enfermeiros referiram realizar tal avaliação.

Avaliar a nutrição materna e sua relação com o crescimento fetal é um procedimento recomendado pelo MS e também uma das habilidades básicas adotadas pelas competências essenciais da ICM. É um procedimento de grande importância, pois permite a identificação das gestantes com déficit nutricional ou com sobrepeso. O aumento insuficiente de peso materno está associado ao crescimento intra-uterino retardado, à hiperêmese gravídica, às infecções, parasitoses, anemias e a outras doenças debilitantes. Enquanto o aumento excessivo de peso predispõe à macrossomia fetal, ao polidrâmnio, ao edema e à gravidez múltipla. Na detecção 
desses casos, a gestante deverá ser encaminhada ao serviço de alto risco. (BRASIL, 2000a; INTERNATIONAL CONFEDERATION OF MIDWIVES, 2002).

Durante as consultas, observamos que a inspeção da pele e mucosas foi realizada em apenas 20 consultas (32,79\%), percentual baixo, quando se considera que esse tipo de informação muitas vezes orienta a presença de anemia, situação deletérica tanto para a gestante quanto para o feto, daí a importância da realização desse procedimento pelos enfermeiros (KONDO, 1994). Na pesquisa de Moura e Rodrigues (2002), esse procedimento foi feito em $25 \%$ das consultas realizadas pelas enfermeiras.

O procedimento de palpação da tireóide foi realizado apenas pelos profissionais dos CSs em 02 consultas. Essa é uma informação que também não foi referida durante a entrevista com os profissionais que participaram deste estudo. Por outro lado, é um procedimento que faz parte do exame físico geral da gestante preconizado pelo MS, e o profissional deve estar atento para o aumento fisiológico da glândula da tireóide, e, na dúvida, solicitar exames ou referir a gestante para serviço especializado (KONDO, 1994; BRASIL, 2000a).

A pesquisa de edema e o exame dos MMII podem estar associados com o quadro de pré-eclâmpsia ou outras situações patológicas. Em nosso estudo, essa avaliação foi realizada em mais de $60 \%$ das consultas, enquanto a pesquisa de Moura e Rodrigues (2002) foi apenas em 37,5\%. O objetivo desse procedimento é detectar precocemente a ocorrência de edema patológico. Contudo, algumas características, como localização, associação do edema com a postura, período do dia em que o mesmo ocorre, aumento de temperatura, tipo de calçado, se o mesmo está limitado aos MMII, devem ser averiguadas. Nessas situações, orientações sobre repouso e acompanhamento da condição são de vital importância para a 
saúde materna e fetal. Em caso de edema generalizado (face, tronco e membros), ou que o edema se manifesta ao acordar, a gestante deve ser encaminhada ao prénatal de risco (BRASIL, 2000a).

A baixa freqüência $(39,34 \%)$ da realização do exame de mamas chama atenção em nossa observação. Esse é um exame obstétrico recomendo pelo MS que deve ser orientado, também, para o aleitamento materno (BRASIL, 2000a). No estudo de Moura e Rodrigues (2002), estes observaram que metade (50\%) das enfermeiras realizou o exame clínico das mamas. Outro estudo, realizado com enfermeiros que trabalham em PSF e atuam no pré-natal, verificou que $41,66 \%$ dos enfermeiros entrevistados referiram fazer exame nas mamas em todas as consultas (BENIGNA; NASCIMENTO; MARTINS, 2004).

Outros estudos, no país, encontraram freqüência superior à observada por nós, no que se refere à realização do exame de mamas no pré-natal: 50,6\% em Criciúma (SC); 60,8\% em Embu (SP) e 74\% em Caxias do Sul (SC) (TREVISAN et al., 2002; NEUMANN et al., 2003; PUCCINI et al., 2003).

Lacava e Barros (2002) salientam que a enfermeira, durante a realização do exame de mama, deve aproveitar deste momento para orientar sobre os aspectos relacionados ao cuidado pré-natal das mamas e mamilos, à amamentação, cujo conteúdo deve estar de acordo com a idade gestacional em que se encontra a gestante e com o tipo de mamilos identificado. Deve-se averiguar a presença de nódulos ou anormalidades, assim como a presença de secreção sanguinolenta. Nesses casos, a enfermeira deve encaminhar a gestante ao serviço especializado para a realização de propedêutica complementar.

Segundo Puccini et al. (2003), a realização do exame de mamas não requer muito tempo ou recursos tecnológicos. A não-realização do exame reflete, 
possivelmente, uma fragmentação do atendimento e ausência de uma abordagem com base no cuidado e na integralidade da atenção à mulher.

A ausculta dos batimentos cardiofetais é uma atividade fundamental no acompanhamento pré-natal. No presente estudo, se considerarmos que nos locais estudados havia unidade que não possuía Sonar Doppler ou estetoscópio de Pinard, e seis gestantes estavam com menos de 23 semanas de gestação cujas unidades de atendimento contavam com estetoscópio de Pinard, a ausculta só não foi feita em duas gestantes. De acordo com o manual de normas do MS (2000), a ausculta de BCF se torna mais viável entre a sétima e a décima semanas de gestação com auxílio do Sonar Doppler, e com o estetoscópio de Pinard, após a $24^{a}$ semana (BRASIL, 2000a).

O procedimento de ausculta de BCF no pré-natal tem como objetivo a constatação da presença, ritmo, freqüência e a normalidade dos batimentos cardiofetais (BRASIL, 2000a).

Uma pesquisa realizada com registros em prontuários, em uma instituição de São Paulo (SP), onde o atendimento do serviço de pré-natal de gestantes de baixo risco é de responsabilidade de enfermeiras obstétricas, docentes de enfermagem, alunos da pós-graduação e graduação em enfermagem, foi encontrado um registro de $96,7 \%$ de realização da ausculta de batimentos cardiofetais (KOFFMAN; BONADIO, 2005).

Os dados da pesquisa de Carvalho et al. (2004), realizada em uma maternidade de São Paulo (SP), sobre a análise dos registros nos cartões de prénatal como fonte de informação para a continuidade da assistência à mulher no período gravídico-puerperal, foram semelhantes ao deste estudo, apontando que 79\% dos cartões tinham o registro da freqüência ou pelo menos a presença de 
batimentos cardiofetais.

Outro estudo de observação de consultas de pré-natal identificou que 75\% das enfermeiras realizaram ausculta dos BCFs, no entanto não mensuraram a freqüência, registraram apenas sua presença com o sinal $(+)$, e as que não realizaram tal procedimento, referiram não se sentirem seguras para tanto (MOURA; RODRIGUES, 2002).

Em nosso estudo, em todas as auscultas, os enfermeiros registraram os valores da freqüência cardíaca fetal. Entretanto, observamos que muitos não realizaram a palpação do útero em todas as gestantes quando auscultadas, especialmente quando se preconiza a importância da identificação do dorso fetal, um dos parâmetros para a ausculta dos BCFs. Cabe destacar que alguns enfermeiros referiram, durante o momento da entrevista, ter dificuldade de realizar palpação em grávidas obesas.

O procedimento de verificação da apresentação fetal foi observado em apenas 20 consultas, diferindo do resultado da pesquisa de Koffman e Bonadio (2005) que verificaram que $97,6 \%$ dos prontuários das gestantes tinham registro da realização de tal procedimento.

A verificação da apresentação fetal é realizada através da palpação obstétrica com a finalidade de identificar os pólos cefálico e pélvico. As apresentações mais freqüentes são a cefálica e a pélvica. Em caso de situação transversa e pélvica no final da gestação, o MS recomenda referir a gestante para parto hospitalar, porque essas situações podem significar risco no momento do parto (BRASIL, 2000a).

A medida da altura uterina é recomendada pelo MS como sendo de grande importância para identificar o crescimento normal do feto e detectar seus 
desvios. É possível fazer o diagnóstico das causas do desvio do crescimento fetal e suas respectivas intervenções (BRASIL, 2000a). Neste estudo, observamos que a verificação da altura uterina foi uma habilidade desenvolvida pelos enfermeiros na maioria das consultas.

Moura e Rodrigues (2002) encontraram, em suas pesquisas, situação similar onde $87,5 \%$ das enfermeiras observadas, em seu estudo, verificaram a medida da altura uterina. Outros estudos encontraram que o procedimento de verificação da altura uterina foi realizado em $97,0 \%$ e $100 \%$, respectivamente, em todas as consultas realizadas por enfermeiros (BENIGNA; NASCIMENTO; MARTINS, 2004; KOFFMAN; BONADIO, 2005).

O exame de inspeção dos genitais externos, exame especular e coleta de Papanicolau não foram observados nas unidades pesquisadas. A possível explicação para este achado é que, nas unidades pesquisadas, o exame de PCCU é oferecido em dia específico. Cabe salientar que cinco enfermeiros participantes desta pesquisa durante a entrevista referiram realizar o referido exame.

A colpocitologia oncótica (exame de Papanicolau) conforme recomendação do MS, deverá ser realizada nas gestantes, cujo último exame tenha ocorrido há mais de três anos, sendo o último exame com diagnóstico negativo para a neoplasia. É um procedimento dentro dos níveis de execução da assistência prénatal, como sendo de competência da enfermeira além do médico (BRASIL, 2000a).

Outro estudo identificou que apenas $12,5 \%$ das enfermeiras observadas realizaram tais exames na ocasião da consulta. Segundo as autoras daquele estudo, esse dado merece toda atenção, pois para muitas mulheres, principalmente as de zona rural, a vinda na unidade de saúde é cercada de dificuldades, devendo o profissional, portanto, oferecer uma assistência integral à gestante (MOURA; 
RODRIGUES, 2002). Por outro lado, o estudo de Trevisan et al. (2002) mostrou que 51\% das entrevistadas referiram ter realizado o exame de Papanicolau, durante o pré-natal.

A detecção precoce da neoplasia cervical deve ser feita sempre que ocorrer oportunidade, uma vez que o diagnóstico precoce é a chave do sucesso no controle desta doença. O ciclo gravídico-puerperal se constitui em oportunidade ímpar onde os serviços de saúde recebem as mulheres e, portanto, não podem perder a chance de realizar tal exame (KONDO, 1994).

A freqüência observada das orientações com relação à amamentação e alimentação (44,26\%), neste estudo, mostrou-se inferior aos 100\% e 91,66\% observados por Benigna, Nascimento e Martins (2004). Por outro lado, a freqüência da orientação quanto ao uso de medicamentos, em nossa observação, foi superior $(47,54 \%)$ ao encontrado por esses mesmos autores $(4,16 \%)$.

Segundo as normas do MS, o profissional, ao realizar o exame de mamas na gestante, deve orientar também sobre o aleitamento materno. A prática da amamentação oferece benefícios tanto para o crescimento e desenvolvimento de lactentes como para a mãe, criança e família, do ponto de vista biológico e psicossocial (BRASIL, 2000a; BRASIL, 2003a).

Birungi e Onyango-Ouma (2006) observaram, no Quênia, por meio dos dados de uma pesquisa focalizada no cuidado pré-natal, que os profissionais na primeira consulta orientaram as gestantes sobre a qualidade da alimentação (32\%), higiene pessoal (25\%) e importância do repouso e exercício físico (14\%), durante a gravidez. Comparando com o encontrado em nosso estudo, vê-se que apenas a orientação quanto à alimentação é realizada com maior freqüência $(44,26 \%)$, nas unidades aqui estudadas. Cabe salientar que, se separarmos as unidades do nosso 
estudo, a freqüência da orientação com relação à higiene pessoal realizada pelos enfermeiros dos CSs foi similar $(28,57 \%)$ ao estudo desses mesmos autores.

Os resultados da pesquisa de Benigna, Nascimento e Martins (2004), sobre as orientações quanto à importância do exercício físico e sono (4,16\%), foram similares ao nosso estudo. Por outro lado, os autores verificaram uma freqüência superior de orientações, sobre cuidados com o recém-nascido (100\%), alimentação $(91,66 \%)$ e o uso de cigarros e bebidas alcoólicas $(33,33 \%)$, ao encontrado neste estudo. Se analisarmos as unidades estudadas separadamente verificaremos que a orientação quanto ao cuidado com o recém-nascido foi realizada com maior freqüência pelos profissionais dos CSs.

Orientar e esclarecer as mulheres sobre sinais de perigo na gestação, quando e como procurar o profissional ou o serviço de saúde e medidas para diminuir os desconfortos comuns da gravidez, foram habilidades básicas desempenhadas pelos enfermeiros aqui estudados. Estas observações vêm reforçar a necessidade de estimular tais práticas na rotina de atendimento à gestante, conforme recomendações das competências essenciais adotadas pelas ICM (INTERNATIONAL CONFEDERATION OF MIDWIVES, 2002).

O MS preconiza a realização dos seguintes exames laboratoriais de rotina na primeira consulta: grupo sangüíneo e fator $\mathrm{Rh}$ (quando não realizado anteriormente); sorologia para sífilis (VDRL); urina (tipo I); hemoglobina (Hb); glicemia de jejum; colpocitologia oncótica (se necessário); bacterioscopia do conteúdo vaginal (se necessário); Teste Anti-HIV (deve ser sempre voluntário) (BRASIL, 2000a).

Em nosso estudo, esses exames foram solicitados em todas as consultas observadas, considerando que apenas para uma gestante não foram solicitados o 
grupo sangüíneo e fator Rh, porque a mesma já tinha realizado anteriormente. Além dos exames de rotina, observamos que os enfermeiros solicitaram também os exames considerados como complementares, de acordo com as normas do MS para a assistência pré-natal e também outros que não constam em tais normas (BRASIL, 2000a).

Os resultados da pesquisa de Moura e Rodrigues (2002) foram similares ao encontrado neste estudo, ou seja, constataram que $100 \%$ dos exames laboratoriais de rotina, na primeira consulta, foram solicitados pelas enfermeiras nas unidades estudadas. Outras pesquisas realizadas com enfermeiros e puérperas constataram que alguns exames não foram $100 \%$ solicitados, a exemplo da glicemia (58,33\%); urina tipo I (83,33\%); Teste anti-HIV (41,66\%); e VDRL $(95,4 \%)$ (TREVISAN et al., 2002; BENIGNA; NASCIMENTO; MARTINS, 2004).

Koffman e Bonadio (2005) salientam a importância dos exames laboratoriais no rastreamento de doenças, cujos tratamentos, em sua grande maioria, são disponíveis e de baixo custo, como aqueles para detecção de sífilis e anemia ferropriva, cujos resultados positivos podem comprometer a saúde materna e perinatal.

No presente estudo, observamos que são solicitados os exames para sorologia de hepatite e toxoplasmose, diferindo do encontrado na pesquisa realizada por Benigna, Nascimento e Martins (2004), quando constataram que esses exames não são solicitados pelos enfermeiros entrevistados. A justificativa dada pela maioria dos profissionais para a não-solicitação desses exames relaciona-se à demora tanto na realização como na entrega dos resultados. Com relação ao exame de hemograma, esses autores encontraram resultado similar (100\%) ao nosso, já o exame parasitológico de fezes foi solicitado com menor freqüência (75\%) do que 
este estudo que foi de $100 \%$.

O exame de ultra-sonografia foi solicitado, em nossa pesquisa, para a metade das gestantes, na primeira consulta. Um estudo de corte transversal com um grupo de 702 puérperas constatou que $96,8 \%$ delas confirmaram ter se submetido a exames de ultra-sonografia durante a gestação (TREVISAN et al., 2002)

A recomendação do MS é que deve ser solicitado o exame de ultra-som, quando não for possível determinar a idade gestacional clinicamente (BRASIL, 2000a). Por outro lado, justifica-se a realização deste exame no primeiro trimestre gestacional (11 ${ }^{\mathrm{a}}-14^{\mathrm{a}}$ semanas), para determinar a medida da translucência nucal, a fim de rastrear anomalias cromossômicas, dentre elas a síndrome de Down, além de confirmar a presença de batimentos cardíacos fetais para estabelecer a vitalidade embrionária (REZENDE; MONTENEGRO, 2003).

Um estudo realizado com enfermeiros que trabalham em PSF revelou que os profissionais referiram ter conhecimento da necessidade deste exame, porém enfrentam dificuldades na demora e realização. Segundo eles, em alguns casos a demora é tão acentuada que a gestante passa todo o período gestacional sem conseguir realizar uma ultra-sonografia, fato este considerado negativo para a qualidade de um serviço de pré-natal (BENIGNA; NASCIMENTO; MARTINS, 2004).

Cabe destacar que os enfermeiros participantes deste estudo explicaram o motivo de realização dos exames às gestantes. Acreditamos que, ao esclarecer a importância e o motivo da realização dos exames laboratoriais às gestantes, os enfermeiros estão contribuindo de forma efetiva para a melhoria da qualidade da assistência no atendimento pré-natal, no sentido de permitir um melhor direcionamento da realização destes.

A prescrição de medicações (sulfato ferroso, ácido fólico, nistatina creme 
vaginal, metronidazol creme vaginal, paracetamol, buscopan, ampicilina, cefalexina, miconazol creme vaginal, complexo B e benzoato de benzila), prática realizada pelos enfermeiros participantes deste estudo, está respaldada em legislação nacional e estadual como: Resolução 317/2007 COFEN; Portaria da Prefeitura Municipal de Rio Branco - Acre e Secretaria Municipal de Saúde (SEMSA) no 110/2004 publicada no Diário Oficial do Estado, em 06 de dezembro de 2004, e no Art. 8ª parágrafo IV do Regimento Interno do Serviço de Enfermagem publicado no Manual de Protocolos pelo Departamento de Ações Básicas de Saúde e Divisão de Centros e Postos de Saúde da SEMSA, em 2004.

A Portaria da SEMSA n0110/2004, em seu Art. $1^{\circ}$, normatiza a consulta, o diagnóstico, a prescrição e transcrição de medicamentos e a solicitação de exames de rotina e complementares por enfermeiros, no âmbito da Secretaria Municipal de Saúde de Rio Branco, em conformidade com as normas dos programas de saúde pública e com as rotinas adotadas pelo secretário de saúde e suas diretorias (RIO BRANCO, 2004a).

Observamos que todas as medicações prescritas, neste estudo, constam na relação dos medicamentos preconizados pelo MS e específicos dos Programas de Saúde Pública (RIO BRANCO, 2004a). Cabe salientar que a exigência de uma atenção rigorosa na prescrição de medicamentos, no primeiro trimestre de gestação, é de suma importância, uma vez que não são poucos fármacos que podem ter efeito teratogênico sobre a organogênese (LOPES, et al., 2000).

As medicações prescritas pelos enfermeiros participantes da presente pesquisa foram para gestantes depois do primeiro trimestre de gestação, com exceção da prescrição de ferro e ácido fólico. O MS preconiza a suplementação de ferro a partir da $20^{\mathrm{a}}$ semana, independentemente de apresentar ou não anemia. 
(BRASIL, 2000a). A prescrição de ferro, neste estudo, foi a mais realizada, seguida da prescrição de ácido fólico.

A anemia é comum na gravidez, e a depleção das reservas de ferro é universal. É recomendável a prescrição de sulfato ferroso na gestação, devendo ser continuada a suplementação após o parto, para recompor as reservas maternas, até o término da lactação ou por dois a três meses nas não-lactantes (REZENDE; MONTENEGRO, 2003).

As medicações: nistatina, metronidazol, miconazol, paracetamol (acetominofen) e a cefalexina são drogas em que, segundo os estudos, não há evidências de riscos para o feto, acima do primeiro trimestre de gestação (SANCOVSKI, 1994). Quanto à suplementação vitamínica, também não se têm registrado efeitos danosos sobre o feto, exceto para as vitaminas $\mathrm{D}$ e $\mathrm{K}$ quando tomadas em dosagem excessiva (REZENDE; MONTENEGRO, 2003).

Ao prescrever as medicações, os enfermeiros anotaram na ficha perinatal das gestantes o motivo da prescrição. Na Tabela 17, observamos que o conteúdo das anotações sobre os motivos da prescrição confirma a pertinência das condutas tomadas pelos estudados, revelando um desempenho responsável e adequado por parte dos enfermeiros participantes desta pesquisa. Da mesma forma, reforça a exigência de um perfil profissional na atenção obstétrica que constitua de habilidades para fazer o que é necessário, incluindo habilidades relacionadas à conduta respeitosa e dignificante ao ser humano (QUALITY ASSURANCE PROJECT, 2005).

A freqüência de anotação do motivo da reposição de ferro e anemia foi maior do que a prescrição, porque os profissionais fizeram as duas anotações (reposição de ferro e anemia) na ficha perinatal de três gestantes. Situação 
semelhante se deu com a freqüência de anotação do prurido vaginal e corrimento vaginal, onde foram anotados os dois sintomas na ficha perinatal de uma gestante. Por outro lado, observamos que não foram anotados os motivos da prescrição medicamentosa para dor no baixo ventre e infecção urinária em um prontuário.

Cabe salientar que a maioria dos profissionais explicou para as gestantes o motivo da prescrição, bem como a forma de utilização da mesma. Esta é uma conduta importante, porque alguns estudos apresentam índices de $65 \%$ de automedicação na gestação. Por outro lado, o inverso é freqüentemente encontrado quando, por ansiedade e receio sobre possíveis efeitos adversos sobre o feto, a gestante deixa de tomar as medicações prescritas (SANCOVSKI, 1994).

O encaminhamento da gestante para a vacinação antitetânica foi observado em quase todas as consultas, considerando as que já tinham sido vacinadas ou estavam em dia com a vacina. Recomendada pelo MS, a vacinação é realizada para a prevenção do tétano no recém-nascido e para a proteção da gestante. (BRASIL, 2000a). O estudo de Moura e Rodrigues (2002) identificou um excelente (100\%) desempenho das enfermeiras, durante a consulta de pré-natal, no manejo do esquema vacinal contra o tétano. Outro estudo de corte transversal realizado em Santa Catarina (RS) detectou que 79,3\% das gestantes receberam orientação sobre imunização antitetânica durante as consultas de pré-natal (NEUMANN et al., 2003).

Com relação à explicação sobre a importância da vacinação, em nosso estudo, ela foi feita com menor freqüência do que o encaminhamento. Acreditamos que uma vez que a gestante foi encaminhada para realizar um procedimento, a mesma deveria ser informada sobre a finalidade do mesmo.

Observamos que o encaminhamento para a realização do exame de 
PCCU foi realizado com pouca freqüência. Esse é um exame recomendado e identificado como complementar pelo MS (BRASIL, 2000a). É de fundamental importância que o exame de PCCU seja incorporado a uma prática educativa mais abrangente, uma vez que o pré-natal constitui-se em oportunidade para educar a gestante sobre a importância e a finalidade deste.

As cinco gestantes que foram encaminhadas ao médico, foram por apresentarem fatores de risco gestacional e nesses casos a gestante deve ser referida ao pré-natal de alto risco, conforme preconizam as normas do MS (BRASIL, 2000a).

O agendamento para as consultas subseqüentes foi identificado na maioria das consultas observadas. O calendário de atendimento pré-natal deve ser programado em função de alguns fatores: idade gestacional na primeira consulta; períodos mais adequados para a coleta de dados necessários ao bom seguimento da gestação; períodos nos quais se necessita intensificar a vigilância, pela possibilidade maior de incidência de complicações e dos recursos disponíveis nos serviços de saúde e da possibilidade de acesso da clientela aos mesmos. No geral, o intervalo entre as consultas deve ser de quatro semanas e, após a 36ª semana, a cada 15 dias (BRASIL, 2000a).

A anotação no prontuário e no cartão da gestante foi realizada em quase todas as consultas observadas. O registro dos achados da história clínica, incluindo as atividades realizadas e as que necessitam de seguimento, é uma das habilidades básicas preconizadas pela ICM (INTERNATIONAL CONFEDERATION OF MIDWIVES, 2002). Também é recomendação do MS que as condutas e os achados diagnósticos sempre devem ser anotados na ficha perinatal e no cartão da gestante, em toda consulta pré-natal (BRASIL, 2000a). 
Observamos que a maioria das mulheres, no período pós-parto, retorna ao serviço de saúde apenas para o cuidado com o recém-nascido. Esse resultado corrobora com os resultados do panorama da assistência pré-natal no Brasil (SERRUYA; LAGO; CECATTI, 2004a).

Nas três consultas puerperais observadas, as puérperas estavam com 15 a 30 dias de puerpério, e apenas uma puérpera apresentou queixa. A realização do exame físico não foi observada durante a observação das consultas. As condutas foram baseadas nas queixas das puérperas. As orientações com relação aos cuidados com o recém-nascido foram observadas em duas consultas, já com relação à amamentação foram realizadas nas três consultas. As questões sobre alimentação e atividade sexual foram mencionadas em apenas uma consulta. Foi ainda fornecido preservativo e contraceptivo oral (minipílula) em duas consultas e um encaminhamento médico.

O MS preconiza que a revisão puerperal precoce deve ser marcada em torno do $7^{\circ}$ ao $10^{\circ}$ dia de puerpério. Nesta revisão, o profissional deve ouvir as queixas da puérpera, proceder ao exame físico adequado, com ênfase ao estado hematológico, rastreamento de infecção (puerperal ou ferida operatória). São fundamentais o exame das mamas e o incentivo para a continuação do aleitamento materno (BRASIL, 2003a).

A puérpera deve ser orientada a retornar para nova avaliação entre o $30^{\circ}$ e o $42^{\circ}$ dia pós-parto. Neste retorno, procede-se a um novo exame físico, ouvem-se as queixas, e, nas puérperas que não completaram o esquema de vacinação e não realizaram o PCCU, deve-se aproveitar este momento para fazê-los. Nesta ocasião também podem ser liberados os exercícios físicos e a atividade sexual (BRASIL, 2003a). 
Constatamos em nossa observação, nas unidades pesquisadas, que os procedimentos da consulta de pré-natal preconizados pelo Manual de Normas Técnicas para Assistência Pré-Natal do MS e Confederação Internacional das Parteiras (ICM) são em grande parte seguidos pelos enfermeiros. O desempenho de competências representa o conhecimento do profissional de saúde, as habilidades herdadas ou adquiridas através da experiência e treinamentos, ou das características pessoais que predispõem uma pessoa a comportar-se em certa situação (MARQUEZ, 2001).

Contudo, desempenhar atividades baseadas em padrões é uma questão complexa e envolve muitos fatores: organizacional, social e comportamental. A maioria dos profissionais de saúde pode não estar familiarizada com os padrões recomendados para uma boa prática profissional por vários motivos, entre eles o desconhecimento, a falta de clareza sobre o recomendado, o que parece não ser o caso dos enfermeiros aqui estudados. Por outro lado, a falta de suplementos ou equipamentos necessários, para desempenhar de acordo com os padrões, pode ser um motivo de não-adesão aos padrões recomendados (MARQUEZ, 2001).

A definição sobre o desempenho, de acordo com padrões, deve começar com o entendimento do que seja significativo a um padrão de saúde. As definições de medidas de como o cuidado de saúde deve ser realizado devem estar explícitas nos padrões. Em algumas instituições, o termo "normas" é usado para descrever vários tipos de padrões e é freqüentemente usado como sinônimo de padrões. Este conceito é uma forma de facilitar a adesão aos padrões que são adotados para serem adequados, efetivos e aceitos no serviço de saúde. As normas e os protocolos são fundamentais para guiar e respaldar a atenção de qualidade, por parte do profissional qualificado, assim como para medir seu 
desempenho/rendimento e promover seu sentido de responsabilidade (MARQUEZ, 2001; MAcDONALD; STARRS, 2003).

Identificamos, na realidade estudada, que são as enfermeiras que acompanham integralmente as gestantes de baixo risco na assistência pré-natal. Quando é detectada alguma anormalidade, a gestante é referida ao pré-natal de alto risco.

Do universo estudado, apenas duas $(11,76 \%)$ enfermeiras têm especialização em obstetrícia, e com os demais enfermeiros estes têm contribuído sobremaneira no atendimento à mulher no processo de gestação no município de Rio Branco. Cabe ressaltar que, pela característica da enfermeira obstétrica, esta é detentora de conhecimentos e habilidades complementares que a tornam uma profissional capacitada a prestar assistência de enfermagem à gestante, podendo contribuir de maneira significativa para a redução dos índices de mortalidade materna e perinatal (LACAVA; BARROS, 2002).

Portanto, a participação de enfermeiros e enfermeiras obstétricas tem fundamental importância para o fortalecimento da assistência pré-natal, entretanto, são necessários investimentos na formação de pessoal qualificado, para o atendimento à mulher no ciclo grávido-puerperal, a fim de melhorar cada vez mais a qualidade de atendimento nos serviços de saúde materna e neonatal. 
Os dados oriundos das entrevistas com os profissionais de enfermagem que prestam atendimento pré-natal, no município de Rio Branco-Acre, e da observação sistemática nas unidades de atuação dos mesmos nos permitiram tecer as seguintes conclusões:

A equipe de enfermagem que atende a mulher na assistência pré-natal no município de Rio Branco, nas unidades estudadas, é composta de enfermeiras obstétricas, enfermeiros, técnicas e auxiliares de enfermagem;

Os profissionais entrevistados são predominantemente do sexo feminino (91,3\%), com idade média de 34,3 anos, mais da metade deles é casada, 47,83\% possuem mais de cinco anos de formação profissional, 52,17\% trabalham em mais de uma instituição, a carga horária semanal trabalhada é de 53,26 horas, existe diferença de salários nos dois modelos estudados (CS e USF), as enfermeiras possuem maior tempo de experiência na assistência pré-natal (51 meses) do que os profissionais de nível médio;

$11,76 \%$ são enfermeiras obstétricas, e os demais enfermeiros fizeram uma capacitação para a assistência pré-natal de 24 a 40 horas de duração;

Os enfermeiros são responsáveis pela consulta pré-natal, e os profissionais de enfermagem de nível médio atuam na pré-consulta da gestante;

O desenvolvimento das competências essenciais para a assistência pré-natal pelos profissionais de enfermagem faz parte da realidade 
estudada;

A grande maioria das competências essenciais esperadas na assistência pré-natal, neste estudo, foi desenvolvida, entretanto, algumas foram realizadas com baixa freqüência, ou seja, não foram realizadas em todas as consultas;

As ações e os procedimentos mais freqüentemente realizados foram: aferição da PA, verificação do peso e altura, acolhimento, realização da história inicial (anamnese), data de última menstruação, data provável do parto, idade gestacional, exame de MMII, pesquisa de edema, ausculta do BCF, medida da altura uterina, solicitação de exames laboratoriais, orientações (aleitamento materno, alimentação e uso de medicamentos), prescrição de ferro, encaminhamento para vacinação antitetânica, agendamento de consultas subseqüentes, anotações no prontuário e no cartão das gestantes;

Os procedimentos menos freqüentes foram: avaliação do estado nutricional, inspeção de pele e mucosas, palpação da tireóide, exame clínico de mamas, palpação abdominal para verificação da posição e apresentação fetal e encaminhamento para o exame de PCCU. Os procedimentos menos realizados, nas consultas observadas, fazem parte do exame físico geral e obstétrico das gestantes. São necessários, portanto, investimentos na formação dos enfermeiros que atendem a mulher na atenção pré-natal, para que possam desempenhar estas atividades de forma qualificada.

As ações e procedimentos não realizados foram: ações educativas, inspeção dos genitais externos, exame especular e coleta de 
Papanicolau;

Os enfermeiros utilizam a ficha perinatal como guia para a prática assistencial nas consultas de pré-natal. 
7 IMMPLICAÇÕES PARA O ENSINO, ASSISTËNCIA E PESQUISA 
Os resultados do presente estudo ofereceram oportunidade para refletir sobre a qualidade da atenção pré-natal nos serviços estudados e a relevância do trabalho realizado pelos enfermeiros, para o município e para as gestantes em particular. Por outro lado, possibilitaram identificar aspectos que poderão ser fortalecidos na prática assistencial e na formação de recursos humanos em enfermagem, para o atendimento pré-natal.

O estudo aponta para a necessidade de desenvolvimento de habilidades relacionadas à prática do exame físico geral e obstétrico das gestantes e atividades relacionadas à educação em saúde, para o alcance de um nível ótimo de competência na atenção pré-natal.

Da mesma forma, a análise das competências essenciais desenvolvidas na assistência pré-natal, no município estudado, pelos profissionais de enfermagem aponta para a necessidade de esclarecimentos sobre a importância da incorporação de protocolos assistenciais para a melhoria da qualidade dos serviços bem como a definição dos mesmos.

Estudos sobre avaliação de qualidade e impacto do atendimento pré-natal realizado por enfermeiros na redução de morbimortalidade materna e neonatal, no município, seriam de grande relevância para a consolidação de uma prática bemsucedida em Rio Branco. 
REFEREATCIAS BIBLIOGRÁFICAS 
ACRE. Governo do Estado do Acre. Agenda Estadual de Saúde. Rio Branco, 2001.

ACRE. Governo do Estado do Acre. Secretaria de Estado de Saúde. Plano Estadual de Saúde 2004 a 2007. Rio Branco, 2004.

ACRE. Governo do Estado do Acre. Portal do Governo do Estado. 2006. Disponível em: <http://www.ac.gov.br > . Acesso em 18 fev. 2008.

ALEXANDER, G. R.; KOTELCHUCK M. Assessing the role and effectiveness of prenatal care: history, challenges and directions for future research. Public Health Reports, Boston, v. 116, p. 306-316, Jul./Aug. 2001.

ASHTON, J. Taxonomy of health system standards. Monographs \& methodology, Bethesda, p. 1-25. $\quad$ s.d. Diponível <http://www.qaproject.org/pubs/PDFs/taxhlthsybook.pdf>. Acesso em: 21 nov. 2007.

BENIGNA, M. J. C.; NASCIMENTO, W. G.; MARTINS, J. L. Pré-natal no Programa Saúde da Família (PSF): com a palavra, os enfermeiros. Cogitare Enferm., v. 9, n. 2, p. 23-31, jun./dez. 2004.

BIRUNGI, H.; ONYANGO-OUMA, W. Acceptability and sustainability of the WHO focused antenatal care package in Kenya. Betlesda: Frontiers in Reproductive Health Program, Population Council - Institute of African Studies, University of Nairobi, Jun. 2006.

BOCARDI, M. I. B.; MAMEDE, M. V.; CLAPIS, M. J. Assistência pré-natal na adolescência: o espaço das adolescentes e dos profissionais de saúde. In: BESSA, L. F., CUNHA, M. A.; FERREIRA, T. F. (org.). Saúde da mulher: desafios a vencer. Rio Branco: EDUFAC, 2004.

BOSE, S.; OLIVERAS, E.; EDSON, W. N. How can self-assessment improve the quality of healthcare? Operations Res. Issue Paper. Bethesda, v. 2, n. 4, p. 1-28, Sep. 2001. Disponível em: <http//www.qaproject.org/pubs/PDFs/selfassess402.pdf> Acesso em: 9 de ago. 2006.

BRASIL, Ministério da Saúde. Secretaria de Assistência à Saúde. Coordenação Materno-Infantil. Plano de ação para redução da mortalidade materna. Brasília: MS., 1995.

BRASIL, Ministério da Saúde. Assistência pré-natal. 3. ed. Brasília: MS, 2000a.

BRASIL, Ministério da Saúde. Programa de humanização do pré-natal e nascimento. Brasília: MS, 2000b.

BRASIL, Ministério da Saúde. Gestação de alto risco. 3. ed. Brasília: MS, 2000c.

BRASIL, Ministério da Saúde. Manual de Comitês de Mortalidade Materna. 2. ed. Brasília: MS, 2002. 
BRASIL, Ministério da Saúde. Federação Brasileira das Sociedades de Ginecologia e Obstetrícia - FEBRASGO. Associação Brasileira de Obstetrizes e Enfermeiras Obstetras - ABENFO. Parto, aborto e puerpério: assistência humanizada à mulher. Brasília: MS, 2003a.

BRASIL, Ministério da Saúde. Federação Brasileira das Sociedades de Ginecologia e Obstetrícia - FEBRASGO. Associação Brasileira de Obstetrizes e Enfermeiras Obstetras - ABENFO. Urgências e emergências maternas: guia para diagnóstico e conduta em situações de risco de morte materna. 2. ed. rev. Brasília: MS, 2003b.

BRASIL, Ministério da Saúde. Pacto nacional pela redução da mortalidade materna e neonatal. Informe da Atenção Básica. Brasília, ano 5, mai.-jun. 2004.

BRASIL, DATASUS. Informações de saúde. 2005. Disponível em: <http://w3.datasus.gov.br/datasus/datasus.php?> Acesso em: 06 ago. 2006.

BRASIL, Ministério da Saúde. Sistema de Informações Ambulatoriais do SUS SIA/SUS. Datasus. Informações de Saúde. 2005. Disponível em: <http://www.datasus.gov.br.> Acesso em: 19 jun 2006.

BRIENZA, A. M. O processo de trabalho das enfermeiras na assistência pré-natal da rede básica de saúde do município de Ribeirão Preto. 2005. 168 f. Tese (Doutorado) - Escola de Enfermagem de Ribeirão Preto, Universidade de São Paulo, Ribeirão Preto, 2005.

BUCKINGHAM, S. Clinical Competency: the right assessment tools? J. Chid Healthcare, Oxford, v. 4, n. 1, p. 19-22, Spring 2000.

CARVALHO, G. M. et al. Análise dos registros nos cartões de pré-natal como fonte de informação para a continuidade da assistência à mulher no período gravídicopuerperal. REME, Belo Horizonte, v. 8, n. 4, p. 449-454, out.-dez. 2004.

CLAPIS, M. J. Competências de enfermeiras obstétricas na atenção qualificada ao parto: contribuição do Curso de Especialização em Enfermagem Obstétrica e Neonatal - modalidade residência. 2005. 121 f. Tese (Livre-Docência) - Escola de Enfermagem de Ribeirão Preto, Universidade de São Paulo, Ribeirão Preto, 2005.

CONSELHO FEDERAL DE ENFERMAGEM - CONFEN. Resolução COFEN-317/07. Regulamenta ações do enfermeiro na consulta, prescrição de medicamentos e requisição de exames. Rio de Janeiro: COFEN, 2007.

CONSELHO NACIONAL DE SAÚDE - CNS. Resolução 196/96. Regulamentação da Bioética no Brasil. Rio de Janeiro: Fundação Oswaldo Cruz, 1997.

CORRÊA, M. D; OLIVEIRA, M. J. V. Assistência Pré-Natal. In: CORRÊA, M.D. Noções práticas de obstetrícia. 12. ed. São Paulo: MEDSI, 1999. Cap. 3, p. 19-52.

COSTA, A. M.; GUILHEM, D.; WALTER, M. I. M. T. Atendimento a gestantes no Sistema Único de Saúde. Rev. de Saúde Pública, São Paulo, v. 39, n. 5, p. 768-774, out. 2005. 
DOTTO, L. M. G. Atenção qualificada ao parto: a realidade da assistência de enfermagem em Rio Branco - AC. 2006. 148f. Tese (Doutorado) - Escola de Enfermagem de Ribeirão Preto, Universidade de São Paulo, Ribeirão Preto, 2006.

DOTTO, L. M. G.; MOULIN, N. M.; MAMEDE, M. V. Assistência pré-natal: dificuldades vivenciadas pelas enfermeiras. Rev. Latino-am. Enfermagem, Ribeirão Preto, v. 14, n. 5, p. 682-688, set.-out. 2006.

FERRARI, R. A. P.; THOMSON, Z.; MELCHIOR, R. Estratégia da saúde da família: perfil dos médicos e enfermeiros, Londrina, Paraná. Semina Cienc. Biol. Saúde, Londrina, v. 26, n. 2, p. 101-108, out.-dez. 2005.

GARDENAL, C. L. C. et al. Perfil das enfermeiras que atuam na assistência à gestante, parturiente e puérpera, em instituições de Sorocaba/SP (1999). Rev. Latino-am. Enfermagem, Ribeirão Preto, v. 10, n. 4, p. 478-484, jul.-ago. 2002.

GIRARDI, S. N.; CARVALHO, C. L. Mercado de trabalho e regulação das profissões de saúde. In: NEGRI, B.; FARIA, R.; VIANA, A. L. D'A. (Org.) Recursos humanos em saúde: política, desenvolvimento e mercado de trabalho. Campinas: Unicamp, 2002. Cap. 3.2, p.221-256.

GOMES, F. A.; MAMEDE, M. V.; COSTA-JUNIOR, M. L. Mortes maternas mascaradas. In: BESSA, L. F.; CUNHA, M. A.; FERREIRA, T. F. (Org.). Saúde da mulher: desafios a vencer. Rio Branco: EDUFAC, 2004.

HADAD, S., FRANÇA, E., UCHÔA, E. Preventable infant mortality and quality of health care: maternal perception of the child's ilness and treatment. Cad Saúde Pública, Rio de Janeiro, v. 18, n. 6, p. 1519-1527, nov./dez. 2002.

INSTITUTO BRASILEIRO DE GEOGRAFIA E ESTATÍSTICA. IBGE. Censo demográfico 2000. 2000a. Disponível em: <http://www.ibge.gov.br>. Acesso em: 01 de jul. 2005.

INSTITUTO BRASILEIRO DE GEOGRAFIA E ESTATÍSTICA. IBGE. Cidades@. Resultados da amostra do censo demográfico 2000. 2000b. Disponível em: <http://www.ibge.gov.br/cidadesat>. Acesso em: 21 jun. 2006.

INSTITUTO BRASILEIRO DE GEOGRAFIA E ESTATÍSTICA. IBGE. Cidades@. 2002. Disponível em: <http://www.ibge.gov.br/cidadesat>. Acesso em: 21 jun. 2006.

INTERNATIONAL CONFEDERATION OF MIDWIVES. Competencies. New York: ICM, 2002. Disponível em: <http://www.internationalmidwives.org>. Acesso em: 20 set. 2004.

KAK, N.; BURKHALTER, B.; COOPER, M. A. Measuring the competence of healthcare providers. Operations Res. Issue Paper, Bethesda, v. 2, n. 1, p. 1-28, July 2001. Disponível em: http://www.qaproject.org/pubs/PDFs/competence.pdf. Acesso em: 21 nov.2007. 
KOFFMAN, M. D.; BONADIO, I. C. Avaliação da atenção pré-natal em uma instituição filantrópica da cidade de São Paulo. Rev. Bras. Saúde Mater. Infant., Recife, v. 5, supl. 1, p. S23-S32, dez. 2005.

KONDO, A. M. Exame Físico. In: ZUGAIB, M.; SANCOVSKI, M. O pré-natal. 2. ed. São Paulo: Atheneu, 1994. Cap. 5, p. 31-35.

KWAST, B. E. Quality of care in reproductive health programmes: monitoring and evaluation of quality improvement. Midwifery, Edinburg, v. 14, n. 3, p. 131-136, Sep. 1998.

LACAVA; R. M. V. B; BARROS, S. M. A prática de enfermagem durante a gravidez. In: BARROS, S. M.; MARIN, H. F.; ABRÃO, A. C. F. V. Enfermagem obstétrica e ginecológica: guia para a prática assistencial. São Paulo: Roca, 2002. Cap. 7, p. 116-141.

LAURENTI, R. Mortalidade materna no Brasil: faltam dados de uma assistência digna. Jornal da Rede Saúde, São Paulo. Informativo da Rede Nacional Feminista de Saúde e Direitos Reprodutivos, n. 15, p. 3-4, mai. 1998.

LAURENTI, R.; JORGE M. H. P. M.; GOTLIEB S. L. D. Reflexões sobre a mensuração da mortalidade materna. Cad. Saúde Pública, Rio de Janeiro v. 16, n. 1, p. 23-30, jan.-mar. 2000.

LAURENTI, R.; JORGE M. H. P. M.; GOTLIEB S. L. D. A mortalidade materna nas capitais brasileiras: algumas características e estimativa de um fator de ajuste. Rev. Bras. Epidemiol., São Paulo, v. 7, n. 4, p. 449-460, dez. 2004.

LIMA, C. P. Análise crítica da importância da assistência pré-natal. FEMINA, Rio de Janeiro, v. 25, n. 1, p. 85-86, 90-92, jan.-fev.1997.

LOPES, G. T. et al. Construindo uma proposta terapêutica de enfermagem no prénatal de baixo risco. Esc. Anna Nery Rev. Enferm., Rio de Janeiro, v. 4, n. 1, p. 115128, abril 2000.

LOPES, G. T.; PORTELLA, V. B.; PAES, T. O. A enfermeira e o cuidado de enfermagem no pré-natal. Rev. Enferm. UERJ, Rio de Janeiro, v. 9, n. 2, p. 152-157, mai./ago. 2001.

MAcDONALD, M.; STARRS A. La atencion calificada durante el parto: un cuaderno informativo para salvar la vida de las mujeres y mejorar la salud de los recién nacidos. New York: Family Care Internacional, 2003.

MALVÁREZ, S. M.; AGUDELO, M. C. C. Panorama de la fuerza de trabajo en enfermería en América Latina. Washington-DC: OPS, 2005, 69 p. (Serie de Desarrollo de Recursos Humanos, 39). 
MANFREDI, S. M. Trabalho, qualificação e competência profissional: das dimensões conceituais e políticas. Educação \& Sociedade, Campinas, v. 19, n. 64, p. 13-49, set. 1998.

MARCONI, M. A.; LAKATOS E. M. Técnicas de pesquisa. São Paulo: Atlas, 1996. 231p.

MARQUEZ, L. Helping healthcare providers perform according to standards. Operations Res. Issue Paper, Betlesda, v. 2, n. 3, p 1-34, Sep. 2001. Disponível em: <http://www.qaproject.org/pubs/PDFs/helphcpro3.pdf>. Acesso em: 21 nov. 2007.

MERIGHI, M. A. B. Reflexões sobre a qualidade da assistência de enfermagem à mulher no período gravídico-puerperal. Rev. Enferm. UERJ, Rio de Janeiro, v. 6, n. 1, p. 253-258, jun.1998.

MOURA, C. F. S.; LOPES, G. T. Acompanhamento pré-natal realizado por enfermeiras obstetras: representações das gestantes. Rev. Enferm. UERJ, Rio de Janeiro, v. 11, n. 2, p. 165-170, ago. 2003.

MOURA, E. R. F.; RODRIGUES, M. S. P. Desempenho profissional de enfermeiras na assistência pré-natal. RENE, Fortaleza, v. 3, n. 1, p. 27-33, jan.-jun. 2002.

MOURA, E. R. F.; HOLANDA-JUNIOR F.; RODRIGUES, M. S. P. Avaliação da assistência pré-natal oferecida em uma microrregião de saúde do Ceará, Brasil. Cad. Saúde Pública, Rio de Janeiro, v. 19, n. 6, p. 1791-1799, nov.-dez. 2003.

NEUMANN, N. A. et al. Qualidade e eqüidade da atenção ao pré-natal e ao parto em Criciúma, Santa Catarina, Sul do Brasil. Rev. Bras. Epidemiol., São Paulo, v. 6, n. 4, p. 307-318, dez. 2003.

NUNES, I. M.; FERREIRA, S. L.; PAIVA, M. S. Condições de trabalho de enfermeiras obstetras: aspectos de uma realidade. Rev. Bras. Enferm., Brasília, v. 55, n. 6, p. 652-657, nov.-dez. 2002.

OBA, M. D. V.; TAVARES, M. S. G. Assistência pré-natal no município de Ribeirão Preto: sugestões e recomendações para ações futuras. Rev. Paul. Enferm., São Paulo, v. 16, n. 1/3, p. 35-42, jan.-dez. 1997.

OBA, M. D. V.; TAVARES, M. S. G. Aspectos positivos e negativos da assistência pré-natal no município de Ribeirão Preto. Rev. Latino-am Enfermagem, Ribeirão Preto, v. 8, n. 2, p. 11-17, abril 2000.

ORGANIZAÇÃO MUNDIAL DE SAÚDE. OMS. Maternidade segura. Assistência ao parto normal: um guia prático. Genebra: OMS, 1996.

ORGANIZAÇÃO PAN-AMERICANA DE SAÚDE. OPAS. Perfil dos serviços de obstetrícia/parteria nas Américas. Washington: OPAS, 2004. 
OSIS, M. J. M. D. Paism: um marco na abordagem da saúde reprodutiva no Brasil. Cad. Saúde Pública, Rio de Janeiro, v. 14, n. 1, supl., p. 25-32, 1998.

PENNA, L. H. G., PROGIANTI J. M., CORREA L. M. Enfermagem obstétrica no acompanhamento pré-natal. Rev. Bras. Enferm., Brasília, v. 52, n. 3, p. 385-390, jul./set. 1999.

PEREIRA, M. G. Epidemiologia: teoria e prática. Rio de Janeiro: Guanabara Koogan, 1995.

POLIT, D. F.; BECK C. T.; HUNGLER B. P.; Fundamentos de pesquisa em Enfermagem: métodos, avaliação e utilização. 5. ed. Porto Alegre: Artmed, 2004.

PUCCINI, R. F. et al. Eqüidade na atenção pré-natal e ao parto em área da Região Metropolitana de São Paulo, 1996. Cad. Saúde Pública, Rio de Janeiro, v. 19, n. 1, p. 35-45, jan.-fev. 2003.

QUALITY ASSURANCE PROJECT. Maximizing quality of care in health sector reform: the role of quality assurance strategies. Technical Reports, Latin America \& the Caribbean, n. 64, p, 1-36, 2005. Disponível em : <http://www.qaproject.org/pubs/PDFs/LACHSR\%20Report\%2064.pdf> Acesso em: 21 nov. 2007.

REZENDE, J.; MONTENEGRO; C. A. B. A assistência pré-natal. In: REZENDE, J.; MONTENEGRO; C. A. B. Obstetrícia fundamental. 9. ed. Rio de Janeiro: Guanabara Koogan, 2003. Cap. 11, p. 144-154.

RIESCO, M. L. G.; TSUNECHIRO M. A. Formação profissional de obstetrizes e enfermeiras obstétricas: velhos problemas ou novas possibilidades? Estudos Feministas, Florianopólis, v. 10, n. 2, p. 449-459, jul.-dez. 2002.

RIO BRANCO. Prefeitura Municipal de Rio Branco - ACRE. Secretaria Municipal da Saúde de Rio Branco - SEMSA. Normatiza a consulta, o diagnóstico, a prescrição, transcrição de medicamentos e solicitação de exames de rotina e complementares por enfermeiros. Portaria $\mathrm{n}^{\circ}$ 110, 06 de dezembro de 2004. Diário Oficial do Estado, Rio Branco, no 8.935, Ano 28, $2004 a$.

RIO BRANCO. Secretaria Municipal de Saúde de Rio Branco - SEMSA. Gerência de Ações Básicas. Coordenação de Centros e Postos de Saúde. Manual de protocolos para os Centros de Saúde, regulamento interno das Unidades Básicas de Saúde, regimento interno do Serviço de Enfermagem. Rio Branco, 2004b.

RIO BRANCO. Secretaria Municipal de Saúde de Rio Branco - SEMSA. Nascidos vivos no município de Rio Branco 2005. Rio Branco, jun.2006a. (Mimeografado).

RIO BRANCO. Secretaria Municipal de Saúde de Rio Branco - SEMSA. Levantamento dos profissionais de saúde lotados nas Unidades Básicas de Saúde e Unidades de Saúde da Família. Rio Branco, abri.-mai. 2006b. (Mimeografado). 
RIOS, C. T. F.; VIEIRA, N. F. C. Ações educativas no pré-natal: reflexão sobre a consulta de enfermagem como um espaço para educação em saúde. Ci. \& Saúde Coletiva, Rio de Janeiro, v. 12, n. 2, p. 477-486, mar.-abril 2007.

RISING, S. S.; KENNEDY, H. P.; KLIMA, C. S. Redesigning prenatal care through centering pregnancy. J. Midwifery \& Women's Health, New York, v. 49, n. 5, p. 398404, Sep.-Oct. 2004.

RODRIGUES, A. V.; SIQUEIRA, A. A. F. Uma análise da implementação dos comitês de estudos de morte materna no Brasil: um estudo de caso do Comitê do estado de São Paulo. Cad. Saúde Pública, Rio de Janeiro, v. 19, n. 1, p. 183-189, jan./fev. 2003.

RODRIGUES FILHO, J., COSTA W., LENO, G. M. L. Determinantes de utilização do cuidado pré-natal entre famílias de baixa renda no Estado da Paraíba, Brasil. Rev. Saúde Pública, São Paulo, v. 28, n. 4, p. 284-289, ago.1994.

SANCOVSKI, M. Drogas e gravidez. In: ZUGAIB, M.; SANCOVSKI, M. O pré-natal. 2. ed. São Paulo: Atheneu, 1994. Cap. 14, p. 115-124.

SANDERS J. et al. To see or not to see? Midwives' perceptions of reduced antenatal attendances for 'low-risk' women. Midwifery, Edinburg, v. 15, p. 257-263, May 1999.

SERRUYA, S. J., LAGO T. D. G., CECATTI J. G. O panorama da atenção pré-natal no Brasil e Programa de Humanização do Pré-natal e Nascimento. Rev. Bras. Saúde Materno Infantil, Recife, v. 4, n. 3, p. 269-279, jul./set. 2004a.

SERRUYA, S. J., LAGO T. D. G., CECATTI J. G. O Programa de Humanização do Pré-natal e Nascimento do Ministério da Saúde no Brasil: resultados iniciais. Cad. Saúde Pública, Rio de Janeiro, v. 20, n. 5, p. 1-15, set./out. 2004b.

SILVA, J. L. P.; CECATTI J. G.; SERRUYA, S. J. A qualidade do pré-natal no Brasil. Editorial. Rev. Bras. Ginecol. Obstet., v. 27, n. 3, p. 103-105, mar. 2005.

TANAKA, A. C. d'A. Mortalidade Materna: reflexo da má qualidade e da desintegração dos serviços de saúde. J. Rede Saúde, Informativo da Rede Nacional Feminista de Saúde e Direitos Reprodutivos, São Paulo, n. 20, p. 5-8, mai. 2000.

TANAKA, A. C. d'A. Dossiê mortalidade materna. Rede Saúde, 2001. Disponível em: $<$ http://www.redesaude.org.br/dossies/html/body_mt-panbrasil.html.> Acesso em: 21 jan. 2004.

TREVISAN, M. R. et. al. Perfil da assistência pré-natal entre usuárias do Sistema Único de Saúde em Caxias do Sul. Rev. Bras. Ginecol. Obstet., Rio de Janeiro, v. 24, n. 5, p. 293-299, jun. 2002.

VALONGUEIRO, S.; LUDERMIR, A. B.; GOMINHO, L. A. F. Avaliação de procedimentos para identificar mortes maternas. Cad. Saúde Pública, Rio de Janeiro, v. 19, supl. 2, p. S293-S301, 2003. 
WALKER, D. S. et al. Reduced frequency prenatal visits in midwifery practice: attitudes and use. J. Mdidwifery \& Women's Health, New York, v. 47, n. 4, p .269277, Jul./Aug. 2002.

WORLD HEALTH ORGANIZATION. Working with individuals, families and communities to improve maternal and newborn health: making pregnancy safer initiative. Reproductive Health and Research. Geneva, 2003. WHO/FCH/RHR/03.11.

WORLD HEALTH ORGANIZATION. Making pregnancy safer: the critical role of the skilled attendant: a joint statement by WHO, ICM, and FIGO. Geneva: WHO, 2004. 
APÊENDICES 


\section{APÊNDICE A - Termo de Consentimento Livre e Esclarecido (profissionais de saúde)}

Meu nome é Margarida de Aquino Cunha, sou aluna do Programa de PósGraduação - Doutorado, da Escola de Enfermagem de Ribeirão Preto - USP, do Programa Interunidades de Doutoramento em Enfermagem. Estou desenvolvendo uma pesquisa intitulada: Caracterização da assistência pré-natal por profissionais de enfermagem no município de Rio Branco-AC: contribuição para o estudo da atenção qualificada no ciclo grávido-puerperal, para obtenção do título de Doutor em Enfermagem.

Com este estudo pretendo saber quais são os profissionais que dão atendimento às gestantes nos serviços de pré-natal no município de Rio Branco-AC e que tipo de atividades eles executam. Para isto, gostaria de convidá-la(o) a participar deste estudo. Você não será identificada (o) em momento algum da pesquisa e terá toda a liberdade de desistir em qualquer fase do estudo. Caso não aceite participar, não terá qualquer prejuízo à sua pessoa. Não haverá ônus para sua participação neste estudo.

Caso você aceite participar do estudo, farei algumas perguntas para obter informações sobre o seu trabalho e sua formação como também farei observação para conhecer a dinâmica do atendimento pré-natal nos serviços de saúde.

Esclareço que sua participação será muito importante, para que possamos conhecer quem são os profissionais que atuam na assistência do pré-natal nos Centros de Saúde e Unidades de Saúde da Família de Rio Branco, e quais as atividades que realizam. 
Agradeço sua colaboração, coloco-me à disposição para os esclarecimentos que se fizerem necessários. O meu endereço: Rua Antônio da Rocha Viana, 2686, Bloco C Apt 304 - Vila Ivonete, telefone (68) 3228-2039 ou e-mail: mguida@uol.com.br.

Obrigada.

Margarida de Aquino Cunha

Após ter lido e compreendido as informações acima, concordo em participar desta pesquisa e autorizo a divulgação dos resultados deste estudo em eventos e revistas científicas.

Entrevistada(o)

DOCUMENTO EM DUAS (2) VIAS, UMA PARA O PESQUISADOR E OUTRA PARA A PESSOA (OU RESPONSÁVEL) QUE VAI PARTICIPAR DA PESQUISA. 


\section{APÊNDICE B - Roteiro de Entrevista}

Número:

\section{I- IDENTIFICAÇÃO}

1- Sexo: ( ) feminino ( ) masculino 2- Idade: anos

3- Estado conjugal: ( ) solteiro(a) （ ) casado(a) ( ) separado(a)
( ) mora junto
( ) divorciado(a)
( ) viúvo(a)

4- Número de filhos:

5- Idade dos filhos:

6- Renda Familiar: R\$

7- Remuneração nesta instituição: R\$

II- FORMAÇÃO E ATIVIDADE PROFISSIONAL

8- Nível de instrução:

( ) ensino fundamental incompleto

( ) ensino médio completo

( ) ensino fundamental completo

( ) ensino superior incompleto

( ) ensino médio incompleto

( ) ensino superior completo

9- Formação:

Básica (anos de estudo):

Ano que concluiu:

Profissional

Auxiliar ( ) Técnico ( ) Graduação ( ) Especialização ( )

Local:

Ano que concluiu: 
10- Fez curso de pós-graduação: ( ) Sim ( ) Não

( ) Especialização (mínimo 360 horas)

Nome:

( ) Concluída. Ano

Financiada pelo Ministério da Saúde （）Sim ( ) Não Carga horária:

( ) Em andamento

Nome:

( ) Concluído. Ano

( ) Mestrado Título:

( ) Concluído. Ano

( ) Em andamento

( ) Doutorado Título:

( ) Concluído. Ano

( ) Em andamento

11- Realizou curso(s)/treinamento(s) de atualização/aprimoramento na área de assistência ao pré-natal, depois de sua formação profissional (últimos anos)?

( ) $\operatorname{Sim}($ ) Não

Nome: Carga horária: Ano:

Nome: Carga horária: Ano:

Nome: Carga horária: Ano:

Nome: Carga horária: Ano:

Nome: Carga horária: Ano:

12- Tem participado de eventos científicos (área de saúde da mulher), após a sua formação profissional? ( ) Sim （ ) Não

Nome: Ano:

Nome: Ano:

Nome: Ano:

13- Tem mais de 01(um) emprego?( ) Sim ( ) Não Quantos? Quais? 
1)

2)

3)

14- Jornada semanal de trabalho:

15- Há quanto tempo trabalha na assistência ao pré-natal?

16 - Experiência na assistência ao pré-natal (local/período):

17 - Realiza pré-natal nesta Unidade? ( ) Sim ( ) Não

18 - Como o pré-natal está organizado neste serviço? Qual é a rotina?

19 - Há programas especiais de atendimento pré-natal para gestantes consideradas especiais? ( adolescente, de alto risco) 
20 - O que você faz na assistência pré-natal? (atividades gerenciais, atividades assistenciais)

21- O serviço oferece cursos? (gestantes, puérperas, planejamento familiar, etc.)

( ) Sim ( ) Não

22- Como funciona? O que é tratado? De quem é a responsabilidade?

23- Você tem dificuldades no atendimento à gestante?

( ) $\operatorname{Sim}($ ) Não

24- Em caso afirmativo, que tipo de dificuldades? 
25- Como é o encaminhamento da gestante para a assistência ao parto? (fluxo)

26- E depois que ela dá à luz? Há um programa específico para a puérpera? Como funciona? 


\section{APÊNDICE C - Roteiro de Observação}

Número:

\section{UNIDADE:}

DATA:

HORA:

\section{FASE DA GESTAÇÃO}

$1^{\circ}$ Trimestre ( ) $\quad 2^{\circ}$ Trimestre ( ) $\quad 3^{\circ}$ Trimestre ( )

Número da Consulta:

Motivo da Consulta:

\section{RECEPCÃ̃O}

1. Profissional que realizou:

2. Peso: ( ) Sim ( ) Não

3. Altura: ( ) Sim ( ) Não

4. Sinais Vitais: （ ) Temperatura （）Pressão Arterial（）Pulso （）Freqüência cardíaca

SALA DE ESPERA

1.Acolhimento:

2. Palestra: ( ) Sim ( ) Não

3. Tema:

4. Outras atividades: 
1. Tempo de espera:

2. Estava acompanhada: ( ) Sim Não ( )

3. Com quem?

\section{ANAMNESE}

1. Profissional que realizou a consulta:

2. Dados sócioeconômicos: ( ) Sim ( ) Não

3. Antecedentes familiares: ( ) Sim ( ) Não

4. Antecedentes pessoais: ( ) Sim ( ) Não

5. Antecedentes ginecológicos: ( ) Sim ( ) Não

6. Antecedentes obstétricos: ( ) Sim ( ) Não

7. Gestação atual: ( ) D.U.M ( ) D.P.P. ( ) Idade gestacional

\section{EXAME FÍSICO}

\section{GERAL:}

1. Avaliação do estado nutricional da gestante e relação com o crescimento fetal:

( ) $\operatorname{Sim}($ ) Não

2. Inspeção da pele e mucosas: ( ) Sim ( ) Não

3. Palpação da tireóide: ( ) Sim ( ) Não

4. Examinou os MMII: ( ) Sim ( ) Não

5. Pesquisou edema: ( ) face ( ) tronco ( ) membros

\section{ESPECÍFICO: GINECO-OBSTÉTRICO}

1. Examinou as mamas: ( ) $\operatorname{Sim}($ ) Não

2. Orientou quanto à amamentação: ( ) Sim ( ) Não

3. Auscultou BCF: ( ) Sim ( ) Não （）Pinard （ ) Sonar

4. Palpação: Posição ( ) Apresentação fetal （）Altura Uterina ( ) 
5. Inspeção dos genitais externos: ( ) Sim ( ) Não

6. Exame especular:

( ) inspeção das paredes vaginais ( ) inspeção do conteúdo vaginal

( ) inspeção do colo uterino ( ) exame colpocitológico ( ) toque vaginal

\section{ORIENTAÇÕES:}

( ) sinais de perigo ( ) quando procurar o serviço de saúde ( ) medidas de desconfortos ( ) alimentação ( ) exercícios ( ) sono/repouso ( ) sexualidade

( ) trabalho ( ) higiene ( ) aleitamento materno ( ) fumo/álcool/drogas

( ) sinais de trabalho de parto ( ) entrega de material didático ( ) teste do pezinho ACQÕES COMPLEMENTARES:

1. Solicitou exames laboratoriais: ( ) Sim ( ) Não

\section{Quais?}

( ) Tipagem Sanguínea ( ) Hemograma ( ) Glicose ( ) Hepatite ( ) Sífilis

( ) Toxoplasmose ( ) HIV ( ) EAS

\section{Outros:}

Explicou os motivos? ( ) Sim ( ) Não 
3. Prescrição medicamentosa: ( ) Sim ( ) Não

Motivo?

Explicou? ( ) Sim ( ) Não

Qual medicamento?

Orientou o uso? ( ) Sim ( ) Não

4. Encaminhamento para vacina antitetânica: ( ) Sim （ ） Não

Explicou o porquê? ( ) Sim Não ( )

5. Agendamento de consultas subseqüentes: ( ) Sim ( ) Não

6. Outras ações/encaminhamentos:

a)

b)

c)

7. Anotações:

( ) prontuário ( ) cartão da gestante

8. Grupo de gestante: ( ) Sim （）Não (descrever o observado) 
9. Retorno Puerpério: ( ) Sim ( ) Não (descrever o observado) 


\section{APÊNDICE D - Termo de Consentimento Livre e Esclarecido (gestantes)}

Meu nome é Margarida de Aquino Cunha, sou aluna do Programa de PósGraduação - Doutorado, da Escola de Enfermagem de Ribeirão Preto - USP, do Programa Interunidades de Doutoramento em Enfermagem. Estou desenvolvendo uma pesquisa intitulada: Caracterização da assistência pré-natal por profissionais de enfermagem no município de Rio Branco-AC: contribuição para o estudo da atenção qualificada no ciclo grávido-puerperal, para obtenção do título de Doutor em Enfermagem.

Com este estudo pretendo saber quais são os profissionais que dão atendimento às gestantes nos serviços de pré-natal no município de Rio Branco-AC e que tipo de atividades eles executam. Para isto, gostaria de convidá-la a participar deste estudo permitindo que eu observe como está sendo a sua consulta pré-natal. Você não será identificada em momento algum da pesquisa e terá toda a liberdade de desistir em qualquer fase do estudo. Caso não aceite participar, não terá qualquer prejuízo ao seu atendimento no serviço de saúde. Não haverá ônus para sua participação neste estudo, pois será realizada enquanto você estiver no serviço de saúde.

Esclareço que sua participação será muito importante para que possamos conhecer como a assistência no pré-natal está sendo desenvolvida no município de Rio Branco - AC. 
Agradeço sua colaboração, coloco-me à disposição para os esclarecimentos que se fizerem necessários. O meu endereço: Rua Antônio da Rocha Viana, 2686, Bloco C Apt 304 - Vila Ivonete, telefone (68) 3228-2039 ou e-mail: mguida@uol.com.br.

Obrigada.

Margarida de Aquino Cunha

Após ter lido e compreendido as informações acima, concordo em participar desta pesquisa e autorizo a utilização dos dados, para o presente estudo, que poderão ser publicados e utilizados em eventos científicos. 
ANEXOS 


\section{ANEXO A}

\section{Prefeitura Municipal de Rio Branco Secretaria Municipal de Saúde}

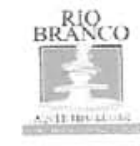

\section{DECLARAÇÃO}

Rio Branco-Acre, 26 de outubro de 2005.

Declaramos para os devidos fins de direito que a Profa MSC. Margarida de Aquino Cunha, doutorando do Programa Interunidades de Doutoramento em Enfermagem da Escola de Enfermagem de Ribeirão Preło - USP, tem permissão para realizar nas estruturas dessa Secretaria Municipal de Saúde a pesquisa: "Caracterização da assistência pré-natal por profissionais de enfermagem no Município de Rio Branco - AC: contribuição para o estudo da atenção qualificada no ciclo gravídico-puerperal ".

Atenciosamente,

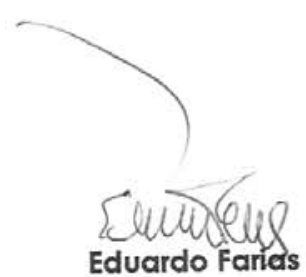

Secretário Municipal de Saúde

Rua Floriano Peixoto, 1092 - Centro.

Rio Branco-Acre

Telefone: $(68),-3211-2114$ 


\section{ANEXO B}
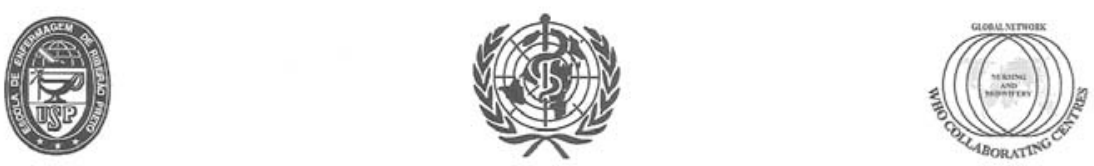

ESCOLA DE ENFERMAGEM DE RIBEIRÃO PRETO - UNIVERSIDADE DE SÃO PAULO

CENTRO COLABORADOR DA ORGANIZAÇÃO MUNDIAL DA SAÚDE PARA

O DESENVOLVIMENTO DA PESQUISA EM ENFERMAGEM

Avenida Bandeirantes, 3900 - Campus Universitário - Ribeirão Preto - CEP 14040-902 - São Paulo - Brasil FAX: (55) - 16-3633-3271/3602-4419/ TELEFONE: (55) - 16-3602-3382

\section{COMITÊ DE ÉTICA EM PESQUISA DA EERPIUSP}

Of.CEP-EERP/USP - 054/2006

Ribeiräo Preto, 20 de abril de 2006.

Prezada Senhora,

Comunicamos que o projeto de pesquisa, abaixo especificado, foi analisado e considerado APROVADO pelo Comitê de Ética em Pesquisa da Escola de Enfermagem de Ribeirăo Preto da Universidade de São Paulo, em sua $85^{a}$ Reunião Ordinária, realizada em 19 de abril de 2006.

Protocolo: $n^{\circ} 0633 / 2005$

Projeto: Caracterização da assistência pré-natal por profissionais de enfermagem no município de Rio Branco - AC: contribuição para o estudo da atenção qualificada no ciclo grávido-puerperal

Pesquisadores: Marli Villela Mamede (Orientadora)

Margarida de Aquino Cunha (Doutoranda)

Em atendimento à Resolução 196/96, deverá ser encaminhado ao CEP o relatório final da pesquisa e a publicação de seus resultados, para acompanhamento, bem como comunicada qualquer intercorrência ou a sua interrupção.

Atenciosamente,

Prof ${ }^{\alpha}{ }^{\alpha}$ Cléa Regina de Oliveira Ribeira-

Coordenadora do CEP-EERP/USP

IIma. Sra.

Prof ${ }^{\mathrm{a}} \mathrm{Dr}^{\mathrm{a}}$. Marli Villela Mamede

Dept $^{\circ}$ de Enfermagem Materno-Infantil e Saúde Pública

Escola de Enfermagem de Ribeirão Preto - USP 